\title{
WestVirginiaUniversity
}

THE RESEARCH REPOSITORY @ WVU

Graduate Theses, Dissertations, and Problem Reports

2015

\section{The Online LaModel User's \& Training Manual Development \& Testing}

Christopher R. Newman

Follow this and additional works at: https://researchrepository.wvu.edu/etd

\section{Recommended Citation}

Newman, Christopher R., "The Online LaModel User's \& Training Manual Development \& Testing" (2015). Graduate Theses, Dissertations, and Problem Reports. 6308.

https://researchrepository.wvu.edu/etd/6308

This Thesis is protected by copyright and/or related rights. It has been brought to you by the The Research Repository @ WVU with permission from the rights-holder(s). You are free to use this Thesis in any way that is permitted by the copyright and related rights legislation that applies to your use. For other uses you must obtain permission from the rights-holder(s) directly, unless additional rights are indicated by a Creative Commons license in the record and/ or on the work itself. This Thesis has been accepted for inclusion in WVU Graduate Theses, Dissertations, and Problem Reports collection by an authorized administrator of The Research Repository @ WVU. For more information, please contact researchrepository@mail.wvu.edu. 


\title{
The Online LaModel
}

\section{User's \& Training Manual}

\section{Development \& Testing}

\author{
Christopher R. Newman \\ This Thesis is submitted to the Benjamin Statler College of \\ Engineering and Mineral Resources at West Virginia University in \\ partial fulfillment of the requirements for the degree of \\ Master of Science in \\ Mining Engineering
}

\author{
Keith A. Heasley, Ph.D., Chair \\ Brijes Mishra, Ph.D. \\ Yi Luo, Ph.D \\ Department of Mining Engineering \\ Morgantown, West Virginia \\ 2015
}

Keywords: LaModel, Displacement-Discontinuity, Boundary-Element, Laminated Overburden Copyright 2015 Christopher R. Newman 


\section{Abstract}

\section{The Online LaModel User's and Training Manual: Development \& Testing Christopher R. Newman}

In order to better inform and train industry professionals, as well as engineering students and new users, an electronic user's manual and comprehensive online training course for LaModel has been developed in an open online learning environment. The online user's manual provides widespread access to detailed information on the installation, proper use, and troubleshooting procedures through a combination of: written documentation, voiced-over and captioned software simulations and slide presentations, and relevant academic articles. Some of the online LaModel material has also been organized into a set of progressive, self-paced training modules using a number of the slide presentations and software demonstrations, with the addition of pedagogically designed learning activities and proficiency quizzes. These training modules are designed such that a new user can complete the sequence of three learning tracks (novice, intermediate, and advanced) to become a proficient user of the LaModel program.

This thesis reports on the development and implementation of the new LaModel user's manual and training course. Currently, the on-line material includes 84 pages of technical notes and 6 hours of slides and hands-on learning activities. In this thesis, the overall layout and format of the user's manual, training modules, and proficiency quizzes are presented along with samples from specific manual sections and classroom lessons.

With an increase in operational difficulties, geologic intricacies, and regulatory review, this generation of mining engineers require complex analyzes to determine the integrity of underground mine works. Through access to the new online user's manual and training modules, novice LaModel users can be effectively trained on the correct operation and analysis techniques for using the LaModel program, while experienced users can quickly access detailed information on the newer and/or more complex LaModel functions. The development of both the user's manual and online training course will ultimately increase the effectiveness of mining engineers within the industry, leading to more productive and safer mine designs. 


\section{Table of Contents}

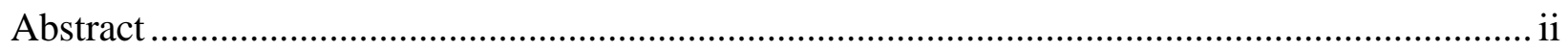

Table of Contents ................................................................................................................

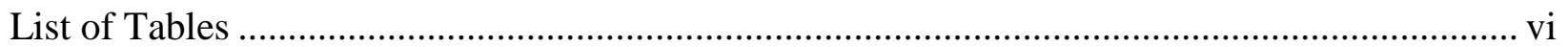

List of Figures .................................................................................................................. vii

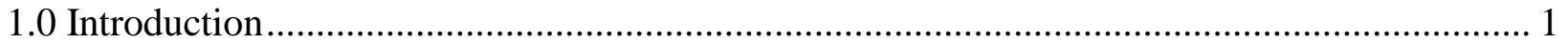

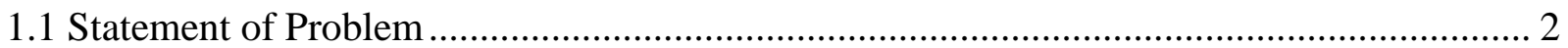

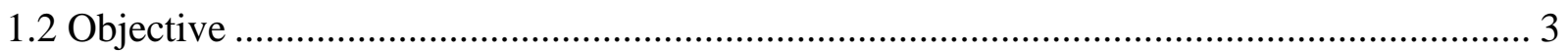

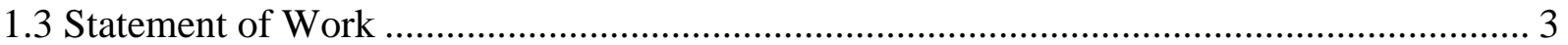

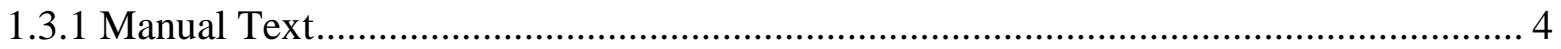

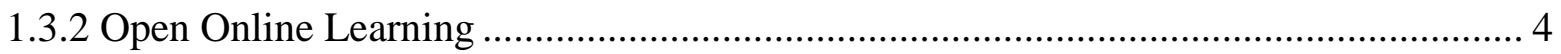

1.3.2.1 Novice Learning Track ........................................................................................... 5

1.3.2.2 Intermediate Learning Track .................................................................................. 5

1.3.2.3 Advanced Learning Track .................................................................................... 6

1.3.2.4 Professional Development Hours ........................................................................ 6

1.3.3 Third party Learning Management System ............................................................... 6

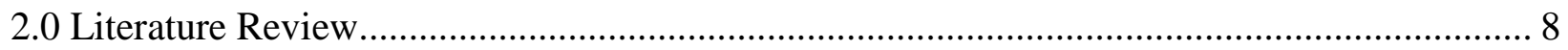

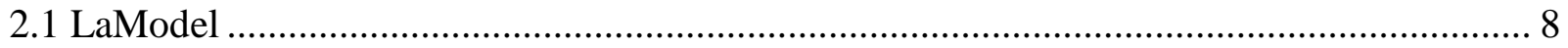

2.1.1 Current LaModel Information \& Training …………….............................................. 10

2.2 Open Online Learning............................................................................................. 12

2.2.1 Kolb's Experiential Learning Model ............................................................................. 13

2.2.2 Bloom's Taxonomy of Educational Objectives ............................................................. 16

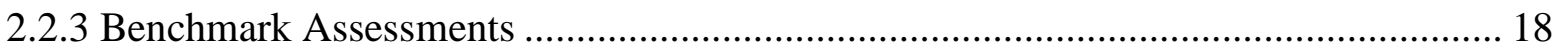

2.2.3.1 Learning for Mastery Model................................................................................ 19

2.3 The Online LaModel User's Manual \& Training Modules ................................................... 21

3.0 Development of LaModel User's Manual ............................................................................... 23

3.1 Architecture/Design of Online Documentation................................................................. 24

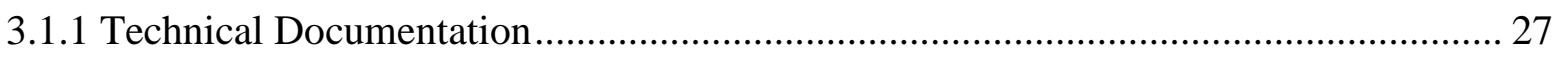

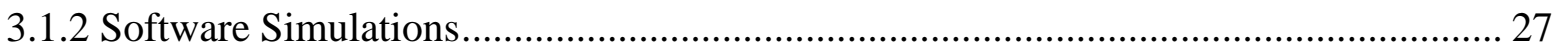

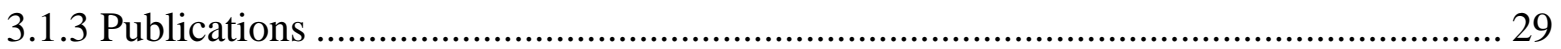




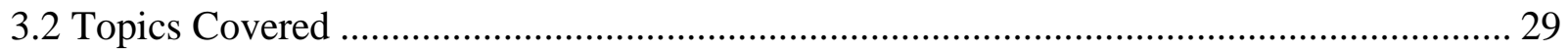

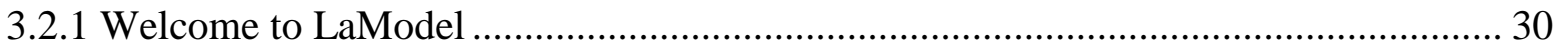

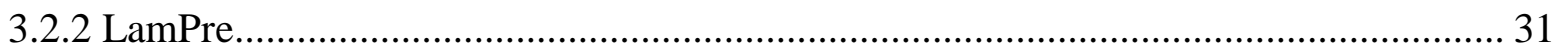

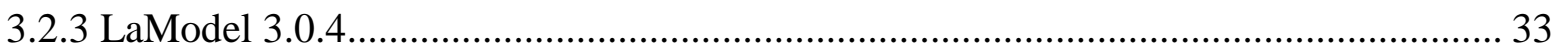

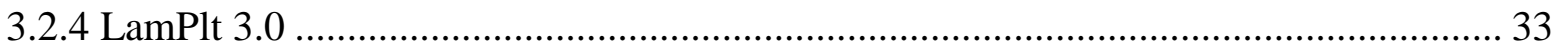

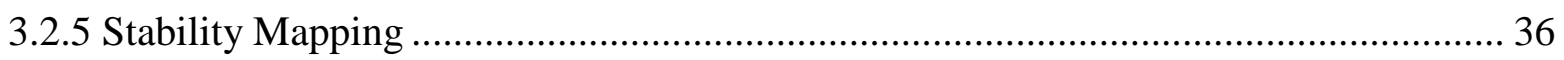

3.3 User's Manual Example for Lamination Thickness …………………………….................. 37

4.0 Development of LaModel Online Training Modules .............................................................. 44

4.1 Open Online Learning Environment .............................................................................. 44

4.1.1 Online Learning Management System ......................................................................... 45

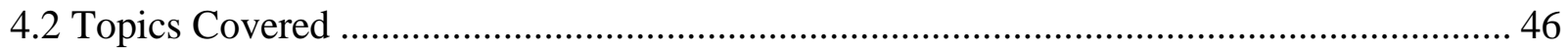

4.2.1 Novice Learning Track ................................................................................................. 47

4.2.2 Intermediate Learning Track ................................................................................. 50

4.2.3 Advanced Learning Track ....................................................................................... 54

4.3 Formative Student Assessments....................................................................................... 58

4.4 Training Module Example for Energy Release Rates ........................................................ 61

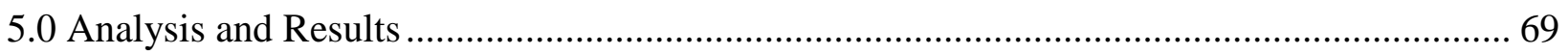

5.1 Description of Learning Environments \& Student Populations............................................ 69

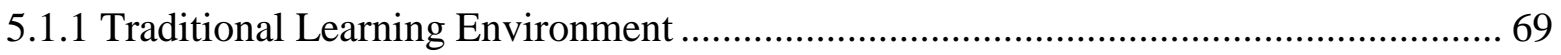

5.1.2 Workshop Learning Environment .................................................................................. 70

5.1.3 Online Learning Environment ................................................................................ 71

5.2 Normal Distribution of Assessment Results by Learning Environment............................... 71

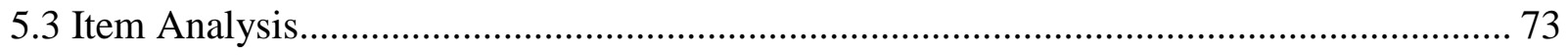

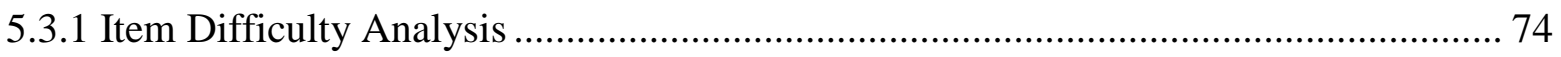

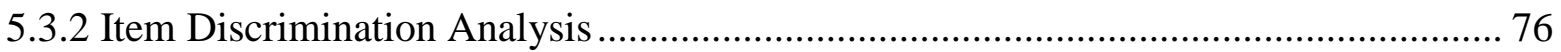

5.3.3 Knowledge Check 1 Item Analysis ............................................................................... 77

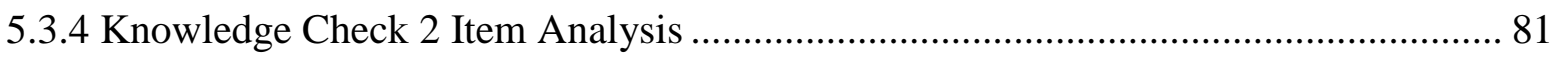

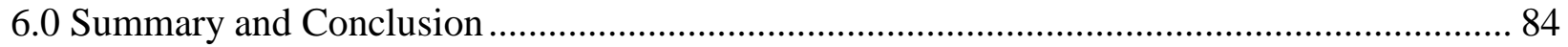

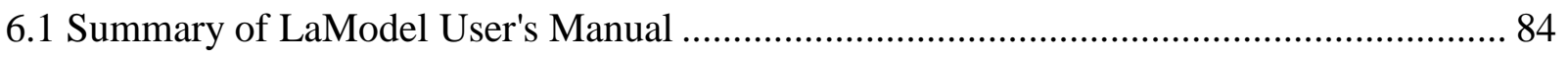

6.2 Summary of LaModel Online Training Modules............................................................... 85

6.3 Summary of Course Analysis............................................................................................ 85 


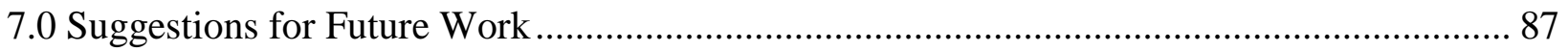

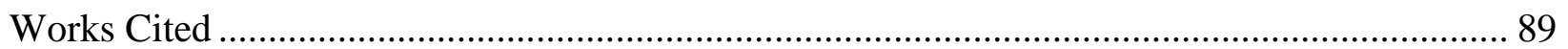

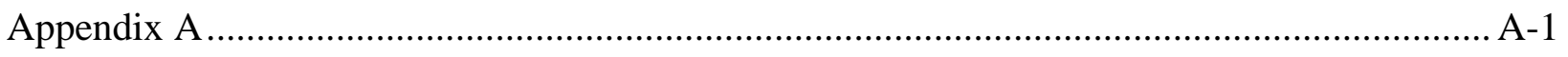

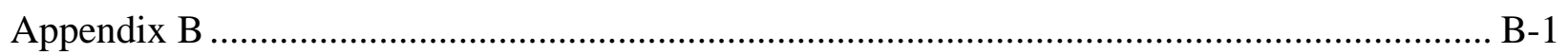

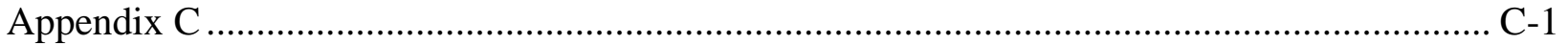




\section{List of Tables}

Table 2.1: Summary of LaModel Workshop history .............................................................

Table 2.2: Kolb's four stages of learning categorized by dimension ..............................................15

Table 2.3: Bloom's Taxonomy action words ............................................................................

Table 3.1: LaModel User's Manual section summary ……………………......................................30

Table 3.2: Summary of Section 1.0 Welcome to LaModel ............................................................30

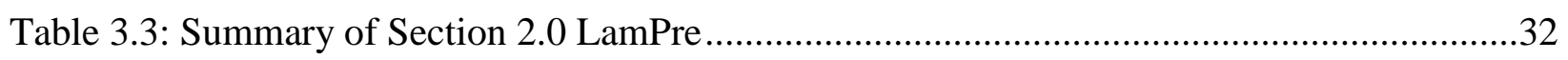

Table 3.4: Summary of Section 3.0 LaModel..........................................................................3

Table 3.5: Summary of Section 4.0 LamPlt...............................................................................

Table 3.6: Summary of Section 5.0 Stability Mapping ..................................................................36

Table 4.1: Summary of Online Learning Tracks ...........................................................................4

Table 4.2: Summary of Novice Learning Track ........................................................................48

Table 4.3: Summary of Tutorial 1 training module series ..............................................................48

Table 4.4: Summary of Huff Creek training module series...........................................................49

Table 4.5: Summary of Intermediate Learning Track .................................................................50

Table 4.6: Summary of Calibration training module series .........................................................51

Table 4.7: Summary of Gory Details I training module series ......................................................52

Table 4.8: Summary of Solution Options I training module series ................................................53

Table 4.9: Summary of Stability Mapping training module series ................................................53

Table 4.10: Summary of Advanced Learning Track ......................................................................55

Table 4.11: Summary of Gory Details II \& Solution Options II training module series................55

Table 4.12: Summary of Miscellaneous Features training module series .......................................57

Table 4.13: Summary of Successive Over-Relaxation Coding Activity training module series...57

Table 5.1: Item Difficulty Analysis ..........................................................................................75

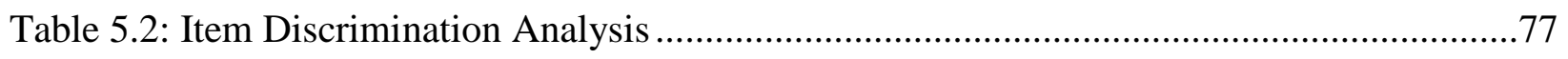

Table 5.3: Knowledge Check 1 Item Analysis Results......................................................................78

Table 5.4: Knowledge Check 2 Item Analysis Results..................................................................82 


\section{List of Figures}

Figure 2.1: Theoretical model of Kolb's experiential learning .................................................14

Figure 2.2: Bloom's Taxonomy of Educational Objectives in the cognitive domain ...................17

Figure 2.3: The mastery learning instructional process ................................................................20

Figure 2.4 Distribution of achievement in the mastery learning classroom ...................................21

Figure 3.1: LaModel User's Manual with content tabs enabled ....................................................25

Figure 3.2: User's Manual with search tab selected......................................................................26

Figure 3.3: Software simulation screen capture recording ………………………………….....28

Figure 3.4: LamPlt plot styles for total vertical stress ..................................................................35

Figure 3.5: Description of lamination thickness in User's Manual text..........................................38

Figure 3.6: Lamination Thickness Wizard HTML topic page..........................................................40

Figure 3.7: Lamination Thickness Wizard simulation.................................................................41

Figure 3.8: Academic paper discussing Lamination Thickness calibration techniques .................42

Figure 4.1: Mastery for learning model for Tutorial 1 training module .........................................59

Figure 4.2: Bloom's Taxonomy for the Cognitive Domain hierarchy .............................................60

Figure 4.3: LaModel Online Training Course home page..............................................................61

Figure 4.4: LaModel Online Training Course's Advanced Learning Track ..................................63

Figure 4.5: Energy Release Rates training module, module instructions .......................................64

Figure 4.6: Presentation slide on dynamic energy release ..............................................................65

Figure 4.7: Software demonstration for modification to the Tutorial 1 seam grids ......................66

Figure 4.8: Correction activity for the Energy Release Rates training module series....................67

Figure 5.1: Assessment grade distribution.................................................................................

Figure 5.2: Item Difficulty plot for Knowledge Check 1 Assessment ...........................................79

Figure 5.3: Item Difficulty plot for Knowledge Check 2 Assessment ..........................................82 


\subsection{Introduction}

Released in 1993, LaModel (pronounced Lam-model) has aided mining engineers and researchers alike in the design and analysis of underground mine stabilities. Recently MSHA (Mine Safety and Health Administration) specifically mentions the use of the LaModel program for the analysis of complex of non-typical roof control plans. While the use of National Institute of Occupational Health and Safety (NIOSH) pillar analysis programs such as ARMPS (Analysis of Retreat Mining Pillar Stability), AMSS (Analysis of Multiple Seam Stability), or ALPS (Analysis of Longwall Pillar Stability) are still recommended, roof control plans and revisions of complex and/or non-typical underground mining situations are to be supplemented with a LaModel analysis. These complex scenarios are defined as either room-and-pillar retreat mining greater than 1000 feet, bump or bounce prone mines or coal seams, or other criteria considered unusual by the District Manager (Stricklin, 2013). While initial developed as an academic tool, the LaModel program has grown immensely adapting to the ground control concerns and problems within the mining industry. Although being the utilized as the primary design program in over 50 research papers published at the International Conference on Ground Control in Mining (ICGCM) and current regulatory reliance on the LaModel have made it a popular design tool, there is not a comprehensive help file for users to access. With a rising number of users and more widespread use of the program, there is now a large demand for better education and training in the practical application and detailed analysis using LaModel.

The LaModel program utilizes a displacement-discontinuity variation of the boundaryelement method for the calculation of stresses and seam displacements in thin bedded deposits such as coal, salt, potash, limestone, or other tabular seams or veins (Heasley and Salamon, 1996). By simplifying the overburden as a series of homogenous laminations within the strata, and by limiting the analysis to the seam itself, the displacement-discontinuity method provides a significant reduction in computation time while providing practical/targeted result over very large areas-of-interest (Heasley and Agioutantis, 2001). The purpose of the LaModel system of programs is to provide mining and geotechnical engineers with a software tool for investigating and optimizing pillar design and mine layout with respect to the overall safety and stabilities of underground works. 


\subsection{Statement of Problem}

Over the past 20 years, mining engineers and researchers have used the LaModel program for improving the design and safety of single and multiple seam mining operations. This boundary-element program calculates the displacements and stresses in thin bedded deposits by assuming a homogeneous laminated overburden. Initially developed for academia and research purposes, LaModel could only analyze small ( 250 x 250) manually gridded areas providing users with text outputs for seam convergence as well as the element, overburden, multiple-seam, and surface-effect stresses. With the adoption of a graphical post-processor and input parameter forms, LaModel was released to the general public in 1999. While the model is simplistic in nature, LaModel showed early success in its ability to accurately represent the behaviors and characteristics of both in-seam and overburden materials. Soon after, with the development of coal and gob wizards to aid in user generation of material properties and updates to the user interface, LaModel quickly became popular within the industry as an accurate and efficient underground design tool.

Through the efforts of academic researchers and mining engineers, the use and capabilities of the LaModel program have grown immensely while adapting to ground control concerns and problems within the mining industry. The current version of LaModel (LaModel 3.1) allows users to analyze large (2000 x 2000) automatically gridded areas for seam convergences, stress distributions, subsidence, pillar safety factors, and bump or bounce prone regions. While these program updates have greatly increased its utilization by mine operators, so too has regulatory reliance on LaModel. Many of these new LaModel functions were published and employed by MSHA for the back analysis of the Crandall Canyon Mine collapse in 2007. Presently, MSHA specifically calls for the use of LaModel in the evaluation of support and pillar stabilities for non-typical mine layouts including but not limited to mining operations with depths greater than 1000 feet and/or in bump or bounce prone seams. Although multiple publications, research projects, and regulatory reliance on LaModel have made the program a popular design tool, there is not a comprehensive help file for users to access when questions about the program arise. With a rising number of users and more widespread use of the program, there now is a large demand for better education and training in the practical application and detailed analysis using LaModel. In order to inform and train industry professionals, as well as engineering students, an electronic user's manual and comprehensive online training are being developed in this thesis. 
The development of an online user's manual and training modules provides users of all educational backgrounds with free mobile access to the details and practical applications of LaModel. Using the electronic manual, users are be able to quickly access information on the installation, use, and troubleshooting procedures of the LaModel program through the incorporations of detailed documentation, software simulations, presentations, and related academic articles. Further information and instruction is obtained by completing the provided self-paced online training modules composed of voiced-over and captioned slide presentations, hands-on software demonstrations, academic articles, as well as related explanations from the manual text. It is the intention of this project to better educate the public on both the capabilities and limitations of the LaModel program through the educational design and online distribution of the LaModel user's manual and training modules.

\subsection{Objective}

The purpose of this work is to better inform and train academic, industry, and regulatory users on the practical application and technical background of LaModel. Such efforts will improve underground pillar and entry stabilities as well as increasing miner safety and production.

\subsection{Statement of Work}

A comprehensive electronic user's manual and training modules has been developed to provide a singular source for LaModel reference and training materials. The user's manual allows one to quickly access information on the installation, operation, and troubleshooting procedures of the LaModel program through the incorporation of detailed documentation, software simulations, presentations, and related academic articles. While the manual provides technical details on all of the intricacies of the program, further information and instruction on LaModel can be obtained by completing the provided self-paced online training modules. Comprised of three different educational tracks pedagogically designed to achieve high levels of student learning, educational instruction are given in the form of voiced-over and captioned slide presentations, hands-on software demonstrations, academic articles, as well as related explanations from the manual text. Using the Adobe Technical Documentation Suite, the manual and all training modules have been organized and presented to LaModel users through the creation of an Open Online Learning environment. It is the purpose of this work to better educate 
the public on both the capabilities and limitations of the LaModel program through the educational design and open online distribution of the LaModel electronic user's manual and training modules.

\subsubsection{Manual Text}

The electronic user's manual has been designed to assist users of all educational and industry backgrounds on the installation, operation, and troubleshooting procedures for the LaModel program. Using a Table of Contents style navigation bar, users are able to quickly access detailed information on the program in the form of technical documentation, voiced-over and captioned software simulations, presentations, and peer-reviewed articles. By engaging in a series of text documents and video simulations, users are introduced to each aspect of the LamPre, LaModel, and LamPlt programs as well as the Stability Mapping application. While the manual text is intended to provide short program descriptions, the available software simulations and presentations provide users with a more hands on approach while academic articles provide users with a secondary source on the operation and solution options available in LaModel. The development of a comprehensive electronic user's manual provides both the new and experienced users with a basic support system for the LaModel program.

\subsubsection{Open Online Learning}

Currently, both private and public educational institutions have become more accepting of the e-learning environment as a means of educating students, foreign based nationals, and working professionals. While the Information Age has brought technological and cultural changes in the form of mobile communications, a new educational revolution steps away from the traditional classroom setting and adopts the online learning environment. According to the New York Times, 2012 was deemed the, "Year of the MOOC" or Massive Open Online Course with the launch of online educational platforms such as edX developed by Massachusetts Institute of Technology (MIT) and Harvard University, Coursera developed by professors from Stanford University, and Udactiy developed by Stanford University Sebastian Thrun and University of Virginia professor David Evans (Pappano, 2012). Due its growing global popularity, in Oxford dictionaries defines MOOC as, "a course of study made available over the internet without charge to a very large number of people" (Oxford, 2013). With current enrollment estimated at 10 million users and courses available from over 200 universities (Shah, 
2013) , the current online learning practices have proven themselves as adequate mediums for the distribution of information and training available to all users with internet access.

LaModel's self-paced online training modules have been divided amongst three online learning tracks or ability groups; novice, intermediate, and advanced. Each module has been designed to increase and maintain user comprehension of LaModel topics through the incorporation of traditional educational pedagogies modified for deployment in the online learning environment. In completing each educational track, users will have mastered a series of concepts and application skills with respect to their current level of experience in the LaModel program.

\subsubsection{Novice Learning Track}

The Novice educational track provides beginning users with training modules for the initial knowledge and skills necessary to adequately prepare, run, and analyze basic single and multiple seam mining scenarios. The novice user is introduced to the LaModel program and Stability Mapping application through a series of discussions and hands-on activities highlighting their basic capabilities and limitations. Users are first introduced to LaModel through an introductory slide presentation followed by building single and multiple seam models in the Tutorial 1 and Huff Creek hands-on learning activities, respectively. User knowledge is evaluated through the implementation and pedagogical design of educational assessments. In achieving the educational objectives of a given assessment, users will have obtained access to more complex training modules, continuing user progress in the completion of the novice educational track.

\subsubsection{Intermediate Learning Track}

Although structurally analogous to the novice educational track, the intermediate track has been designed to provide more experienced users with the knowledge and skills necessary to prepare, calibrate, run, and analyze the more complicated underground mining scenarios. The intermediate user is introduced to the behaviors and characteristics of fundamental equation for the laminated overburden model through the discussions and hands-on learning activities of the Gory Details training module series. User knowledge and operation of the LaModel program is further enhanced in the Calibration module series where users obtain the skill necessary to appropriately modify input parameters to accurately reflect underground behaviors and conditions. The Solution Options training modules educate users on the forms of analysis 
provided by LaModel such as seam convergence, vertical stress, pillar stress safety factors, etc. In the final series of training modules, users are further educated in the practical operation of the Stability Mapping application and LamPlt program. User knowledge is evaluated through the implementation and pedagogical design of educational assessments. In achieving the educational objectives of a given assessment, users will have obtained access to more complex training modules, continuing user progress in the completion of the intermediate educational track.

\subsubsection{Advanced Learning Track}

The advanced educational track has been designed to provide the experienced user with a more detailed understanding of the behaviors and characteristics of the LaModel program. As an expansion of the intermediate track, this series of training modules begins by further investigating the behaviors and characteristics of the fundamental equation for the laminated overburden model in Gory Details II. The Solution Options II series of training modules, similar to its predecessor, educates the user on the more advanced forms of analysis provided in LaModel. As the user comprehension and application of the LaModel program becomes more advanced, the user continues their education in the more intricate features of LaModel. In the final series of training modules, user knowledge in the characteristics and behaviors of the laminated model is further assessed in the programming of a simplified LaModel application in Microsoft Excel. User knowledge will be evaluated through the implementation and pedagogical design of educational assessments. In achieving the educational objectives of a given assessment, users will have obtained access to more complex training modules, continuing user progress in the completion of the final educational track.

\subsubsection{Professional Development Hours}

Upon completion of a given educational track, users will be presented with the option of receiving Professional Development Hours (PDHs) equivalent to an estimated time of completion. If PDHs are requested, then a Certificate of Completion will be generated documenting the user's name, date of completion, the educational track completed, and number of Professional Development Hours earned.

\subsubsection{Third party Learning Management System}

The work composed and discussed in this thesis has been developed for assembly in Coursesites powered by Blackboard, a third party Learning Management System (LMS). While 
the Coursesites provides no aid in the development and design of course materials, it does provide an up-to-date and user friendly online infrastructure for the delivery and management of instructional content, course administration, event management (i.e., scheduling, tracking), and certification management as well as a series of anti-cheating measures. Due to the availability and functionality of this LMS, the development of a unique online management infrastructure was determined to be beyond the scope of work for this project. 


\subsection{Literature Review}

For the past 20 years, as operations continue to mine at greater depths and in more complex geologic conditions, LaModel has been utilized by both academic and industry engineers as a reliable design tool for the analysis of convergence and stress with respect to the laminated overburden model. Currently the LaModel program has been utilized in over 50 academic papers published at the International Conference on Ground Control in Mining (ICGCM) and is required for stability analysis by MSHA for all "non-typical" underground mine plans. However, as reliance on the program has greatly increased, there is a deficiency of up-to-date, accessible information on LaModel development, operation, and analysis procedures.

In an attempt to educate and training the mining community, many previous novice users have been introduced to the LaModel program through a series of academic publications, on-site training workshops, and on-line tutorials. Still, this introductory knowledge of the program does not create a proficient or competent user. It is the purpose of this research to develop a comprehensive online user's manual and training modules through the incorporation of an open online learning environment implementing historically proven educational pedagogical practices for the enhancement of student learning and comprehension. This online reference source will provide all users with increased accessibility to the program as well as educational materials on the development and application of LaModel.

\subsection{LaModel}

The LaModel program, originally developed by Dr. Keith Heasley in 1993, implements a displacement-discontinuity variation of the boundary-element method for the determination of convergence and stress distributions on thin seams or vein deposits (Heasley, 1998). Through the application of a homogeneous laminated overburden, the program more realistically represents the natural flexibilities of the stratified geologic overburden and multiple seam mining interactions (Heasley, 2008). In calculating the in-seam convergence with respect to the programs fundamental differential equations, LaModel can currently produce results for stress concentrations, multiple seam interactions, pillar stabilities, and subsidence. The number of solutions options available allows for an increase in practical design application and analysis with respect to current underground mining practices and regulations. 
Since launching the program in 1994, LaModel has been continually revised and updated with regards to modernized programming languages and industry/regulatory needs/requests such as the previously mentioned deep cover calibration, increasing number of seams available, fault plane, etc. Originally purposed for academic research, the LaModel program could only define 26 in-seam materials for the calculation of seam convergence and stress within a given 250 x 250 element grid. With the development of a graphical post-processor and input parameter forms, LaModel was first released to the public in 1999 (Heasley, 2008). Currently, LaModel 3.1 allows users to define up to 52 in-seam materials for the calculation of seam convergences, stress distributions, subsidence, pillar safety factors, and bounce or bump prone areas within large 2000 x 2000 automatically gridded areas. In program guides or, "Wizards," help users define and calibrate input parameters with respect to the characteristics and behaviors of the overburden and seam (Heasley, 2011). While software updates have expanded the use of the program, the inherent flexibilities and ease of parameter modifications have made LaModel a well accepted industry standard in the stability analysis of underground mine workings.

In 2007 the Mine Safety and Health Administration (MSHA) heavily relied on the LaModel program for the back analysis of the Crandall Canyon mine collapse (Heasley, 2008). In 2009, MSHA released Program Information Bulletin (PIB) 09-03 (2009) posted general guidelines for the use of numerical modeling in proposed ground control plans. As coal production continued, mining operations found themselves in deeper reserves and more complex multiple seam mining geometries. In response the incidents within the industry, MSHA released PIB 12-09 (2012) a Research Report on Coal Pillar Recovery under Deep Cover in which Congress directed the National Institute of Operational Health and Safety (NIOSH) to, "conduct, in collaboration with the University of Utah and West Virginia University, a study of the recovery of coal pillars through retreat room-and-pillar mining practices in underground coal mines at depths greater than 1,500 ft," (Public Law 110-161). The incident at Crandall Canyon lead to the development of the Deep Cover Calibration method for LaModel. In the past five years alone, the LaModel program has been featured in more than fifteen academic papers and current MSHA roof control plan and review procedures specifically call for the use of the LaModel program in the analysis of pillar stabilities for all mining operations at overburden depths greater than 1,000 feet, beyond the scope of NIOSH programs, in historically bounce or bump prone seams, or other criteria the District Manager deems complex or non-typical (Stricklin, 2013). With increased support of 
LaModel from the regulatory agencies, and therefore industry, it has become crucial to increase public accessibility to the program, practical training, and reference materials.

As mining continues to operate at deeper depths and in more complex multiple seam mining geometries there has been an increase in numerical modeling of underground mine works for stability analysis. The LaModel program has had a long history of successful application for nontypical or complex mining scenarios here in the United States and around the world. However, only recently has program seen an influx in users with respect to current mining practices and regulatory requirements. While LaModel provides users with defaulted input parameters to achieve reasonable results for mining conditions, designing specific mine plans or layouts requires the calibration of these parameters to reflect the unique conditions of a given mine site. Currently, users are introduced to the LaModel program through either short online tutorials or 8-16 hour on site workshops. While these methods have allowed for the distribution of the software within the mining industry, user knowledge and program competency is poor. Common LaModel problems typically involve basic operational questions from beginning users and poorly defined model parameters from more experienced users often caused by misconceptions on the implication of their modeling choices. Therefore, in order to increase the knowledge and competency levels of LaModel, a user's manual and training modules will be available online as a reference source to all users.

\subsubsection{Current LaModel Information \& Training}

Basic instruction manuals for the LamPre 2.1 program and on-site LaModel Workshops have been somewhat available to inform and train the general public on the application and limitations of the LaModel program. However, the currently available instructional material is gravely out of date with the most recent tutorial developed and uploaded in 2009 implementing an obsolete version of LaModel, LaModel 2.1. While these early tutorials helped users get started using LaModel, they do not contain explanations on any of the material wizards or the more advanced solution options now available to users. To combat the lack of a comprehensive help file or the availability of up-to-date training materials, one to two day on-site LaModel Workshops are provided as a, "crash course," on the application, calibration, and analysis of the laminated overburden model. After 8 years of providing the workshop service, with the majority of classrooms being at or overcapacity (see Table 2.1), there is still a general need for a singular 
LaModel reference source and increased accessibility to the training material. By increasing accessibility to comprehensive and up-to-date training materials:

1) new users will be provided with a more complete background of the program as well as a basic understanding of LaModel's operational procedures,

2) support for intermediate users in using new program features and understanding the underlying mechanics of the program,

3) and develop expert users with detailed knowledge on program mechanics, parameters, and features.

Table 2.1: Summary of LaModel Workshop History

\begin{tabular}{|c|c|c|c|c|}
\hline Date & Company & Location & $\begin{array}{c}\text { Length } \\
\text { (Hrs) }\end{array}$ & Attendees \\
\hline $7 / 15 / 2015$ & Alliance Coal & Madisonville, KY & 8 & 23 \\
\hline $8 / 15 / 2015$ & MEPCO & Morgantown, WV & 8 & 7 \\
\hline $5 / 22-23 / 2014$ & Grand Cache Coal & Calgary, AB & 12 & 12 \\
\hline $8 / 29-30 / 2013$ & Patriot Coal & Quincy, WV & 16 & 17 \\
\hline $3 / 24 / 2012$ & $\begin{array}{c}\text { UK, SIU, WVU, MSHA, } \\
\text { PADEP, Alpha, \& Patriot }\end{array}$ & Morgantown, WV & 8 & 27 \\
\hline $7 / 21-22 / 2010$ & Patriot Coal & Quincy, WV & 12 & 11 \\
\hline $1 / 21-22 / 2009$ & $\begin{array}{c}\text { MSHA, Arch, Bowie, SUFCO, } \\
\text { etc }\end{array}$ & Denver, CO & 8 & 20 \\
\hline $1 / 8 / 2008$ & Many & Grand Junction, CO & 4 & $\sim 15-20$ \\
\hline $12 / 3 / 2007$ & MSHA & Tridelphia, WV & 8 & 20 \\
\hline $11 / 29 / 2007$ & MSHA & Beckley, WV & 8 & 19 \\
\hline $11 / 26 / 2007$ & MSHA & Denver, CO & 8 & 17 \\
\hline $10 / 17 / 2007$ & Many & Pikeville, KY & 4 & $\sim 15-20$ \\
\hline $10 / 16 / 2007$ & Many & Norton, VA & 4 & $\sim 15-20$ \\
\hline $9 / 20 / 2007$ & Many & Twin Falls, WV & 4 & $\sim 15-20$ \\
\hline 9/19/2007 & Many & Charleston, WV & 4 & $\sim 15-20$ \\
\hline $7 / 30 / 2007$ & Many & Morgantown, WV & 4 & $\sim 20-25$ \\
\hline
\end{tabular}

The lack of a singular source of information for the LaModel program creates initial frustrations for new users learning the basics as well as those more advanced users using new program analysis features. Due to this shortage of up-to-date training information, it is presumed that many LaModel users (novice and experienced) abandon the program out of frustration, or turn to more complex, but not necessarily more appropriate commercial programs with friendlier in-program user support and online training modules or video tutorials. Therefore, a 
comprehensive Online LaModel User's Manual compiled from an updated user's manual and a three track (novice, intermediate, advanced) training course will be developed for the enhancement of public knowledge and understanding of LaModel program and its application to underground stability design. The development of an online user's manual and training modules is intended to replace the majority of on-site workshops and current online tutorials by providing all interested parties with direct access to current and relevant information on the operation and features of the LaModel program.

\subsection{Open Online Learning}

Over the past decade the global rise of internet availability, increase of computational capacities, and a reduction in cost has amplified claims that new streaming and mobile technologies will provide accessible, quality education to the public (Alexander \& Boud, 2001). Currently, both public and private educational institutions have become more accepting of the online environment as a means of educating a variety of students including, but not limited to, on-campus undergraduate and graduate students, foreign based nationals, and working professionals (Marginson \& van der Wende, 2007). With current online enrollment estimated at about 10 million users and courses available from over 200 universities around the world, students are beginning to gravitate away from the traditional classroom in adoption of the MOOC or Massive Open Online Course (Shah, 2013). The largest and most attended online educational platforms are edX, a collaborative project between Massachusetts Institute of Technology (MIT) and Harvard University, Coursera, developed by Stanford University professors Andrew Ng and Daphne, and Udacity developed by Stanford University professor Sebastian Thrun and University of Virginia professor David Evans (Pappano, 2012). The popularity of these online learning environments deemed The New York Times to declare 2012 as the, "Year of the MOOC, " and in 2013 the Oxford University Publishers updated their dictionary defining MOOC as, "a course of study made available over the internet without charge to a very large number of people," (Oxford, 2013).

While, "the benefits of eLearning are highly prophesized," many online educational platforms are falling short due to their limitations of student involvement (O'Neil, Singh, \& Donoghue, 2004).The constraints on participation are directly related to the fact that many online classroom environments are, "little more than lectures that are delivered online in the form of 
text, audio, and/or video," (Alexander \& Boud, 2001) with pedagogical practices either flawed or missing entirely. Through the analysis of the technology and learning relationship, researchers are finding that students, "listening or reading, by themselves, cannot challenge the learner's egocentric thinking sufficiently to generate new learning," (Ertmer, Sadaf, \& Ertmer, 2011).

In an attempt to increase and stimulate student learning, online course designers have been implementing a multitude of activities and secondary methods of participation to increase student involvement in the digital classroom (Stephenson, 2001). Unfortunately there is little research on the effectiveness of these online applications and current research available is often a measurement of a student's ability to use the application effectively (Coomey \& Stephenson, 2001) and not a measure of intellectual growth. In developing an online educational environment, it is important that the pedagogical design is not driven by the technology itself, "rather it depends on developing novel forms of organizational processes and structure while carefully maintaining and enhancing the pedagogical principals," (Mayes, 2001) that align themselves with the fundamentals of visual, auditory, and kinesthetic styles of learning.

The value behind an online classroom should be credited to pedagogical improvements rather than just the use of the technology implemented in its design (Jackson \& Anagnostopoulou, 2001). In our new digital age, designers often trade productive programs that focus on fundamental learning styles and proven pedagogical practices for ornate, eye-catching design. This often creates learning environments that are busy and distracting, thereby degrading the quality of information retained by the student. To be effective, the online user manual and training workshop should be perceived as a useful reference aid to the LaModel program. Through the execution of pedagogical practices, which emphasize the fundamental learning styles, classroom administrators can monitor and maintain the quality of delivery, information, and student learning within the online learning environment.

\subsubsection{Kolb's Experiential Learning Model}

Building on the earlier works of John Dewey (1938) and Kurt Lewin (1947), American educational theorist David Kolb believes that, "learning is the process whereby knowledge is created through the transformation of experience," (Kolb, 1984). Through reflections on their educational experiences, one can gain a better understanding and retention of the presented material. First proposed by Kolb in 1984, the Experiential Learning Model (ELM) provides 
classroom administrators with an outline for designing active, collaborative, and interactive learning experiences that support that student's educational development. The educational theory is presented as a cyclical model of learning consisting of four distinct learning stages; Concrete Experience, Reflective Observation, Abstract Conceptualization, and Active Experimentation as shown in Figure 2.1. Kolb also identified four learning styles which correspond to his four learning stages, highlighting the conditions under which students learn better. These student learning styles are:

1. Assimilators (those who learn better when presented with sound and logical theories),

2. Convergers (those who learn better when provided practical application),

3. Accommodators (those who learn better provided hands-on experiences), and

4. Divergers (those who learn better when observing and collecting a wide range of information) (Kolb and Kolb, 2012).

While students may enter the cycle at any stage, to optimally learn the new task/information one must follow the sequence, participating in each stage, such that the student can observe, think, plan, and apply all educational themes.

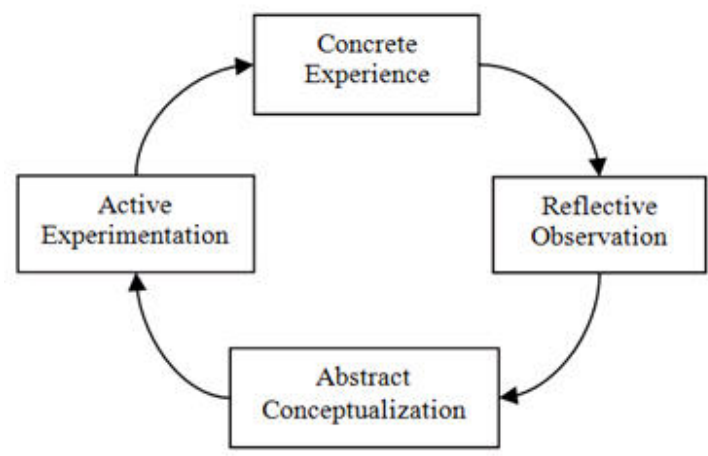

Figure 2.1: Theoretical model of Kolb's experiential learning (Kolb, 1984) 
Table 2.2: Kolb's four stages of learning categorized by dimension

\begin{tabular}{|c|c|c|}
\hline \multirow{2}{*}{ 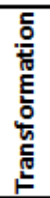 } & Concrete Experience & $\begin{array}{l}\text { A new experience is encountered or a } \\
\text { reinterpretation of an existing experience. }\end{array}$ \\
\hline & Abstract Conceptulization & $\begin{array}{l}\text { Reflection gives rise to a new idea or a } \\
\text { modification of an exisiting abstract concept }\end{array}$ \\
\hline \multirow{2}{*}{ 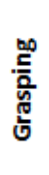 } & Active Experimentation & $\begin{array}{l}\text { Learners apply thier knowledge to the world } \\
\text { around them to see what results. }\end{array}$ \\
\hline & Reflective Observation & $\begin{array}{l}\text { Learners observe in systematic manner and } \\
\text { reflect upon what they have observed. }\end{array}$ \\
\hline
\end{tabular}

Kolb continues by simplifying a student's educational development into two categories (see Table 2.2) or, "dimensions." The first dimension, "transformation," recounts the student's ability to acquire information during the learning process. With respect to ELM, a student obtains information by either envisioning a theory or model of what is observed (Abstract Conceptualization) or actively participates in activity familiarizing themselves with a topic (Concrete Experience). The second dimension, "grasping," recounts the student's ability to construct their own conclusions from the presented materials. For this dimension Kolb distinguished between Reflective Observation, where the emphasis is on reflecting on specific experiences and understanding their meaning, and Active Experimentation, which stresses the practical application of the student's knowledge and understanding.

The use of Kolb's Experiential Learning Model (ELM) has been a suitable for classroom design for not only the online learning environment but the traditional classroom setting as well. While learning is focused on and stimulated by the individual student, the experiential learning model is accommodating to a wide range of classroom diversities and can exist without an available teacher or proctor (Itin, 1999). However, the success of ELM is highly dependent on a student's ability to be self-motivated in order to maintain a high level of learning (Kolb, 1984). Through the use of broad learning styles that embody nearly every learner, the learning cycle presented by Kolb allows students to experience, observe, reflect, and apply all educational themes and objectives. While Kolb's model provides a rigid structure and direction within a learning environment, it does not provide any insights on student intellectual activity or knowledge and therefore needs to be supplemented by further pedagogical practices for the identification of student cognitive learning abilities. 


\subsubsection{Bloom's Taxonomy of Educational Objectives}

Implemented in classroom design as a classification system for educational objectives, Bloom's Taxonomy allows for the differentiation of student cognitive abilities (i.e. thinking, understanding, and applying) allowing administrators to evaluate and monitor the inconsistencies between what students learned and what they were expected to learn at a given stage. Originally published by Dr. Benjamin Bloom in 1965, The Taxonomy of Educational Objectives Handbook 1: Cognitive Domain has remained an effective educational guide for student learning. Educators have used this theory of learning as a means of achieving a higher order of thinking within the classroom. Bloom's initial taxonomy was intended to provide a classification system for educational objectives, "to help teachers, administrators, professional specialists, and research workers...discuss curricular and evaluation problems with greater precision," (Bumen, 2007). Presently, Blooms Taxonomy provides a framework for sustaining high-level thinking processes in the classroom as well as a means of evaluating the level of learning and the quality of the lesson plans. To guarantee the accuracy of Bloom's Taxonomy it is, "important to assess the student across each of the six levels," (Eber \& Parker, 2007) being evaluation, synthesis, analysis, application, comprehension, and knowledge. The hierarchy of the taxonomy is displayed in Figure 2.2 below with each learning level further defined in Table 2.3. Through the use of action verbs listed, one can expand each category to help define different types of learning activities that address a specific cognitive level. Student learning begins at the foundation or Knowledge and progresses to the next cognitive level until the student reaches what Bloom considers the apex of higher order thinking, Evaluation. Through the hierarchy structure, students continually build on previously developed skills obtained from lower levels of learning. For example, in using a mathematical equation for pillar design (Evaluation), one needs to understand the definition (Knowledge), calculation (Application), and consider (Synthesis) the limitations of the given equation. By integrating these previously developed skills into higher levels of learning increases repetition and develops a solid understanding of all skills involved. 


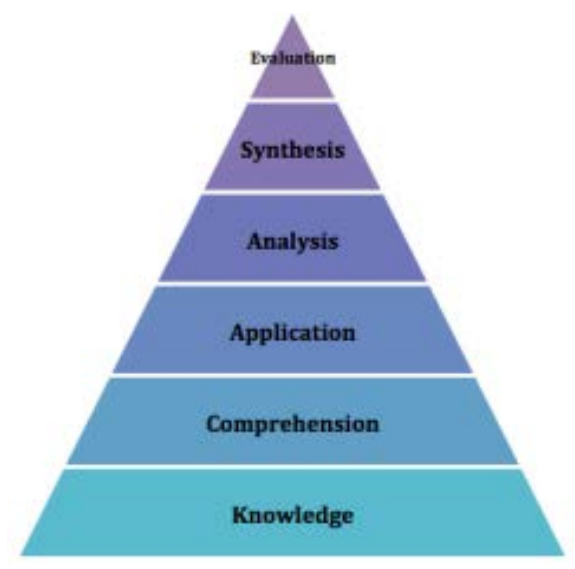

Figure 2.2: Bloom's Taxonomy of Educational Objectives in the cognitive domain

Table 2.3: Bloom's Taxonomy Action Words

\begin{tabular}{|l|l|l|l|l|l|}
\hline \multicolumn{5}{|c|}{ Action Words for B loom's Taxonomy } \\
\hline $\begin{array}{l}\text { Lowest Level } \\
\text { Knowledge }\end{array}$ & \multicolumn{1}{|c|}{ Comprehension } & \multicolumn{1}{c|}{ Application } & \multicolumn{1}{c|}{ Analysis } & \multicolumn{1}{c|}{ Synthesis } & \multicolumn{1}{c|}{ Highest Level } \\
\hline Define & Associate & Administer & Analyze & Appraise & Anticipate \\
Describe & Compare & Apply & Appraise & Compare & Arrange \\
Discover & Define & Calculate & Calculate & Consider & Assemble \\
Identify & Demonstrate & Construct & Compare & Convince & Collaborate \\
Listen & Discover & Demonstrate & Conclude & Criticize & Design \\
Memorize & Estimate & Discover & Deduce & Defend & Formulate \\
Observe & Explain & Illistrate & Differentiate & Evaluate & Hypothesize \\
Read & Indicate & Manipulate & Explain & Judge & Integrate \\
Recite & Recite & Relate & Order & Order & Organize \\
Reproduce & Relate & Solve & Separate & Recommend & Produce \\
\hline
\end{tabular}

Through the use of this differentiated instructional technique, students become more aware of their educational development as well as their own strategies for learning and thinking (Krathwohl, 2002). By structuring online learning modules with respect to the educational objectives previously mentioned, mismatches between what has been taught and what is being assessed are highlighted. These differences will help educational administrators identify the growth and development of a student's cognitive ability with respect to the current or previous course.

With current online enrollment estimated at about 10 million users and courses available from over 200 universities around the world, students are beginning to gravitate away from the traditional classroom in adoption of the MOOC or Massive Open Online Course (Shah, 2013). Unfortunately, for many online administrators and course designers, the primary focus of research has been on the implementation and employment of technology specific to the e- 
learning environments and the creation of new pedagogies to reflect modern material delivery systems. With a singular focus on the technology, many educators fail to realize that course development should not be driven by the technology itself but rather on the development of an organized procedure and structures of enhanced pedagogical principals that remain fundamental to educational learning theories (Mayes, 2001). This simplistic view of, "not reinventing the wheel," has created a resurrection and adaption of the classic Bloom's Taxonomy for the development and assessment of online learning material. Through the use of Bloom's classification scheme, question prompts as well as student responses can be analyzed with respect to the level of critical thinking. Lower levels of thinking involve the recollection, comprehension, and application of the material presented where as higher levels of thinking require analysis, synthesis, or evaluation (Ertmer, Sadaf, \& Ertmer, 2011). Due to the lack of face-to-face contact between student and educator, question prompts are the primary strategy used to facilitate student interactions within the online learning environment. Therefore, it is important to have a clear understanding of the relationship between question/prompt types and their influence on the quality/understanding level of the student response. Through the examination of observed student response patterns, educational administrators are able to collect and analyze qualitative data on the stimulation of higher levels of thinking within the online learning environment such that student achievement gaps are minimized.

\subsubsection{Benchmark Assessments}

The No Child Left Behind Act (NCLB), passed by Congress in 2001, initiated a large increase in the implementation of assessments to measure and improve upon student learning at the secondary school, district, and state levels. The focus of the congressional act is on the annual examinations of a student's educational growth. Benchmark assessments have been introduced and, "are given periodically, from three time a year to as often as once a month," and measure students' understanding of the presented curriculum (Olson, 2005). Benchmarking is a structured process that investigates student performance and the administrations adoption of pedagogical practices to meet and exceed educational quality and standards (Meade, 1998). In order to produce an effective benchmark assessment, all educational objectives and standards should be properly evaluated for their organizational design to facilitate learning and coherence among lessons, assignments, instructional techniques, and assessments. This formative assessment practice places academic-content standards at the highest of priorities and evaluates 
one's ability to meet educational expectations. The validity of a benchmark assessment is determined by the following criteria.

1. Alignment to educational standards,

2. diagnostic value of assessment through test structure and design,

3. fairness for all students,

4. technical data quality,

5. built in utility, and

6. feasibility or practicality of the lesson (Herman \& Baker, 2005)

There are a multitude of adequate benchmark assessments currently being utilized in the classroom, all of which focus on the development and growth of the student through a structured thinking process. Through the internal structure of a benchmark assessment, student learning levels can be tracked and evaluated throughout the curriculum to ensure quality student learning (McKinnon, Walker \& Davis, 2000) and therefore a quality pedagogy.

\subsubsection{Learning for Mastery Model}

Recently, due to NCLB's focus on minimizing achievement deficiencies between educational subgroups, the American educational system has seen revitalization in the, "learning for mastery" method of instruction. This pedagogical practice refers to the idea that teaching should be organized through ordered steps and in order to move forward, students have to master the previous educational step. . First developed in Dr. Benjamin Bloom’s Learning of Mastery (1968), this instructional method implements a feedback and corrective procedure directing students to individually remedy their learning problems (Bloom, 1968). While investigating the research of Dollard \& Miller (1941) on the identification of high achieving students in the traditional classroom setting, Bloom realized that the typical classroom assessment provided nothing but verification of those students whom the instruction was not appropriate or did not reach. Through deployment of formative assessments within learning modules in conjunction with regular correction of individual learning errors, Bloom believed that all students are expected to retain and master the material presented in the unit lesson.

The mastery learning instructional process begins with the organization of student learning materials and skills into individual learning modules represented as, "Unit 1," in Figure 2.4. Each 
instructional unit is followed by an initial benchmark assessment designed to provide students with feedback on their learning progress.

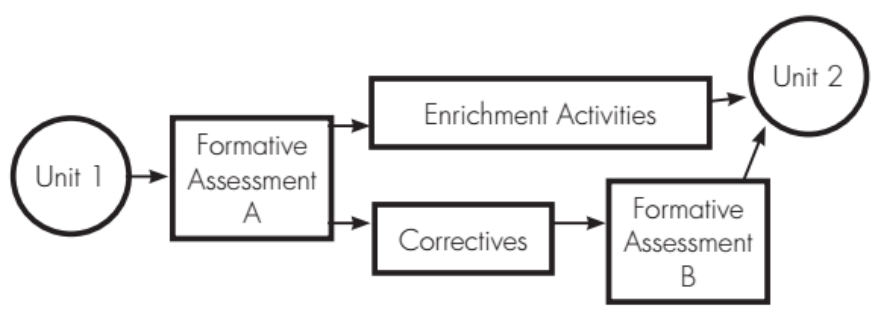

Figure 2.3: The mastery learning instructional process (Guskey, 2007)

Often provided to the students in the form of a unit quizzes, Formative Assessment A provides students with a diagnostic outlook on their progress as it identifies what the student was expected to learn, what they learned well and where there are areas of improvement. For those students whom have not mastered the information or skills necessary to proceed to the next learning module, a corrective activity allows students to individually identify and correct areas of learning difficulty. These correctives are typically present unit concepts differently than in the original instruction offering students alternative learning styles as well as additional time to learn the subject (Bloom, 1976). Once the student has completed their corrective assignment, students will then submit a second formative assessment covering the same concepts and topics as the first before continuing on to the next learning module. This not only offers students a second chance at success but also verifies whether the corrective activities help the user overcome learning complications. For those students who perform well on the initial assessment, demonstrating mastery of the material, enrichment activities are provided to broaden their learning experience. Similar to the correctives, the enrichment activities are to present initial concepts and skills through differing learning methods or styles individualizing the instruction, but beyond the required level of mastery.

Through the implementation of the feedback, corrective, and enrichment procedures the mastery learning model results in student experiences that are more favorable to learning at a higher level of thinking. Modern research has shown mastery learning has provided students with a better understanding of the learned concepts and skills and that the students are better prepared for more advanced units (Clark, et al., 1983). By maintaining the expectation that all students are to truly master unit concepts or goals provided additional and individualized instruction and 
time, variations in student achievement levels are minimized in comparison to the achievement distribution of the traditional classroom as shown in Figure 2.5.

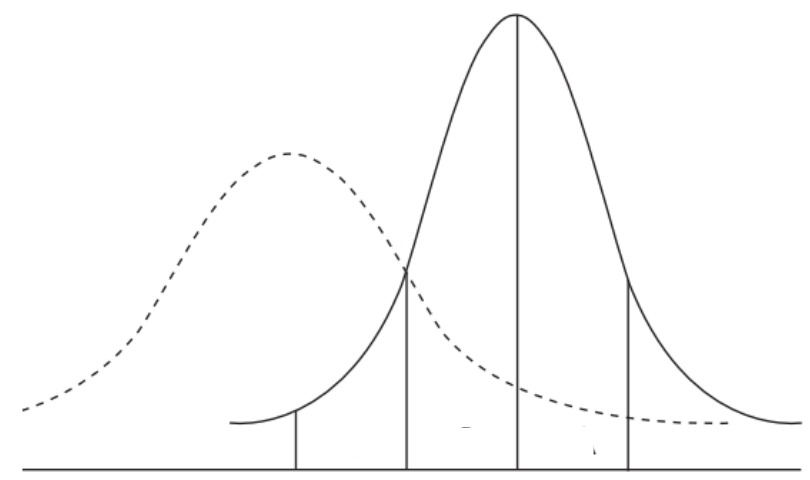

Figure 2.4: Distribution of achievement in mastery learning classroom (Guskey, 2007)

By comparing the achievement results of both the traditional (dashed) and mastery learning (solid) classroom bell curves in the figure above, educators should understand that by reducing the variation of student achievement, one must not assume that each students is learning the same and undoubtedly some students will learn more than others. However, even with varying degrees of student learning, by mastering specific learning objectives and skills outlined within each learning module, all students would reach the same level of knowledge as prescribed by the curriculum. This results in the significant closure of achievement gaps between student groups (Guskey, 2007).

Through the implementation of the mastery learning style in LaModel's online training modules, educational administrators are able to maintain minimal discrepancies in student learning. The feedback, corrective, and enrichment elements of the mastery-learning model involve students in their own education as areas of improvement are identified in conjunction with the correction of learning errors and enhancement of the student's education of the LaModel program.

\subsection{The Online LaModel User's Manual \& Training Modules}

Through the implementation of both a LaModel User’s Manual and Training Modules, users will now have a comprehensive reference source for questions concerning input parameters, modeling techniques, program application, etc. Both the user's manual and the training modules have been developed using the latest adaptations of traditional educational pedagogies and 
technologies for use in the online learning environment. While Kolb's Experiential Learning Model (ELM) provides lesson structure within the provided training modules, Bloom's Taxonomy for the Cognitive Domain and mastery learning model identify and close student achievement gaps, respectively. Carefully planning the implementation of these pedagogies in conjunction with modern technologies allows for the gradual development of the LaModel user from a novice understanding to the advance skills and knowledge necessary to use the LaModel program efficiently and accurately.

While both the written manual and online classroom aim to further the development of the user, their educational approaches are completely separate in theory and execution. For instance, the LaModel User’s Manual has been developed as a quick reference, support aid for the LaModel program. Being such, the manual has been comprised of technical definitions and descriptions as well as software simulations and technical publications for quick accesses to relevant information. The LaModel training modules however, provide users with a more handson approach to the various intricacies of the program. By processing through each of the three learning modules and referencing all provided text, users will be provided with all the materials necessary to be well-versed in the technical aspects of the LaModel program. 


\subsection{Development of LaModel User's Manual}

Since its inception in 1994, LaModel has proven itself as a reliable and practical numerical modeling program for the determination of displacements and stress distributions associated with mining operations across large single- and multiple-seam mining areas. While program features have been greatly expanded to meet the needs of ground control engineers within the industry and the program capabilities have been documented in numerous academic publications, research projects, and industry designs, LaModel's lack of a formal user's manual has limited the program's ability to expand its user base within the industry. Over the past decade, the global rise of internet availability and the development of new streaming and mobile technologies have produced a new generation of product users who want and expect quick access to detailed program information available at the press of a key or swipe of a finger. Currently, many technology companies have switched to an electronic, HTML based, system of delivery for reference documentation in order to increase product circulation while reducing overhead costs. While many companies have adopted these more modern computer-human interfaces incorporating social media feeds and hi-definition multimedia outputs, users have sometimes found them to be extremely lacking in providing relevant, current, or complete information and incorrectly presume user knowledge of given topics. Therefore in designing a the LaModel User's Manual, the HTML content maintains its focus on the LaModel program itself providing detailed descriptions on the application, derivation, and current program features. In providing users with a simplified, structurally rigorous, and comprehensive online reference sources, the LaModel user's manual looks to lower barriers of entry to knowledge, reduce user training costs, increase user acquisition of program concepts that will make them more productive, and increase the overall use of the LaModel product.

The electronic user's manual for LaModel has been designed to assist users of all educational and industry backgrounds on software installation, basic program operation, and troubleshooting procedures. A Table of Contents style navigation pane enables users to quickly access and review detailed information on the program, toggling at their own speed through technical documentation, interactive software simulations, slide presentations, and/or technical conference proceedings on the application of LaModel for the analysis of underground mine reserves. While the manual text is intended to provide users with short program descriptions, the 
available software simulations and slide presentations provide users with a more hands-on approach alongside academic articles that provide information about the operation and solution options available in LaModel through actual case studies and academic exercises. The development of a comprehensive electronic user's manual will provide both the novice and experienced user with the basic support system necessary to adequately prepare, calibrate, run, and analyze underground stability effectively and efficiently using LaModel.

\subsection{Architecture/Design of Online Documentation}

LaModel's electronic user's manual has been developed as an all-inclusive reference and support aid through the use of the Adobe Technical Communication Suite, and more specifically, the RoboHelp 10 program. This technical communication suite provides help authors and instructional designers with organizational tools and development software to deliver detailed and aesthetically pleasing content. Using RoboHelp, LaModel documentation was organized into a series of HTML-based topics allowing for the optimization of manual content such that materials can be delivered to Windows-based personal computers (Microsoft Compiled HTML Help) as well as smart phones, tablets, and eBook readers using the multi-screen functionality of the HTML5 responsive layout. Due to the communication suite's seamless integration with other programs such as Adobe Captivate, Microsoft Word, Microsoft PowerPoint, and other popular applications in heavy use by industry professionals, users are able to quickly access detailed information on LaModel and the Stability Mapping application. When the LaModel manual is opened, users will see a menu bar across the top of the window. This menu bar contains action buttons, such as Content, Search, and Index, to help one locate and explore specific information or topics. 


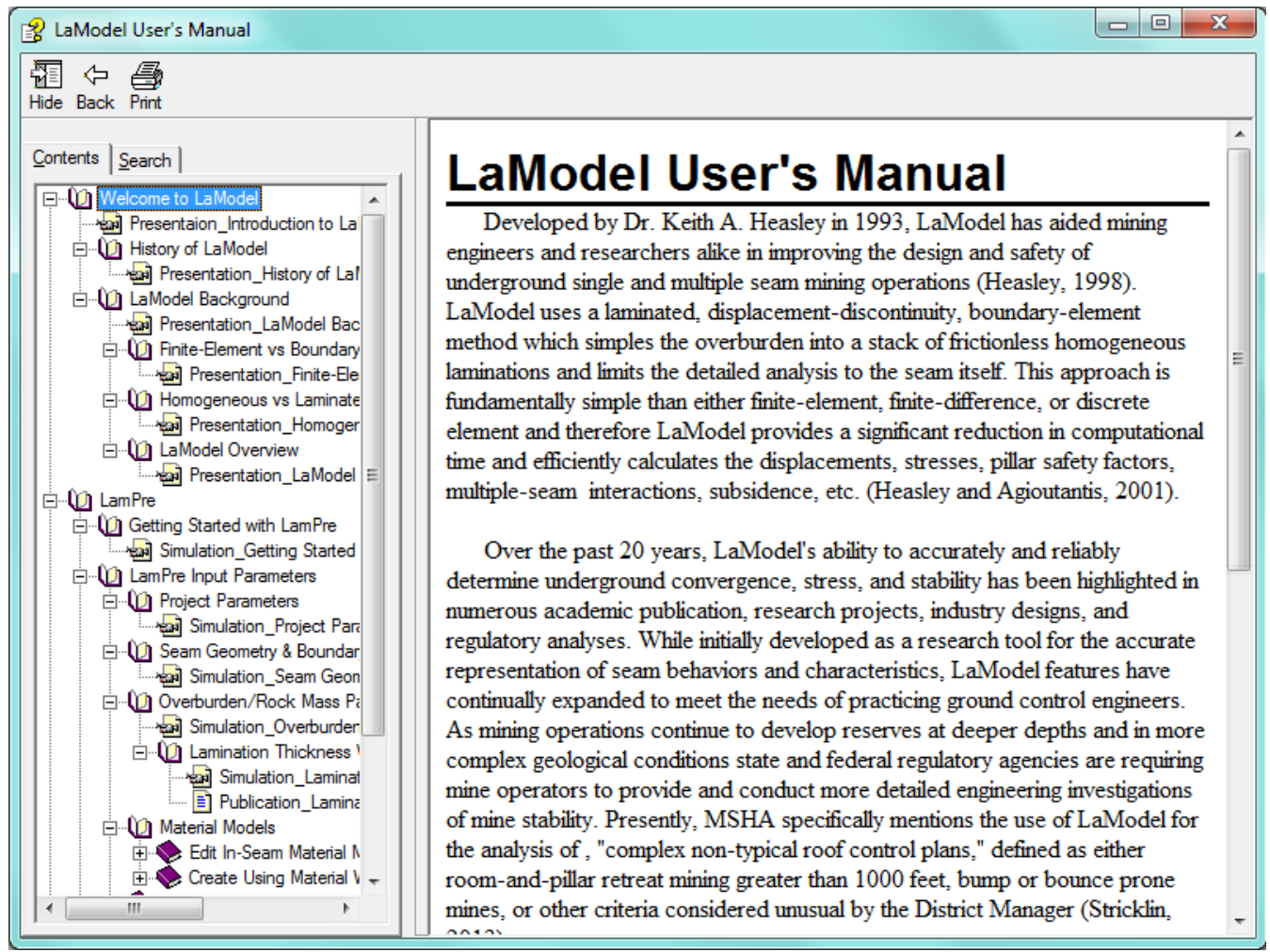

Figure 3.1: LaModel User's Manual with Contents tab enabled

As shown in the Figure 3.1, the Contents tab enables users to quickly navigate through the manual, exploring the more intricate details of LaModel through the expandable/collapsible content headings listed in the navigation pane. Once a topic has been selected, the corresponding HTML page will be displayed in the main window. The information displayed contains short descriptions of program features followed by more detailed explanations of input parameters along with any associated software simulations, presentations, and recommended publications on LaModel features and examples of their application in industry. Using the Search tab, shown in Figure 3.2, allows one to search the entire manual through the use of keywords or phrases. By selecting the List Topics button, a list will be generated below of manual topic pages in which the designated keyword or phrase has been located. Selecting a topic from the list, the corresponding HTML page will be displayed in the main window. 


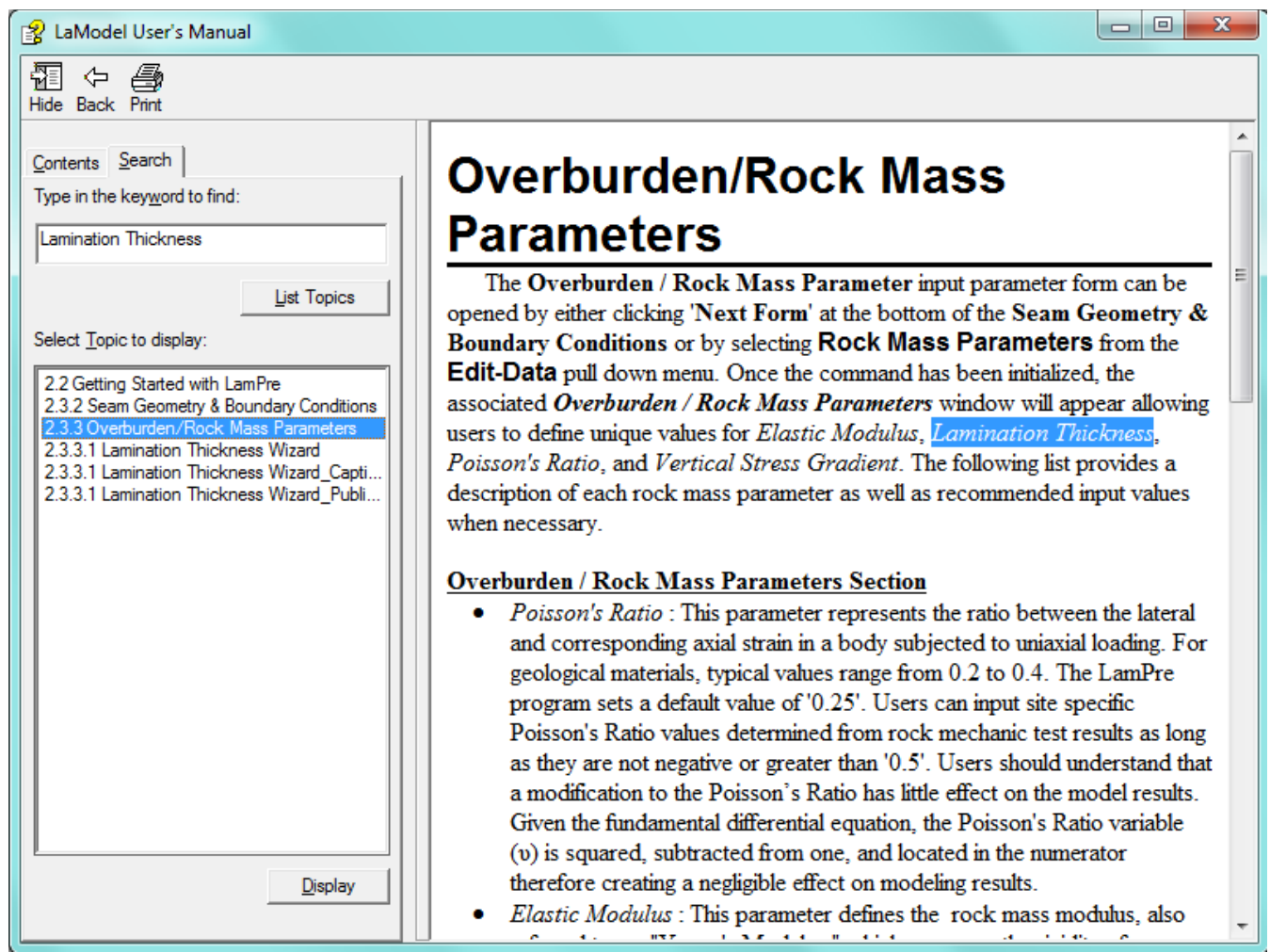

Figure 3.2: User's Manual with Search Tab Selected

This user's manual implements a three-pronged approach in the organizations of document text: Tutorial, Thematic, and Reference. These categories are based on the best practice prescriptions for online reference guides (Woelz, 2009). Tutorial approaches to software simulations are considered to be the most effective in providing users with detailed information on the installation, application, and program operations. These simulations guide users step-bystep in accomplishing a given task. The thematic approach, implemented in the technical documentation of the LaModel program, organizes the manual into chapters or units that focus on a single aspect of the program and thus are more appropriate for intermediate users. The final organizational principle employed in this user's manual is the reference or list approach. This approach groups lessons together in logically organized topics, often cross-referencing software information from across the manual when appropriate (Woelz, 2009). This indexing style of organization is more advantageous to a more experienced user who knows the exact information they seek while at the same time providing a rigid path of progression for novice users. The development of this comprehensive electronic user's manual will provide both novice, 
intermediate, and advanced users with the support system necessary to adequately and efficiently prepare, run, calibrate, and analyze complex underground mining scenarios.

\subsubsection{Technical Documentation}

The increase of internet availability and online distribution of software expansions and updates has made technical communication and documentation vital for software products that can change drastically in short period of time. The technical documentation of the LaModel program describes the architecture, functionality, and operation of the LamPre 3.0.2, LaModel 3.0.4, and LamPlt 3.0 programs as well as the Stability Mapping 2010 application currently in use. In contrast to the surface level instruction of most manuals, this technical document looks to communicate both the function and the reasoning for these functions to better train a proficient end user through details on the mathematical derivation and limitations of the LaModel programs.

\subsubsection{Software Simulations}

LaModel's software simulations have been developed to provide users with not only an audiovisual support aid for the textual documentation but also a hands-on approach to the application and derivation of the LaModel program. These video simulations allow users to follow along with program demonstrations and training videos so that the user can learn how to operate unique features of the program. 


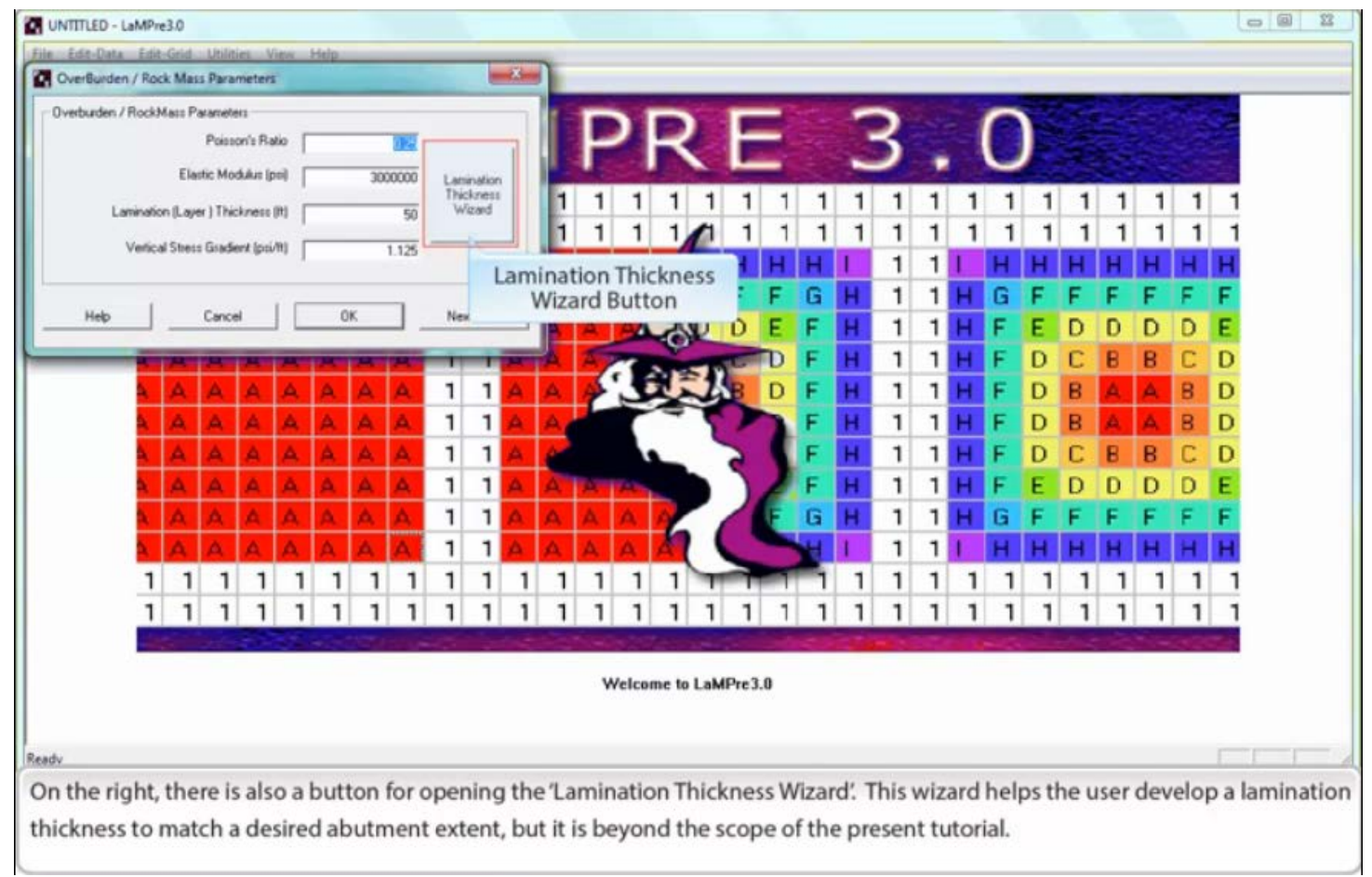

Figure 3.3: Software Simulation Screen Capture Recording

Using the Adobe Captivate program for simulation construction and publication, high quality LaModel and Stability Mapping video simulations have been developed employing screen capture movements, recorded audio, and open captioning as shown in Figure 3.3. Slide presentations have also been incorporated into software simulations as a way to thoroughly define and explain the mathematical concepts behind the proposed modeling methodologies. Through the use of these software simulations in conjunction with the manual text, users are provided with a more detailed reference source for the more complicated concepts and features of the LaModel program and Stability Mapping application.

The Adobe Captivate program was selected for the construction and publication of LaModel software simulations due to its simplicity in developing responsive HTML interface that allows for the seamless delivery of content to multiple devices with the gesture or multi-touch technology commonly embedded into modern computer-user interfaces. While these software simulations have been placed throughout the manual text as a secondary source of information, it is important to note that, when running a given software simulation, users do not have to have LaModel or any multimedia plug-ins installed on their content viewing devices. Developing the 
software simulations in such a way not only allows for more open access to reference content but also keeps user focus within the manual and uninhibited by unnecessary distractions perpetuated by working outside the manual application.

\subsubsection{Publications}

A series of peer reviewed publications have been included in the LaModel User's Manual in order to provide users with original and secondary sources of information on the more complicated features of the LaModel suite of programs and Stability Mapping application. Each conference proceeding, case study, and dissertation provides users with specific information on program applications, operational procedures, features, and analysis techniques for LaModel. In conjunction with the provided manual text and software simulations, these academic articles provide the user with the information necessary to relate methods for defining site-specific input parameters to the mathematical derivation of the laminated overburden model. These publications allow the user to further their own comprehension and understanding of the LaModel program through expert technical descriptions and explanations of program behaviors, characteristics, and features as well as on-the-ground application of these concepts.

\subsection{Topics Covered}

The User's Manual contains five main sections beginning with basic introduction to the LaModel program followed by instructions on program navigations and operations of the LamPre, LaModel, LamPlt, and the Stability Mapping application (see Table 3.1). Comprised from a series of technical documents, software simulations, and peer-reviewed articles, the LaModel user's manual introduces the new and experienced user to the LaModel program and associated Stability Mapping application. The electronic user's manual can be considered as an encyclopedia for, or companion guide to LaModel that provides users with information and hands-on learning activities discussing each feature of the program, application, and operational control. 
Table 3.1: LaModel User's Manual Section Summary

\begin{tabular}{|c|c|c|c|c|c|c|c|}
\hline \multirow[t]{2}{*}{ Section Title } & Manual Text & $\begin{array}{l}\text { PowerPoint } \\
\text { Presentations }\end{array}$ & Captivate Videos & Captioned Dialog & $\begin{array}{l}\text { Recorded } \\
\text { Audio }\end{array}$ & \multirow[t]{2}{*}{ Papers } & \multirow[t]{2}{*}{ Theses } \\
\hline & words & slides & frames & words & hours & & \\
\hline 1.0 Welcome to LaModel & 924 & 56 & 0 & 3,758 & 0.41 & 0 & 0 \\
\hline 2.0 LamPre & $>17,759$ & $>79$ & $>312$ & $>13,998$ & $\sim 1.57$ & 7 & 3 \\
\hline 3.0 LaModel & 2,071 & 2 & 62 & 3,847 & $\sim 0.41$ & 0 & 0 \\
\hline 4.0 LamPlt & 4,749 & 50 & 108 & 7,096 & $\sim 0.78$ & 1 & 1 \\
\hline 5.0 Stability Mapping & 7,281 & 28 & 133 & 4,718 & $\sim 0.52$ & 1 & 1 \\
\hline Prreliminary Manual Totals & $>32,784$ & $>215$ & $>615$ & $>33,417$ & $\sim 3.69$ & 9 & 5 \\
\hline
\end{tabular}

Through the incorporation of supplemental slide presentations, software simulations, and peerreviewed publications, users are able to follow step-by-step instructions for each facet of LaModel suite of programs.

\subsubsection{Welcome to LaModel}

The first section of the manual welcomes users to the LaModel suite of programs - LamPre, LaModel, LamPlt and Stability Mapping - through entry-level presentations which provide an overview, history, and mathematical background of the program. As shown in the detailed outline of the LaModel user's manual in Table 3.2, the Welcome to LaModel chapter begins by initiating users to the program in sub-section 1.1, Introduction to LaModel. Here users are informed of LaModel's use of the displacement-discontinuity boundary-element method for the simulation of numerous mining scenarios given the flexibility of the laminated overburden model.

Table 3.2: Summary of Section 1.0 Welcome to LaModel

\begin{tabular}{|l|c|c|c|c|c|c|c|}
\hline \multirow{2}{*}{ Section Title } & Manual Text & $\begin{array}{c}\text { PowerPoint } \\
\text { Presentations }\end{array}$ & Captivate Videos & Captioned Dialog & $\begin{array}{c}\text { Recorded } \\
\text { Audio }\end{array}$ & \multirow{2}{*}{ Papers } & Theses \\
\cline { 2 - 7 } & words & slides & frames & words & hours & \\
\hline \hline 1.0 Welcome to La Model & 924 & 56 & 0 & 3,758 & 0.42 & 0 & 0 \\
\hline 1.1 Introduction to LaModel & 216 & 5 & - & 338 & 0.06 & - & - \\
\hline 1.2 History of LaModel & 93 & 16 & - & 1,106 & 0.12 & - & - \\
\hline 1.3 LaModel Background & 99 & 31 & - & 2,119 & 0.24 & - & - \\
\hline 1.4 LaModel Software Package & 138 & - & - & - & - & - & - \\
\hline
\end{tabular}


Users then continue their introduction with sub-section 1.2 which provides a chronological timeline of LaModel developments and enhancements over the past 20 years. Building upon the knowledge gained in sub-sections 1.1 and 1.2, users further their understanding of the program with a more technical presentation on the derivation and application of LaModel. Further broken down into three sub-categories, sub-section 1.3 provides users with a more mathematical introduction to the displacement-discontinuity boundary-element, laminated overburden model followed by a procedural overview of model development and analysis as seen in Appendix I. Concluding this introductory section, users are provided with a series of hyperlinks for downloading LamPre 3.0.2, LaModel 3.0.4, LamPlt 3.0, and Stability Mapping 2010 files in subsection 1.4, LaModel Suite of Programs.

\subsubsection{LamPre}

The LamPre program was developed to provide a user-friendly preprocessor for the input of the required program parameters. As shown in Appendix I, Section 2 of the user's manual, LamPre, has been broken down into a total 17 sub-sections (accounting for $38 \%$ of the user's manual) detailing the many facets of the LamPre program. Within each sub-section, users are supplied with: manual text defining each available parameter along with suggested parameter ranges and limitations, software demonstrations of parameter input, as well as slide presentations and technical articles providing a more detailed explanation of parameter generation when appropriate. While sub-sections 2.1, Introduction to LamPre, and 2.2, Getting Started with LamPre, initiate users to the preprocessor's structure and navigation procedures, the majority of the LamPre materials are found in the Input Parameters and Grid Editor sub-sections (see Table 3.3). 
Table 3.3: Summary of Section 2.0 LamPre

\begin{tabular}{|l|c|c|c|c|c|c|c|}
\hline \multicolumn{1}{|c|}{ Section Title } & Manual Text & $\begin{array}{c}\text { PowerPoint } \\
\text { Presentations }\end{array}$ & Captivate Videos & Captioned Dialog & $\begin{array}{c}\text { Recorded } \\
\text { Audio }\end{array}$ & Papers & Theses \\
\cline { 2 - 6 } & words & slides & frames & words & hours & \\
\hline \hline 2.0 LamPre & $>17,759$ & $>79$ & $>312$ & $>13,998$ & $\sim 1.57$ & 7 & 3 \\
\hline 2.1 Introduction to LamPre & 212 & - & - & - & - & - & - \\
\hline 2.2 Getting Started with LamPre & 1,491 & 1 & 12 & 433 & 0.04 & - & - \\
\hline 2.3 LamPre Input Parameters & 242 & - & - & - & - & - & \\
\hline 2.3.1 Project Parameters & 882 & - & 11 & 459 & 0.04 & - & \\
\hline 2.3.2 Seam Geometry \& Boundary Conditions & 1,474 & - & 15 & 544 & 0.05 & - & \\
\hline 2.3.3 Overburden / Rock Mass Parameters & 2,188 & - & 24 & 1,081 & $\sim 0.12$ & 1 & 1 \\
\hline 2.3.4 Material Models & 5,799 & $>7$ & $>28$ & $>2040$ & $>0.21$ & 3 & 1 \\
\hline 2.3.5 Program Controls & $>1,260$ & $>58$ & $>69$ & $>5,704$ & $\sim 0.70$ & 1 & 1 \\
\hline 2.3.6 off-Seam Plane & 884 & 13 & 40 & 2,302 & $\sim 0.25$ & 1 & \\
\hline 2.3.7 Fault Plane & 660 & TBA & TBA & TBA & TBA & 1 & \\
\hline 2.4 Introduction to the Grid Editor & 2,566 & - & 113 & 1,435 & $\sim 0.16$ & \\
\hline
\end{tabular}

The LaModel program relies entirely on the input parameters from LamPre and therefore, the accuracy of a LaModel analysis depends entirely on the accuracy of user defined parameters in LamPre. In sub-section 2.3, LamPre Input Parameters, users are instructed on the numerical definition of modeling parameters for: in-seam geometries, boundary conditions, behaviors of inseam materials (coal and gob) and overburden materials, solution algorithm controls, and stress calculations. These parameters are explained through detailed explanations of input parameter forms and material generating wizards. Compiled from a total of 14 sub-sections (Project Parameters, Seam Geometries and Boundary Conditions, Overburden/Rock Mass Parameters, Create Using Material Wizards, etc.), users are inform on the input techniques for each parameters form and material wizard as well as the mathematical derivations and limitations for the accurate representation of site-specific convergence and stress.

In sub-section 2.4, users are introduced to LamPre's graphical grid editor. Operating much like a typical spreadsheet, users are able to create and modify seam grids by defining individual cells as any of the 52 available in-seam materials (A-z) or void material (1). Educating users on the operational controls and techniques within the editor allows for greater efficiency in user creation and modification of seam grid files with respect to mine geometries and user defined material sets. It is often the case that pillar layouts for underground mining operations do not follow the perfect alignment of a gridding format. Using the automatic yield zone generator, 
users are able to quickly produce pillar yield zones for non-symmetric pillars with respect to the previously defined coal properties.

\subsubsection{LaModel 3.0.4}

Using a Successive Over-Relaxation (SOR) iterative scheme and employing a batch element process for solution approximation, the LaModel program provides users with an efficient means of calculating accurate results with respect to the solution options previously selected in LamPre. Beginning with sub-section 3.1, shown in Table 3.4, users are informed on the basic operational procedures of LaModel and provided detailed explanations of the displayed run-time data for a better understanding of model progression through the calculation phase.

\section{Table 3.4: Summary of Section 3.0 LaModel}

\begin{tabular}{|l|c|c|c|c|c|c|c|}
\hline \multicolumn{1}{|c|}{ Section Title } & Manual Text & $\begin{array}{c}\text { PowerPoint } \\
\text { Presentations }\end{array}$ & Captivate Videos & Captioned Dialog & $\begin{array}{c}\text { Recorded } \\
\text { Audio }\end{array}$ & Papers & Theses \\
\cline { 2 - 7 } & words & slides & frames & words & hours & & \\
\hline \hline 3.0 LaModel & 2,071 & 2 & 62 & 3,847 & $\sim 0.41$ & 0 & 0 \\
\hline 3.1 Getting Started in LaModel & - & 1 & 10 & 500 & $\sim 0.05$ & - & - \\
\hline 3.1.1 LaModel Input File & - & - & 17 & 920 & $\sim 0.10$ & - & - \\
\hline 3.1.2 LaModel Topography File & - & - & 2 & 298 & $\sim 0.03$ & - & - \\
\hline 3.1.3 LaModel Output File & - & 1 & 29 & 1,841 & $\sim 0.20$ & - & - \\
\hline 3.1.4 LaModel Results File & - & - & 4 & 288 & $\sim 0.03$ & - & - \\
\hline
\end{tabular}

Following the introduction to the LaModel program, sub-sections 3.1.1 through 3.1.3 provide users with detailed walkthroughs of LaModel's input (.inp), output (.out), and results (.f1,2,3 etc.) files. While the amount of documentation on the LaModel program in the user's manual may seem insignificant in comparison to other portions of the user's manual, the knowledge and skills available in this section are indispensable as users are able to quickly identify and correct errors as well as efficiently manipulate models for a more accurate representation of underground conditions without the use of the LamPre program.

\subsubsection{LamPlt 3.0}

The post-processing program LamPlt allows users to quickly plot and analyze seam convergence and stress solutions calculated in LaModel. Data output files such as .top, .off, and .f1, 2, 3 etc. can be viewed using the available plot types or exported as an ASCII file for further data manipulations by the user. Beginning with sub-section 4.1, Getting Started with LamPlt, 
shown in Table 3.5, users are informed of the basic operational procedures of LamPlt through introductions to the four available plot types each of which provides users with a unique representation of model solutions.

Table 3.5: Summary of Section 4.0 LamPlt

\begin{tabular}{|c|c|c|c|c|c|c|c|}
\hline 4.0 LamPlt & 4,749 & 50 & 108 & 7,096 & $\sim 0.78$ & 1 & 1 \\
\hline 4.1 Getting Started in LamPlt & 1,301 & - & 39 & 1,392 & $\sim 0.15$ & & \\
\hline 4.1.1 Colored Square Plot & 284 & - & - & - & - & - & - \\
\hline 4.1.2 Cross Section Plot & 224 & - & - & - & - & - & - \\
\hline 4.1.3 History Plot & 228 & - & - & - & - & - & - \\
\hline 4.1.4 FishNet Plot & 221 & - & - & - & - & - & - \\
\hline 4.2 Stress Items & - & - & - & - & - & - & - \\
\hline 4.2.1 Default Solutions & 392 & 3 & 17 & 600 & $\sim 0.07$ & - & \\
\hline 4.2.2 Surface Effect Stress & 136 & 9 & 19 & 1,118 & $\sim 0.12$ & - & - \\
\hline 4.2.3 Safety Factor Solutions & 353 & 7 & - & 461 & $\sim 0.05$ & - & - \\
\hline 4.2.4 Multiple Seam Subsidence Solutions & 332 & 8 & 21 & 1,171 & $\sim 0.13$ & - & - \\
\hline 4.2.5 Energy Release Rate Solutions & 636 & 13 & - & 903 & $\sim 0.10$ & 1 & 1 \\
\hline 4.2.6 Roof Beam Bending Solutions & 642 & 10 & 12 & 1,451 & $\sim 0.16$ & - & - \\
\hline
\end{tabular}

The Colored Square Plot provides users with a pseudo, three-dimensional depiction of solution result where individual grid elements have been assigned a color indicative of its calculated value as shown in Figure 3.4(a). The available Cross Section plots, Figure 3.4 (b), present graphical representation of LaModel results as either vertical or horizontal slices through the seam used to either clarify or interpret relationships between solution magnitudes and their location within the seam. The third plot type, History Plot, compares the change of a given stress item in a given area across multiple modeling steps providing the user with a visually representation the progression of average or total magnitudes of a given stress item throughout a mining process; Figure 3.4(c). The final plot type, FishNet, provides users with a threedimensional wireframe or surface graph that is represented by lines equal to an elements calculated value along the $\mathrm{X}$ and $\mathrm{Y}$ axes. This graphical depiction of seam results allows users to interpret and locate data peaks and valleys as shown in the Total Vertical Stress plot of Figure 3.4(d). 


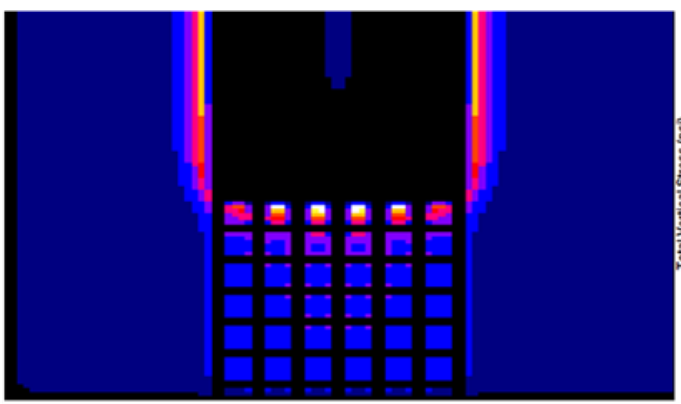

(a) Colored Square Plot

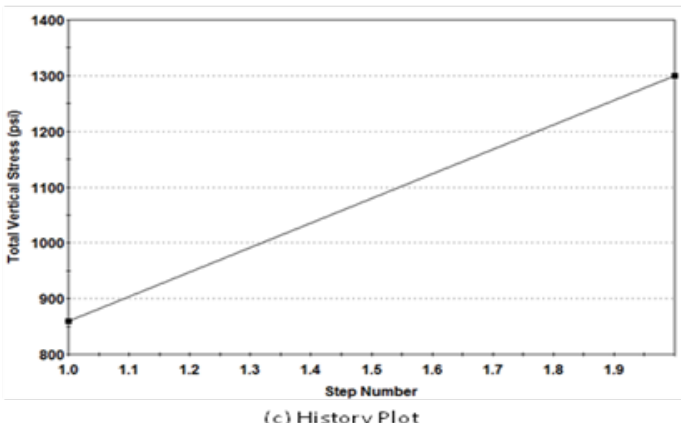

(c) History Plot

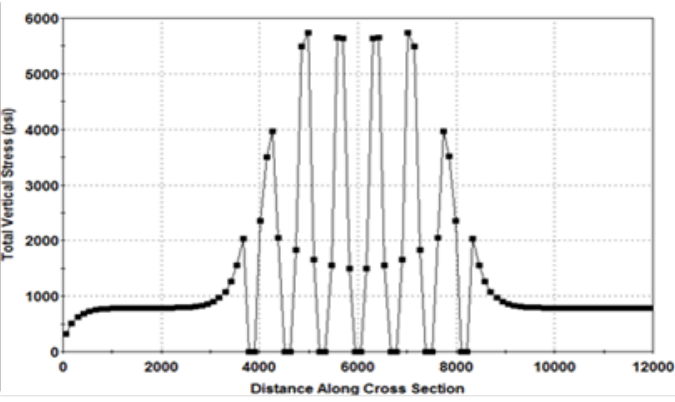

(b) Cross Section Plot

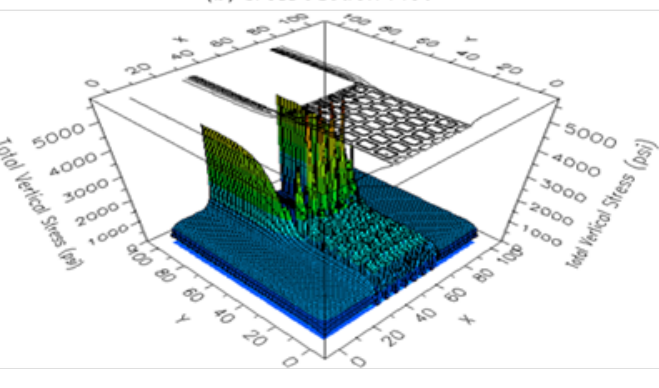

(d) FishNet Plot

Figure 3.4: LamPlt Plot Styles for Total Vertical Stress

Following the discussion on plot types, sub-section 4.2, Stress Items, describes each available output stress item. Within the manual text, these stress analysis items have been grouped with respect their user defined Solution Options in LamPre. By selecting a given Solution Option, a series of associated Stress Items will be calculated within LaModel and then become available for user analysis in the LamPlt post-processor. Whether or not any additional Solution Options have been selected, users will always have access to the four basic, "default" Stress Items: Seam Convergence, Total Vertical Stress, and Overburden Stress, as well as Multiple Seam Stress for all models with two or more seams. The first available solution option in LamPre, "Include Surface Effects,” allows LaModel to calculate the effects of a traction-free plane located at the surface level using the mirror-image seam technique. This surface-effect calculation increases modeling accuracies when the mined seam is close to the surface. The results of this calculation are stored and available for analysis in LamPlt as Surface Effect Stress. Next, by selecting Calculate Safety Factors in LamPre, users are provided with LamPlt's three most popular additional Stress Items: Element Strain SF, Pillar Strain SF, and Pillar Stress SF. The fourth additional analysis option available to users allows for the calculation of multiple-seam subsidence in all models with two or more seams. By selecting this Solution Options, users are able to analyze remote seam vertical displacements as well as subsidence induced strains in both 
the $\mathrm{X}$ and $\mathrm{Y}$ directions. Finally, the roof beam bending Solution Options allows users to evaluate concentrations of stress ( $\mathrm{X}$ and $\mathrm{Y}$ directions), force (compression and tension), as well as the maximum stress magnitudes (positive or negative) within the immediate roof and floor.

\subsubsection{Stability Mapping}

The Stability Mapping application, a run-time extension (.arx) for the AutoCAD drafting program, allows users to effectively combine structural and geological characteristics with stress influences for the evaluation of underground support design and mine planning. While the Stability Mapping System provides engineers with twenty-two available features for the integration of geological data with in-seam stress calculations and observations, Section 5 of this user's manual specifically focuses on the LaModel gridding utilities in the Stability Mapping software which aid LaModel users to import mine and overburden grids and to export LaModel results to AutoCAD.

Table 3.6: Summary of Section 5.0 Stability Mapping

\begin{tabular}{|c|c|c|c|c|c|c|c|}
\hline \multirow[t]{2}{*}{ Section Title } & Manual Text & $\begin{array}{l}\text { PowerPoint } \\
\text { Presentations }\end{array}$ & Captivate Videos & Captioned Dialog & $\begin{array}{c}\text { Recorded } \\
\text { Audio }\end{array}$ & \multirow[t]{2}{*}{ Papers } & \multirow[t]{2}{*}{ Theses } \\
\hline & words & slides & frames & words & hours & & \\
\hline 5.0 Stability Mapping & 13,677 & 70 & 266 & 4,718 & $\sim 0.52$ & 1 & 1 \\
\hline 5.1 Getting Started in Stability Mapping & 885 & 7 & - & 190 & $\sim 0.02$ & 1 & 1 \\
\hline 5.2 Gridding Modules & 4376 & 21 & 45 & 3025 & $\sim 0.34$ & - & - \\
\hline 5.3 Transfer of Results & 2,020 & - & 88 & 1,503 & $\sim 0.16$ & - & - \\
\hline
\end{tabular}

Beginning in sub-section 5.1, Getting Started with Stability Mapping users are first instructed on the application loading procedure which provides access to Stability Mapping through the main AutoCAD menu bar. With access to the application now available, users are formally introduced to the Stability Mapping application through a discussion of its drop-down menu.

Following the introduction, sub-section 5.2 strictly focuses on the automatic topographic and seam grid generation features within Stability Mapping. In order for LaModel to successfully provide detailed solution outputs for seam displacements and stress distributions of single- and multiple-seam mining situations, users must provide fairly detailed geometric inputs on the mine plan and topography. With an understanding of automatic gridding procedures users are able to 
quickly develop grid representations of both the surface topography (5.2.1) and seam geometry (5.2.2) for importation into LamPre.

In Section 5.2 users to the Topographic Grid Generation for LaModel function and its operational procedures. Using the provided mapping forms, users are able to generate overburden or surface grid files from contour lines on the mine map. Once the model has been developed in LamPre and the results calculated in LaModel, users often find the analysis and interpretation of the results using the LamPlt post-processing program to be insufficient. Therefore, sub-section 5.3 explains the transfer of LaModel results from the output files (.f1, 2, 3 etc. and .off) into separate grid files and into AutoCAD. Using these grid files within AutoCAD, users are able to then update pillar plans and mine mapping with respect to the results determined by LaModel.

\subsection{User's Manual Example for Lamination Thickness}

In an attempt to present a more detailed explanation of the operation and organization of the user's manual, the following section provides a basic walk-through of the LaModel User's Manual through a specific investigation into the Lamination Thickness. This example looks to highlight the functionality of the provided written documentation, video simulations, and technical publications implemented in the user's manual for detailing and explaining the application, mathematical derivation, and effect the Lamination Thickness has on LaModel output results.

Upon opening the LaModel User's manual (see Figure 3.1), users are presented with the manual home page within the client area on the right as well as access to the each of the five main manual sections within the Table of Contents navigation pane on the left. The manual home page provides a brief written description of the LaModel program with more detailed overview provided in the video presentation available to users at the bottom of the page or through the Table of Contents Navigation pane. However, in this example, the user is more interested in obtaining specific information on the Lamination Thickness. From this point, one could either directly search the entirety of the user's manual for topic pages pertaining to the Lamination Thickness using the Search tab (top left) or further navigate through the manual using the collapsible/expandable Table of Contents navigation pane (left). 
Knowing that the Lamination Thickness input parameter is located in LamPre's Overburden/Rock Mass Parameters form, we will use the Table of Contents. Figure 3.2 shows user access to the appropriate manual page by first selecting the LamPre manual section, followed by the LamPre Input Parameters sub-section, and finally selecting the Overburden/Rock Mass Parameters topic page. Upon opening this topic page, users will be provided with a short description on how to access the form within LamPre and the input parameters presented within the form. Following this introductory description, the Overburden/Rock Mass Parameters form has been broken down by section, the Overburden / Rock Mass Parameters Section, further detailing each accessible input parameter; Poisson's Ratio, Elastic Modulus, Lamination (Layer) Thickness, and the Vertical Stress Gradient.

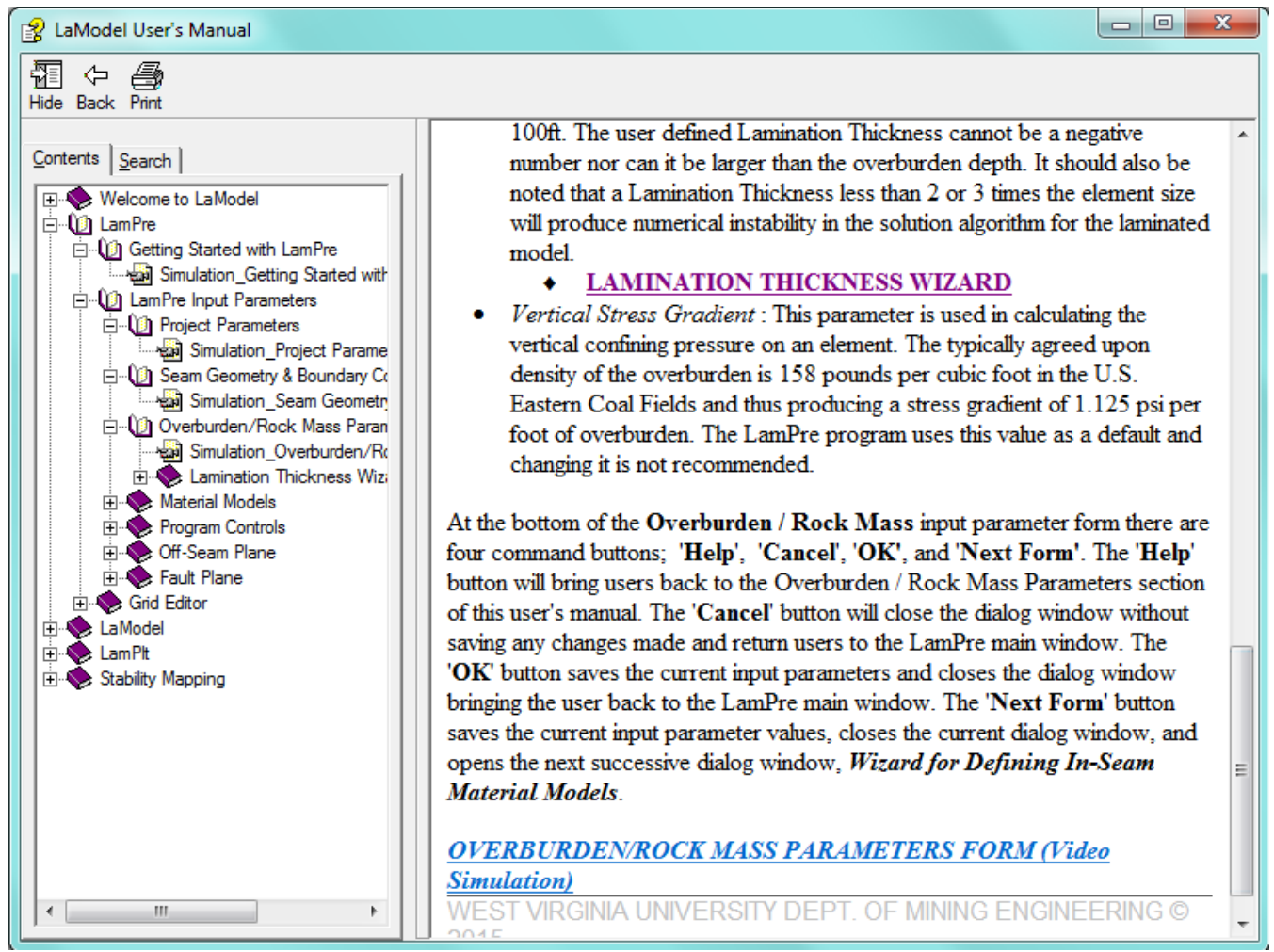

\section{Figure 3.5: Description of Lamination Thickness in User Manual text}

Using the associated scroll bar within the Client Area, users will find a short, detailed explanation of the Lamination Thickness within the documentation of the Overburden/Rock Mass Parameters form as seen in Figure 3.5. While the description of the Lamination Thickness begins with a basic parameter definition, the reader is quickly introduced to the more technical 
aspects of the parameter with respect to the fundamental differential equation for the laminated overburden model. Following this brief mathematical description, users are then provided with suggested value ranges for the Lamination Thickness such that realistic seam convergence and stress distribution results can be obtained by the user. Scrolling to the bottom of the topic page or using the Table of Contents on the left, users have access to a short video introducing the layout of the Overburden/Rock Mass Parameter form and detailing each input parameter and access to the Lamination Thickness Wizard.

By selecting the available simulation using the Table of Contents or hyperlink, users will be routed to a HTML page containing a flash video outlining the Overburden/Rock Mass Parameters form in LamPre shown in Figure 3.3. Through the use of audio recordings, open captioning, and on-screen mouse movements, one is introduced to the form layout as well as the operational procedures for defining appropriate input parameter values. Through the course of this video, users will be informed about each displayed parameter and, if appropriate, their mathematical derivation. In discussing a specific parameter within the form, red highlight boxes and blue dialog bubbles are used to help the user locate and focus their attention on the given parameter of which information is being relayed. In following along with the simulation, user will not only obtain the knowledge and skills necessary for correctly operation the Overburden/Rock Mass Parameters form, but they will also obtain a sense of maneuverability within the form without having to actually open the LaModel program.

If more information is required on the Lamination Thickness and its application within the LaModel program, users are able to access more detailed descriptions on the Lamination Thickness and its associated material wizard through the Lamination Thickness Wizard topic page accessed by either selecting the Lamination Thickness Wizard topic page from the Table of Contents navigation pane or clicking on the associated hyperlink within the textual description of the Lamination Thickness. 


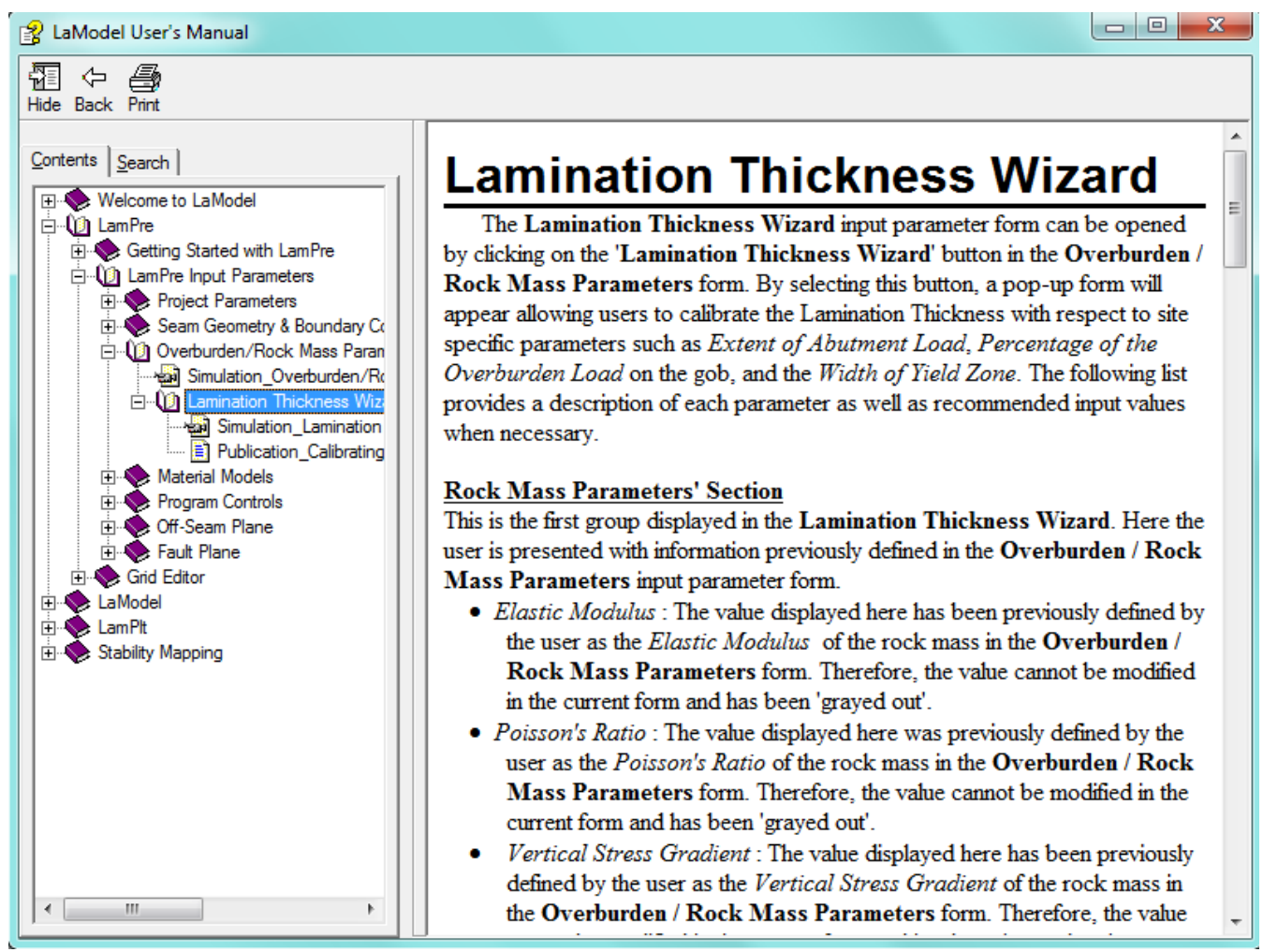

Figure 3.6: Lamination Thickness Wizard HTML Topic Page

Upon opening the Lamination Thickness Wizard topic page within the user's manual, as seen in Figure 3.6, users are first presented with an introductory statement on form access and input parameters available within the given form. Again, similar to the layout of the Overburden/Rock Mass Parameter form, the Lamination Thickness Wizard form has been broken down into a series of thoroughly explained sections with each parameter described along with recommended value ranges for that parameter. Different than the previously discussed pages, the Lamination Thickness Wizard provides users with a set of supporting materials in the form of software simulations which can be accessed by selecting the available in text hyperlinks or the associated Table of Contents item. These software simulations discuss the layout of the thickness wizard, available input parameters, mathematical background, and calibration of the Lamination Thickness with respect to a site-specific measurement of the Extent of Abutment Zone through an integration of both screen captured recordings and slide presentations. Along with these simulations, a paper published at the International Conference on Ground Control Mining (Heasley, 2012) detailing the procedural steps for the calibration of the Lamination Thickness, Coal Strength, and Gob Modulus for deep cover seams is also available to users. 


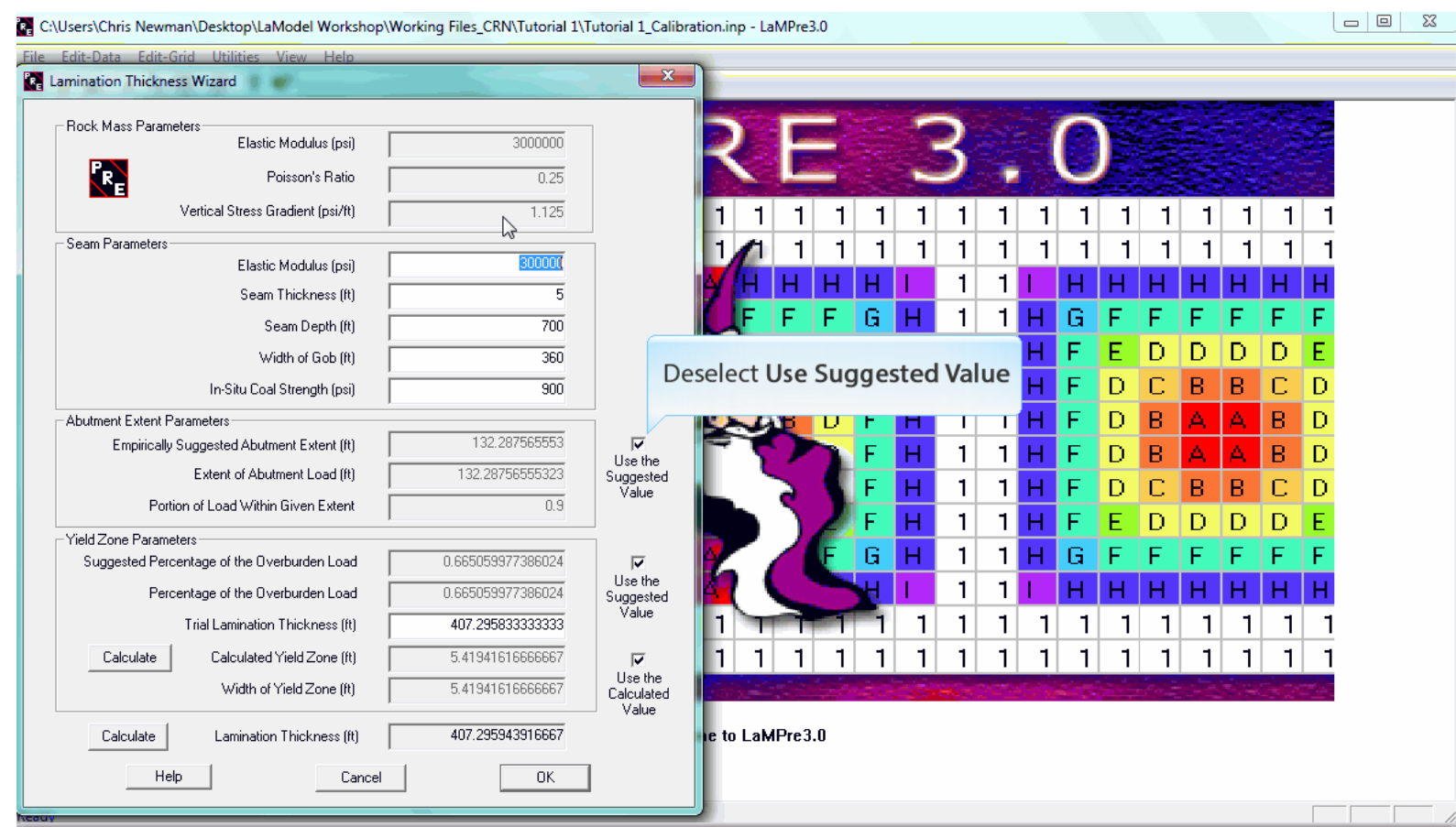

Using the Lamination Thickness Wizard, users are able to determine the lamination thickness using either the suggested value or user input parameters derived from site specific observations, measurements, or engineering judgment.

4x Fast Forward Speed

Figure 3.7: Lamination Thickness Wizard Simulation

By selecting the Lamination Thickness Wizard (Video Simulation) using the available in-text hyperlink or through the Table of Contents, users will be routed to a HTML page containing a flash video simulation of the Lamination Thickness Wizard in LamPre (Figure 3.7). Unlike the previous simulation example, this software simulation begins with an introduction into the more technical background of the Lamination Thickness using presentation slides containing audio recordings and open captions. Through the use of these slides, users are able to obtain a large amount of information on a given topic through the clean presentation of bulleted topics, mathematical equations, as well as illustrations and graphical depictions. After providing the user with a technical description of the Lamination Thickness Wizard, the video simulation continues with screen-capture software recordings detailing the calibration procedures for the Lamination Thickness similar to what was seen in the video simulation provided for Overburden/Rock Mass Parameters form.

In completing the software simulation, if more information about the calibration of the Lamination Thickness using the associated wizard is necessary, users can return to the 
Lamination Thickness Wizard topic page, using either the Table of Contents navigation pane or Back button located on the toolbar, and select the provided technical paper publication.

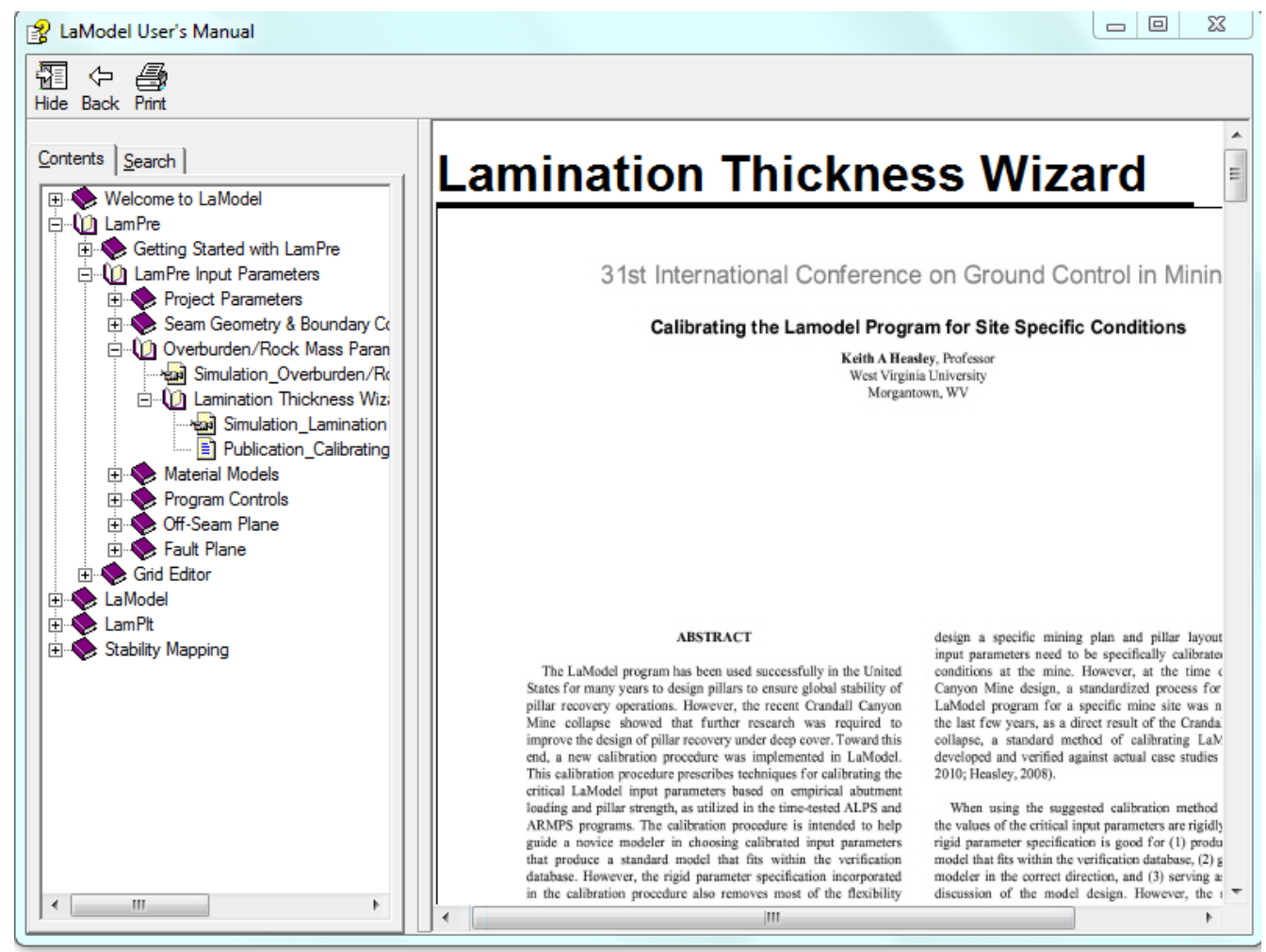

Figure 3.8: Academic Paper discussing Lamination Thickness calibration techniques

By selecting the available publication, users will gain access to the "Calibrating the LaModel Program for Site Specific Conditions," conference paper (Heasley, 2012). Here users will be further introduced to the importance of model calibrations as well as very technical details on those input parameters which control the mechanical response of the laminated overburden model. Through discussions on the Rock Mass Stiffness through modifications to the Lamination Thickness, gob stiffness, and coal strength users will obtain a complete understanding of not only the recommended calibration process but the interactions these parameters play through a sensitivity analysis of the input parameters.

The LaModel User's Manual has been developed as a comprehensive practical and technical documentation for the LaModel suite of programs. This manual provides knowledge and practical experience with the LaModel programs through the incorporation of: technical documentations, software simulations, and technical papers. In progressing though the provided 
materials, users of all educational and industry backgrounds are able to quickly access and review detailed information on the program at their own speed and with respect to their own need for program information. The development of a comprehensive electronic user's manual provides both the novice and experienced user with a basic on-demand support system necessary to adequately prepare, calibrate, run, and analyze underground stability analysis models using LaModel. 


\subsection{Development of LaModel Online Training Modules}

Over the past decade, mining operations have continued to mine at greater depths as well as in more difficult geological and multiple-seam mining scenarios. With greater complexities in mine design, industry engineers and regulatory agencies have become more reliant on the use of numerical models to determine underground stabilities. By means of a displacementdiscontinuity variation of the boundary-element method, LaModel is able to determine the displacements and stress concentrations within thin bedded seams with respect to user defined input parameters (Heasley, 2012). As MSHA, and therefore the mining industry, becomes more reliant on LaModel as an available program for stability analysis of complex and non-typical mining geometries (Skiles and Stricklin, 2009), it is important the users have a clear understanding of the behaviors and characteristics of both overburden and seam parameters as well as the appropriate application and analysis techniques necessary for a given project or problem.

Although multiple publications, research projects, and MSHA regulations rely on LaModel for numerical analysis, there are only minimal instructional resources for users to access when trying to learn the program. With more widespread use of the program, there is now a large demand for better training and education in both the basic functionality and practical application of LaModel. Currently, users have access to training in the form of outdated online PDF tutorials or occasionally LaModel Workshops offered in eight- to twelve-hour sessions that acquaint users with the program application, operation, and derivation. While these tutorials and workshops provide important information on the functionality of LaModel, the tutorials and do not provide users with a comprehensive understanding of all program capabilities and limitations, and the workshops are extremely limited in availability. In order to better inform and train academic, industry, and regulatory users, this thesis research is developing training modules for distribution in an Open Online Learning Environment.

\subsection{Open Online Learning Environment}

Advances in both computer technologies and internet availability have given rise to claims that modern mobile and streaming communication outlets can better provide accessible, quality education to the public (Alexander \& Boud, 2001). The deployment of these modern technologies within the traditional classroom—such as one-to-one student/iPad and off-site 
streaming programs - has not only facilitated the initial introduction, but also the spread of online learning itself. The online learning environment, or e-Learning, has been defined as the use of electronic media for the education of student populations, where the internet is utilized as a global network for the distribution of classroom materials and communication with users (Oxford, 2014). While the material accessibility, flexibility, and cost benefits of the online learning environment are often touted, research has shown a lack of student involvement within the digital classroom hampering intellectual growth. Surveys by Stanford University indicate that while $25 \%$ of enrollees complete a majority of the class work, many do not fully complete the course (Finder, 2013). This can often be attributed to the limited architectural design of the lessons only providing users with little more than recorded or documented traditional lectures. However, even in the face of these adversities, large student enrollment in today's online classrooms have both public and private educational institutions becoming more accepting of the online learning environments, such as edX, Coursera, and Udacity, as a means of effectively educating diverse student populations across the globe with the development of the Massive Open Online Course (MOOC) (Pappano, 2012).

For LaModel users, an online learning environment can provides users with instantaneous access to LaModel training, application, and information. The advantages of the online learning environment include, but are not limited to, classroom accessibility, schedule flexibilities, increased student-material interaction, effective communication/networking, and cost effectiveness. These online learning advantages have caused students to gravitate away from the traditional classroom in adoption of e-Learning as a means of educating themselves on individual topics of interest (Shah, 2013). While the typical open online classroom provides students with a back of the room view of a recorded lecture, the LaModel online training modules have been developed with the individual learner in mind. Using traditional educational pedagogies, these learning modules have been designed such that users of all educational backgrounds can adequately and efficiently learn, understand, and apply the LaModel program to a multitude of underground mining scenarios.

\subsubsection{Online Learning Management System}

The CourseSites online learning management system (LMS) has been utilized for the distribution and management of LaModel training modules. CourseSites, powered by 
Blackboard, provides individual educators the means of hosting web-based courses. This LMS provides educators with up-to-date and user friendly online infrastructure for the delivery and management of instructional content, course administration, event management (i.e. scheduling, tracking), and certification management. Utilizing CourseSites, students are able to access learning materials and communicate with other students within the classroom from a variety of devices including Windows, iOS, Android, Palm webOS, and BlackBerry. Upon creating a student account, users are able to search for the LaModel Online Training Course within the available MOOC (Massive Open Online Course) catalog. With the course selected, one may self enroll in the course gaining access to the class through their CourseSites student homepage, My CourseSites.

\subsection{Topics Covered}

By adopting Kolb's Experiential Learning Model (ELM), knowledge is created by building upon the student's learning experiences within the program providing a clear understanding of each LaModel concept and feature. Through the implementation of textual, visual, and problembased learning activities, LaModel's self-paced online training modules provide users of diverse educational and occupational backgrounds with detailed information on how to properly prepare, calibrate, run, and analyze both single and multiple seam mining scenarios. Through the utilization of ELM as the framework for each module, users are introduced to each learning objective through stages of experimentation, observation, reflection, and application. By

progressing through each learning module, users will have obtained enhanced level of proficiency with the LaModel program. By the end of the online course, student abilities will have expanded from the analysis of simple, single-seam models to the development of a simplified LaModel (successive over-relaxation) source code in Microsoft Excel. In completing each module, users will have obtained both a detailed technical background and hands-on experience with each feature and procedure necessary to adequately prepare, run, and analyze underground stabilities using the LaModel program. 
Table 4.1: Summary of Online Learning Tracks

\begin{tabular}{|l|c|c|c|c|c|c|}
\hline \multicolumn{1}{|c|}{ Section Title } & $\begin{array}{c}\text { Captioned } \\
\text { Dialog }\end{array}$ & $\begin{array}{c}\text { Power Point } \\
\text { Presentation }\end{array}$ & $\begin{array}{c}\text { Captivate } \\
\text { Video }\end{array}$ & $\begin{array}{c}\text { Recorded } \\
\text { Audio }\end{array}$ & \multirow{2}{*}{ Papers } & \multirow{2}{*}{ Theses } \\
\cline { 2 - 6 } & words & slides & frames & hr:min:sec & \\
\hline \hline Novice Learning Track & 20,921 & 74 & 543 & $\sim 2.21$ & 3 & 0 \\
\hline Intermediate Learning Track & 17,345 & 162 & 243 & $\sim 1.84$ & 4 & 3 \\
\hline Advanced Learning Track & 19,796 & 105 & 960 & $\sim 2.14$ & 6 & 4 \\
\hline
\end{tabular}

Due to the wide range of topics presented in the online training course, as well as the various skills necessary to complete each lesson, LaModel's online training modules have been subdivided into three (3) learning tracks or ability groups: novice, intermediate, and advanced (Table 4.1). Each module has been designed to increase user comprehension of the LaModel topics through the incorporation of traditional educational pedagogies modified for the online learning environment. While Kolb's Experiential Learning model has been used as a framework for the entire online course allowing students to experience, observe, reflect, and apply all educational themes and objectives, Bloom's Mastery of Learning concept has also been implemented in contrast to the conventional lecture style to provide more individualized, one-toone instruction (Guskey, 2007). In completing each learning track, users will have mastered a critical series of concepts and application skills with respect to their current level of experience with the LaModel program. In developing the LaModel course as a series of learning modules, the modeling and analysis processes have been broken down into manageable chunks of information such that the user can explore and experiment with LaModel at a level appropriate to their skills or needs.

\subsubsection{Novice Learning Track}

The Novice Learning Track has been designed to provide the initial knowledge and skills necessary to prepare, run, and analyze basic single- and multiple-seam mining scenarios. The user is introduced to the LaModel program and Stability Mapping application through an introductory slide presentation followed by a series of hands-on learning activities and technical articles that highlight the basic capabilities and limitations of the program. 
Table 4.2: Summary of Novice Learning Track

\begin{tabular}{|l|c|c|c|c|c|c|}
\hline \multicolumn{1}{|c|}{ Section Title } & $\begin{array}{c}\text { Captioned } \\
\text { Dialog }\end{array}$ & $\begin{array}{c}\text { Power Point } \\
\text { Presentation }\end{array}$ & $\begin{array}{c}\text { Captivate } \\
\text { Video }\end{array}$ & $\begin{array}{c}\text { Recorded } \\
\text { Audio }\end{array}$ & \multirow{2}{*}{ Papers } & \multirow{2}{*}{ Theses } \\
\cline { 2 - 6 } & words & slides & frames & \multicolumn{2}{c|}{ hours } & \\
\hline \hline Novice Learning Track & $\mathbf{2 0 , 9 2 1}$ & $\mathbf{7 4}$ & $\mathbf{5 4 3}$ & $\sim 2.21$ & $\mathbf{3}$ & $\mathbf{0}$ \\
\hline 1.0 Introduction \& Background & 3,758 & 57 & 0 & $\sim 0.41$ & 1 & 0 \\
\hline 2.0 Tutorial 1 & 7,281 & 13 & 237 & $\sim 0.72$ & 1 & 0 \\
\hline 3.0 Tutorial 2 - Huff Creek & 9,882 & 4 & 306 & $\sim 1.07$ & 1 & 0 \\
\hline
\end{tabular}

As seen in Table 4.2, this series of modules begins with an introduction to the suite of LaModel programs, LamPre, LaModel, LamPlt and Stability Mapping, through entry-level presentations that provide an overview and historical background. Following this basic introduction, users are then immediately immersed in LaModel as they investigate basic program features and solution options through Tutorial 1 and the Huff Creek hands-on training exercises. Here, users will be educated on LaModel's theoretical approach in determining underground convergences and stress states and using these learned concepts to solve realistic mining scenarios. The Novice Learning track allows users to be quickly introduced to the practical application and usefulness of the LaModel program.

After completing the introductory and background LaModel presentations, users are asked to build a simple single-seam model that assumes a constant overburden in the Tutorial1 training module. Through a series of software demonstrations and slide presentations (Table 4.3), users are introduced to the basic operations and analysis options available in the LaModel suite of programs.

Table 4.3 Summary of Tutorial 1 Training Module Series

\begin{tabular}{|c|c|c|c|c|c|c|}
\hline \multirow[t]{2}{*}{ Section Title } & $\begin{array}{c}\text { Captioned } \\
\text { Dialog }\end{array}$ & $\begin{array}{l}\text { Power Point } \\
\text { Presentation }\end{array}$ & $\begin{array}{c}\text { Captivate } \\
\text { Video }\end{array}$ & $\begin{array}{c}\text { Recorded } \\
\text { Audio }\end{array}$ & \multirow[t]{2}{*}{ Papers } & \multirow[t]{2}{*}{ Theses } \\
\hline & words & slides & frames & hours & & \\
\hline 2.0 Tutorial 1 & 7,281 & 13 & 237 & $\sim 0.72$ & 1 & 0 \\
\hline 2.1 Introduction to Tutorial 1 & 222 & 3 & - & $\sim 0.02$ & - & - \\
\hline 2.2 Getting Started with LamPre 3.0.2 & 4,060 & 8 & 75 & $\sim 0.38$ & - & - \\
\hline 2.3 Getting Started with the Grid Editor & 1,435 & - & 114 & $\sim 0.15$ & - & - \\
\hline 2.4 Getting Started with LaModel 3.0.4 & 172 & 1 & 10 & $\sim 0.02$ & - & - \\
\hline 2.5 Getting Started with LamPlt 3.0 & 1,392 & 1 & 38 & $\sim 0.15$ & - & - \\
\hline
\end{tabular}


Following an introduction to the basic forms, parameters, and interactive grid editing interface of the LamPre program, users are then introduced to the layout, operation, and outputs of the LaModel program. In the final stage of Tutorial 1, users are introduced to the basic layout and default colored square plot options available for LaModel results analysis. After completing the Tutorial 1 training module, users will have obtained a basic understanding of the LaModel program that they will then apply to the more complicated Huff Creek multiple-seam training module.

The Huff Creek training modules builds upon the skills achieved in the Tutorial 1 module to develop of a basic multiple seam model with varying overburden given a site-specific mine map. The Huff Creek tutorial provides users with a more realistic representation of the steps necessary for field investigations of ground control issues through the analysis of a multiple-seam roomand-pillar coal mining operation located in Eastern Kentucky. By accessing a series of software demonstrations and slide presentations on the Stability Mapping application, users build upon the basic skills they mastered in the LamPre, LaModel, and LamPlt modules.

Table 4.4 Summary of Huff Creek Training Module Series

\begin{tabular}{|c|c|c|c|c|c|c|}
\hline \multirow[t]{2}{*}{ Section Title } & $\begin{array}{c}\text { Captioned } \\
\text { Dialog }\end{array}$ & $\begin{array}{l}\text { Power Point } \\
\text { Presentation }\end{array}$ & $\begin{array}{c}\text { Captivate } \\
\text { Video }\end{array}$ & $\begin{array}{c}\text { Recorded } \\
\text { Audio } \\
\end{array}$ & \multirow[t]{2}{*}{ Papers } & \multirow[t]{2}{*}{ Theses } \\
\hline & words & slides & frames & hours & & \\
\hline 3.0 Tutorial 2 - Huff Creek & 9,882 & 4 & 306 & $\sim 1.07$ & 1 & 0 \\
\hline 3.1 Introduction to Huff Creek & 177 & 4 & - & $\sim 0.02$ & - & - \\
\hline 3.2 Stability Mapping Grid Generation & 3,105 & - & 88 & $\sim 0.33$ & - & - \\
\hline 3.3 LamPre 3.0.2 for Huff Creek & 3,228 & - & 125 & $\sim 0.36$ & - & - \\
\hline 3.4 LaModel 3.0.4 for Huff Creek & 46 & - & 1 & $\sim 0.01$ & - & - \\
\hline 3.5 LamPlt 3.0 for Huff Creek & 827 & - & 19 & $\sim 0.09$ & - & - \\
\hline 3.6 Stability Mapping for Huff Creek & 2,499 & - & 73 & $\sim 0.26$ & - & - \\
\hline
\end{tabular}

Users start their work with the Stability Mapping application by generating seam and topography grids for importation into the LamPre program based upon actual mine mapping and overburden data. Once they’ve completed the LaModel grid files, users utilize their knowledge of the LamPre, LaModel, and LamPlt programs for the creation of a multiple-seam model incorporating surface topography. In the completing the Huff Creek module series, users are asked to use the Stability Mapping application to import their LaModel results back into the AutoCAD program so that both mine mapping and LaModel stress and convergence results are 
integrated. Once they’ve completed the Huff Creek training module, users will have obtained a basic understanding of multiple-seam modeling in LaModel, and may progress to the intermediate educational track.

\subsubsection{Intermediate Learning Track}

The Intermediate learning track is designed to provide the more experienced user with the knowledge and skills necessary to prepare, calibrate, run, and analyze more complicated underground mining scenarios. Developed from previous LaModel Workshop presentations, the Intermediate training modules introduce the user to the more complicated behaviors and characteristics of the laminated overburden model, as well as the more intricate analysis options available. Each module within the intermediate track begins by reintroducing previous LaModel content and/or skills followed by slight modifications to these existing concepts giving rise to a new idea or experience within the LaModel program. Users then further their understanding of a given topic by applying their knowledge and understanding of LaModel through structured hands-on learning activities and reflecting on the capabilities of and systematic approach taken to achieve a given outcome. The Intermediate Learning Track introduces the more technical aspects of the program and code such that users obtain a better comprehension of both the capabilities and limitations of LaModel.

Table 4.5: Summary of Intermediate Learning Track

\begin{tabular}{|l|c|c|c|c|c|c|}
\hline \multicolumn{1}{|c|}{ Section Title } & $\begin{array}{c}\text { Captioned } \\
\text { Dialog }\end{array}$ & $\begin{array}{c}\text { Power Point } \\
\text { Presentation }\end{array}$ & $\begin{array}{c}\text { Captivate } \\
\text { Video }\end{array}$ & $\begin{array}{c}\text { Recorded } \\
\text { Audio }\end{array}$ & \multirow{2}{*}{ Papers } & \multirow{2}{*}{ Theses } \\
\cline { 2 - 6 } & words & slides & frames & hours & \\
\hline \hline Intermediate Learning Track & 17,345 & 162 & 243 & $\sim 1.84$ & 4 & 3 \\
\hline 4.0 Calibration of LaModel & 6,668 & 46 & 131 & $\sim 0.71$ & 1 & 1 \\
\hline 5.0 Gory Details I - The Derivation of LaModel & 5,128 & 72 & 0 & $\sim 0.55$ & 0 & 1 \\
\hline 6.0 Solution Options I & 2,250 & 19 & 36 & $\sim 0.24$ & 2 & 0 \\
\hline 7.0 Stability Mapping & 3,299 & 25 & 76 & $\sim 0.34$ & 1 & 1 \\
\hline
\end{tabular}

Beginning with the Calibration learning module, user knowledge and operation of LaModel features and functionality is further enhanced. This training module series introduces users to systematic approaches appropriate for the modification of input parameters such that site-specific underground behaviors and conditions are accurately reflected in their model. 
Table 4.6: Summary of Calibration Training Module Series

\begin{tabular}{|c|c|c|c|c|c|c|}
\hline \multirow[t]{2}{*}{ Section Title } & $\begin{array}{c}\text { Captioned } \\
\text { Dialog }\end{array}$ & $\begin{array}{l}\text { Power Point } \\
\text { Presentation }\end{array}$ & $\begin{array}{c}\text { Captivate } \\
\text { Video }\end{array}$ & $\begin{array}{c}\text { Recorded } \\
\text { Audio }\end{array}$ & \multirow[t]{2}{*}{ Papers } & \multirow[t]{2}{*}{ Theses } \\
\hline & words & slides & frames & hours & & \\
\hline 4.0 Calibration of LaModel & 6,668 & 46 & 131 & $\sim 0.71$ & 1 & 1 \\
\hline 4.1 Introduction to LaModel Calibration & 529 & 11 & - & $\sim 0.06$ & - & - \\
\hline 4.1.1 Calibration of Tutorial 1 & 1,417 & 3 & 39 & $\sim 0.15$ & - & - \\
\hline 4.2 Rock Mass Stiffness & 1,807 & 12 & 37 & $\sim 0.19$ & - & - \\
\hline 4.3 Gob Stiffness & 1,756 & 11 & 31 & $\sim 0.19$ & - & - \\
\hline 4.4 Coal Strength & 1,159 & 9 & 24 & $\sim 0.12$ & - & - \\
\hline
\end{tabular}

Users begin with an initial introductory presentation on LaModel's recommended calibration techniques followed by a software demonstration where users perform a basic calibration of both the Lamination Thickness and Final Gob Modulus within their Tutorial 1 model previously built in the Novice Learning Track. With a simple understanding of the calibration process, users further investigate the details of the standardized calibration methods through mathematical discussions and program experimentation. These hands-on learning activities, coupled with technical publications, educate users on the modeling effects of Lamination Thickness, Final Gob Modulus, and Coal Strength. With a better understanding of these standardized calibration techniques, users are taught how to accurately and efficiently represent site-specific convergence and stress magnitudes. After mastering the educational objectives of the Calibration training module series, users will be directed to the Solution Options module series.

In the Gory Details training series, users investigate the characteristics and behaviors of the fundamental differential equation used in the laminated overburden model. Through software demonstrations, slide presentations, and technical publications, users learn the mathematical derivation of the programs, features and functions that underpin the LaModel suite. 
Table 4.7: Summary of Gory Details I Training Module Series

\begin{tabular}{|c|c|c|c|c|c|c|}
\hline \multirow{2}{*}{ Section Title } & $\begin{array}{c}\text { Captioned } \\
\text { Dialog }\end{array}$ & $\begin{array}{c}\text { Power Point } \\
\text { Presentation }\end{array}$ & $\begin{array}{c}\text { Captivate } \\
\text { Video }\end{array}$ & $\begin{array}{c}\text { Recorded } \\
\text { Audio }\end{array}$ & \multirow{2}{*}{ Papers } & Theses \\
\cline { 2 - 5 } & words & slides & frames & hours & \\
\hline \hline 5.0 Gory Details I- The Derivation of LaModel & 5,128 & 72 & 0 & $\sim 0.55$ & - & 1 \\
\hline 5.1 The Derivation of La Model & 307 & 6 & - & $\sim 0.03$ & - & - \\
\hline 5.1.1 Displacement-Discontinuity Boundary-Element Method & 324 & 4 & - & $\sim 0.03$ & - & - \\
\hline 5.1.2 Laminated Overbruden Model & 253 & 4 & - & $\sim 0.03$ & - & - \\
\hline 5.1.3 Fundamental Differential Equation & 1,768 & 20 & - & $\sim 0.19$ & - & - \\
\hline 5.2 Derivation Learning Activities & 44 & 1 & - & $\sim 0.01$ & - & - \\
\hline 5.2.1 Behavior of the Laminated Overburden Model & 790 & 16 & - & $\sim 0.08$ & - & - \\
\hline 5.2.2 Investigation on Element Size Effect & 654 & 8 & - & $\sim 0.07$ & - & - \\
\hline 5.2.3 Investigation on the Over-Relaxation Factor & 255 & 4 & - & $\sim 0.03$ & - & - \\
\hline 5.2.4 Investigation on Multiple Seam Stess & 733 & 9 & - & $\sim 0.08$ & - & - \\
\hline
\end{tabular}

The Gory Details I module begins with a discussion of the displacement-discontinuity boundary-element method and the programs’ implementation of a homogenous laminated overburden. The material shows that the seam convergence can be derived as a function of the overburden material properties and the induced stress on the seam using a second-order partial derivative equation. Users are able to experiment and observe LaModel behavior as a result of this formulation through slight modification to the program input parameters represented in the fundamental differential equation and influence functions. After completing the Gory Details learning module, user mastery will be evaluated through educational assessments that track how well they understand the mathematical concepts essential to LaModel's functionality. Following the Gory Details module, users will move on to the Calibration training module.

In the Solution Options training module, users learn the various forms of analysis provided by LaModel, including seam convergence, pillar safety factors, and free surface effect. Here users are instructed on proper analysis techniques using the LamPlt program. Beginning with a training module series on the available default solution options for Seam Convergence, Total Vertical Stress, Overburden Stress and Multiple Seam Stress, users are introduced to the more basic program outputs available for analysis. 
Table 4.8: Summary of Solution Options Training Module Series

\begin{tabular}{|c|c|c|c|c|c|c|}
\hline \multirow[t]{2}{*}{ Section Title } & $\begin{array}{c}\text { Captioned } \\
\text { Dialog }\end{array}$ & $\begin{array}{l}\text { Power Point } \\
\text { Presentation }\end{array}$ & $\begin{array}{c}\text { Captivate } \\
\text { Video }\end{array}$ & $\begin{array}{c}\text { Recorded } \\
\text { Audio } \\
\end{array}$ & \multirow[t]{2}{*}{ Papers } & \multirow[t]{2}{*}{ Theses } \\
\hline & words & slides & frames & hours & & \\
\hline 6.0 Solution Options I & 2,250 & 19 & 36 & $\sim 0.24$ & 2 & 0 \\
\hline 6.1 Default Stress Items & 625 & 3 & 17 & $\sim 0.07$ & - & - \\
\hline 6.1.1 Seam Convergence & - & - & - & - & - & - \\
\hline 6.1.2 Total Vertical Stress & - & - & - & - & - & - \\
\hline 6.1.3 Overburden Stress & - & - & - & - & - & - \\
\hline 6.1.4 Multiple Seam Stress & - & - & - & - & - & - \\
\hline 6.2 Safety Factor Stress Items & 1,152 & 9 & 19 & $\sim 0.12$ & - & - \\
\hline 6.2.1 Element Strain Safety Factor & - & - & - & - & - & - \\
\hline 6.2.2 Pillar Stress Safety Factor & - & - & - & - & - & - \\
\hline 6.2.3 Pillar Strain Safety Factor & - & - & - & - & - & - \\
\hline 6.2.4 Stress vs Strain Safety Factor & - & - & - & - & - & - \\
\hline 6.4 Free Surface Effect & 473 & 7 & - & $\sim 0.05$ & - & - \\
\hline
\end{tabular}

With an understanding of these default options, users develop proper analysis techniques with an investigation into pillar stress safety factors. Users are taught how to analyze coal pillar and barrier pillar stabilities with respect to both strain and stress safety factors. In the final lesson of this module, users investigate the mathematical effects of implementing a free-surface on a sample model. After progressing through the Solution Options I training module series, users will master the skills necessary to properly analyze and evaluate the basic single- and multipleseam mining scenarios for in-seam convergences, stress concentrations, and pillar stabilities. Following the Solution Options modules, users will continue their LaModel education in the LamPlt/Stability Mapping training module.

Table 4.9: Summary of Stability Mapping Training Module Series

\begin{tabular}{|l|c|c|c|c|c|c|}
\hline \multicolumn{1}{|c|}{ Section Title } & $\begin{array}{c}\text { Captioned } \\
\text { Dialog }\end{array}$ & $\begin{array}{c}\text { Power Point } \\
\text { Presentation }\end{array}$ & $\begin{array}{c}\text { Captivate } \\
\text { Video }\end{array}$ & $\begin{array}{c}\text { Recorded } \\
\text { Audio }\end{array}$ & \multirow{2}{*}{ Papers } & \multirow{2}{*}{ Theses } \\
\cline { 2 - 6 } & words & slides & frames & hours & \\
\hline \hline 7.0 Stability Mapping & 3,299 & 25 & 76 & $\sim 0.34$ & 1 & 1 \\
\hline 7.1 Overburden/Topography Element Sizing & 566 & 10 & - & $\sim 0.06$ & - & - \\
\hline 7.2 Insitu Stress Results & 569 & 11 & - & $\sim 0.06$ & - & - \\
\hline 7.3 Insitu Stress Results & 1,182 & 2 & 43 & $\sim 0.12$ & - & - \\
\hline 7.4 LamPlt Scaling & 982 & 2 & 33 & $\sim 0.10$ & - & - \\
\hline
\end{tabular}


The final module, LamPlt/Stability Mapping, introduces users to the analysis procedures and limitations for the LamPlt program and Stability Mapping application. Beginning with the Stability Mapping application, users learn the details of the topographic stresses calculations through a hands-on learning activity in which they investigate proper offset distances and the sizing of surface elements. Building upon prior user knowledge of the calculations and limitations of varying topography, the next module furthers user proficiency with the Stability Mapping application by having them build and analyze in-seam in-situ, or initial stress states. In the last module, users continue to improve their skills in LamPlt analysis by working through proper plot scaling procedures with the goal of providing a more accurate determination and representation of results. By working with the Stability Mapping application and LamPlt program in this module, users learn to better represent and analyze the effect of varying surface topography on in-seam convergence and stress results. After completing the learning objectives of the Intermediate Learning Track, users will have acquired the basic proficiency in modeling and analysis abilities necessary for starting the advanced learning track.

\subsubsection{Advanced Learning Track}

The advanced learning track has been designed to provide veteran LaModel users with the knowledge and skills necessary to prepare, calibrate, run, and analyze the most complicated underground mining scenarios. Expanding on the topics covered in the novice and intermediate tracks, the Advanced Learning Track has been developed from previous LaModel workshop presentations and graduate-level classroom presentations. The advanced track commences with a discussion on the characteristics and behaviors of the fundamental equation for the laminated overburden model in the Gory Details II training module. At the conclusion of this learning module, users will be given the opportunity to develop their own successive over-relaxation source code with respect to the fundamental differential equation and influence functions implemented in the LaModel program. 
Table 4.10 Summary of Advanced Learning Track

\begin{tabular}{|l|c|c|c|c|c|c|}
\hline \multicolumn{1}{|c|}{ Section Title } & $\begin{array}{c}\text { Captioned } \\
\text { Dialog }\end{array}$ & $\begin{array}{c}\text { Power Point } \\
\text { Presentation }\end{array}$ & $\begin{array}{c}\text { Captivate } \\
\text { Video }\end{array}$ & $\begin{array}{c}\text { Recorded } \\
\text { Audio }\end{array}$ & \multirow{2}{*}{ Papers } & \multirow{2}{*}{ Theses } \\
\cline { 2 - 6 } & words & slides & frames & hours & & \\
\hline \hline Advanced Learning Track & 19,796 & 105 & 960 & $\sim 2.14$ & 6 & 4 \\
\hline 8.0 Gory Details II - Mathematical Behaviors & 3,171 & 13 & 157 & $\sim 0.34$ & 0 & 1 \\
\hline 9.0 Solution Options II & 7,130 & 51 & 130 & $\sim 0.75$ & 4 & 2 \\
\hline 10.0 Miscellaneous Features & 2,805 & 25 & 40 & $\sim 0.3$ & 2 & 1 \\
\hline 11.0 Successive Over-Relaxation Coding Activity & 6,690 & 16 & 633 & $\sim 0.75$ & 0 & 0 \\
\hline
\end{tabular}

The Gory Details II modules build upon the knowledge and skills obtained in the previous Gory Details I module of the Intermediate Learning Track. This second level module investigates the more complex parameter relationships within the LaModel code through a series of comprehensive training modules. Users begin this module series with an introduction and educational activity examining the effects of the rock mass modulus and lamination thickness on seam displacement and stress distribution results. With an understanding of the intricacies of the fundamental equation, the Gory Details II module series continues with an investigation into LaModel's central difference iterative solution method through a Visual Basic for Application (VBA) coding activity in the Microsoft Excel program. After completing this module, users will have obtained a thorough mathematical understanding of the capabilities and limitations of the laminated overburden model. In completing all discussions and activities within the Gory Details II module, users will obtain access to the Solution Options II training module series.

Table 4.11 Summary of the Gory Details II \& Solution Options II Training Module Series

\begin{tabular}{|l|c|c|c|c|c|c|}
\hline \multicolumn{1}{|c|}{ Section Title } & $\begin{array}{c}\text { Captioned } \\
\text { Dialog }\end{array}$ & $\begin{array}{c}\text { Power Point } \\
\text { Presentation }\end{array}$ & $\begin{array}{c}\text { Captivate } \\
\text { Video }\end{array}$ & $\begin{array}{c}\text { Recorded } \\
\text { Audio }\end{array}$ & \multirow{2}{*}{ Papers } & Theses \\
\cline { 2 - 5 } & words & slides & frames & hours & \\
\hline \hline 8.0 Gory Details II - Mathematical Behaviors & 3,171 & 13 & 157 & $\sim 0.34$ & $\mathbf{0}$ & 1 \\
\hline 8.1 Slot Convergence & 1,205 & 8 & 29 & $\sim 0.13$ & & \\
\hline 8.2 Central Difference Method & 1,966 & 5 & 128 & $\sim 0.21$ & & \\
\hline 9.0 Solution Options II & 7,130 & 51 & 130 & $\sim 0.75$ & 4 & $\mathbf{2}$ \\
\hline 9.1 Energy Release Rates & 4,067 & 26 & 89 & $\sim 0.43$ & - & - \\
\hline 9.2 Local Mine Stiffness & 473 & 6 & TBA & $\sim 0.05$ & - & - \\
\hline 9.3 Multiple Seam Subsidence & 1,175 & 8 & 21 & $\sim 0.12$ & - & - \\
\hline 9.4 Roof Beam Bending Stress & 1,415 & 11 & 20 & $\sim 0.15$ & - & - \\
\hline
\end{tabular}


In the Solution Options II learning module, users learn the most complex forms of analysis provided in the LaModel program including: energy release rates, local mine stiffness, multiple seam subsidence, and roof beam bending stresses. This module series begins with discussions of the analysis of bump or bounce proneness in underground coal mines with the energy release rate and local mine stiffness solution options respectively. Through hands-on learning activities and technical articles, users will be familiarized with the mathematical background and procedures for analyzing the possibility of bumps or bounces in the coal seam with LaModel. The second portion of this training series discusses the mathematical background and application of the local mine stiffness calculation in determining bump or bounce proneness of a coal seam. Although this feature is not currently available, it is scheduled to be implemented into LaModel in a future program update. Therefore, as shown in Table 4.11, Captivate Video recordings have been designated by TBA or, "To Be Announced." In the third portion of this training series, users learn the use of the multiple-seam subsidence solution option through a discussion of the mathematical background of displacement influence functions. In the final lesson, users are introduced to the roof beam bending stresses through learning activities that focus on the mathematical derivation of the Euler-Bernoulli Beam Theory. After completing all training module tasks, users will progress to the miscellaneous module and the end of the advanced educational track.

In the Miscellaneous Features training module, users are introduced to a variety of the newest uncategorized LaModel topics. This series of modules begins with a discussion on the proper procedures and analysis techniques necessary for the investigation of surface and sub-surface subsidence. Through the use of a hands-on learning activity, users will be introduced to the capabilities and limitations of the Off-Seam Plane. In the second lesson users are introduced to the mathematical background and application of the Fault Plane. Here users are able to mimic the redistribution of stress in the presence of local and major geologic fault planes. Unfortunately, this feature is not available in the current version of LaModel and is scheduled for distribution in a future program update. Therefore users will not have access to the hands-on learning activity using Captivate Video recordings designated by, "TBA," as shown in Table 4.12. The final lesson within this learning module will introduce users to the application and background of the Strain-Softening for Coal Wizard. Although this material wizard is currently available in 
LaModel, major mathematical changes are currently in development and the new strain-softening material wizard will be available in the next LaModel program update.

Table 4.12: Summary of the Miscellaneous Features Training Module Series

\begin{tabular}{|l|c|c|c|c|c|c|}
\cline { 2 - 5 } \multicolumn{1}{|c|}{ Section Title } & $\begin{array}{c}\text { Captioned } \\
\text { Dialog }\end{array}$ & $\begin{array}{c}\text { Power Point } \\
\text { Presentation }\end{array}$ & $\begin{array}{c}\text { Captivate } \\
\text { Video }\end{array}$ & $\begin{array}{c}\text { Recorded } \\
\text { Audio }\end{array}$ & \multirow{2}{*}{ Papers } & \multirow{2}{*}{ Theses } \\
\cline { 2 - 5 } & words & slides & frames & hours & & \\
\hline \hline 10.0 Miscellaneous Features & 2,805 & 25 & 40 & $\sim 0.30$ & 2 & 1 \\
\hline 10.1 Off-Seam Plane & 1,970 & 11 & 40 & $\sim 0.21$ & - & - \\
\hline 10.2 Fault Plane & 369 & 5 & TBA & $\sim 0.04$ & - & - \\
\hline 10.3 Strain-Softening Coal Wizard & 466 & 9 & TBA & $\sim 0.05$ & - & - \\
\hline
\end{tabular}

Through this series of software demonstrations, slide presentations, and technical publications, users will master the knowledge and skills necessary to properly analyze and evaluate convergences and stress distributions with respect to these newly implemented LaModel features. In completing all discussions and activities within the Miscellaneous training series, users will gain access to the more complicated Successive Over-Relaxation (SOR) training module.

At the conclusion of the Advanced Learning Track, user knowledge of the characteristics and behaviors of the laminated overburden model are further enhanced through the creation of a simplified LaModel application using Microsoft Excel's VBA programming language. Users are guided through the step-by-step construction of a successive over-relaxation code similar to that implemented by the LaModel program, for the determination of in-seam convergence and stress.

Table 4.13: Summary of the Successive Over-Relaxation Coding Training Module Series

\begin{tabular}{|c|c|c|c|c|c|c|}
\hline \multirow[t]{2}{*}{ Section Title } & $\begin{array}{c}\text { Captioned } \\
\text { Dialog }\end{array}$ & $\begin{array}{l}\text { Power Point } \\
\text { Presentation } \\
\end{array}$ & $\begin{array}{c}\text { Captivate } \\
\text { Video }\end{array}$ & $\begin{array}{c}\text { Recorded } \\
\text { Audio } \\
\end{array}$ & \multirow[t]{2}{*}{ Papers } & \multirow[t]{2}{*}{ Theses } \\
\hline & words & slides & frames & hours & & \\
\hline 11.0 Successive Over-Relaxation Coding Activity & 6,690 & 16 & 633 & $\sim 0.70$ & 0 & 0 \\
\hline 11.1 Base Code & 2,962 & 10 & 145 & $\sim 0.31$ & - & - \\
\hline 11.2 Zero Array & 830 & 1 & 135 & $\sim 0.09$ & - & - \\
\hline 11.3 Material Stress & 1,269 & 4 & 153 & $\sim 0.13$ & - & - \\
\hline 11.4 Boundary Conditons & 1,042 & 1 & 155 & $\sim 0.11$ & - & - \\
\hline 11.5 LamLite Run & 587 & - & 45 & $\sim 0.06$ & - & - \\
\hline
\end{tabular}


Through the development of this simplified LaModel application, users will need to rely heavily on their knowledge of the fundamental differential equation, stress influence functions, as well as the basic parameters of the laminated overburden model including: element widths, lamination thickness, and coal strength. After progressing though this series of software demonstrations, users will have shown an understanding of all LaModel topics discussed and therefore demonstrate advanced knowledge, comprehension, and application of the LaModel program and its features. By completing all of the educational objectives of the SOR module, users will have verified their proficiency with the LaModel program and will have completed the online training course.

\subsection{Formative Student Assessments}

In developing an open online training course for the LaModel program, it is important for classroom administrators (or the student themselves) to accurately track student performance and to evaluate course quality throughout the entirety of the course's duration. Due to a lack of faceto-face contact between the student and an educator, online educational assessments will be the primary strategy for investigating a student's grasp of the presented material and the effectiveness of instructional techniques. Currently there are a total of 11 assessments for this course which have been designed in accord with the standards of traditional pedagogies for onsite instruction that facilitate student learning and mastery of content. Through the use of the Mastery for Learning model and Bloom's Taxonomy for the Cognitive Domain, these assessments are not used as a measure of accountability but rather as a source of evidence for student understanding of course materials.

Originally developed by Dr. Benjamin Bloom in 1968, the Learning for Mastery instructional model describes the process by which educators can best achieve student competence in learning objectives. In this learning environment, students progress through a series of discrete topics with frequent and specific feedback provided by diagnostic tests, which both highlight and correct student mistakes along their learning path (Bloom, 1976). 


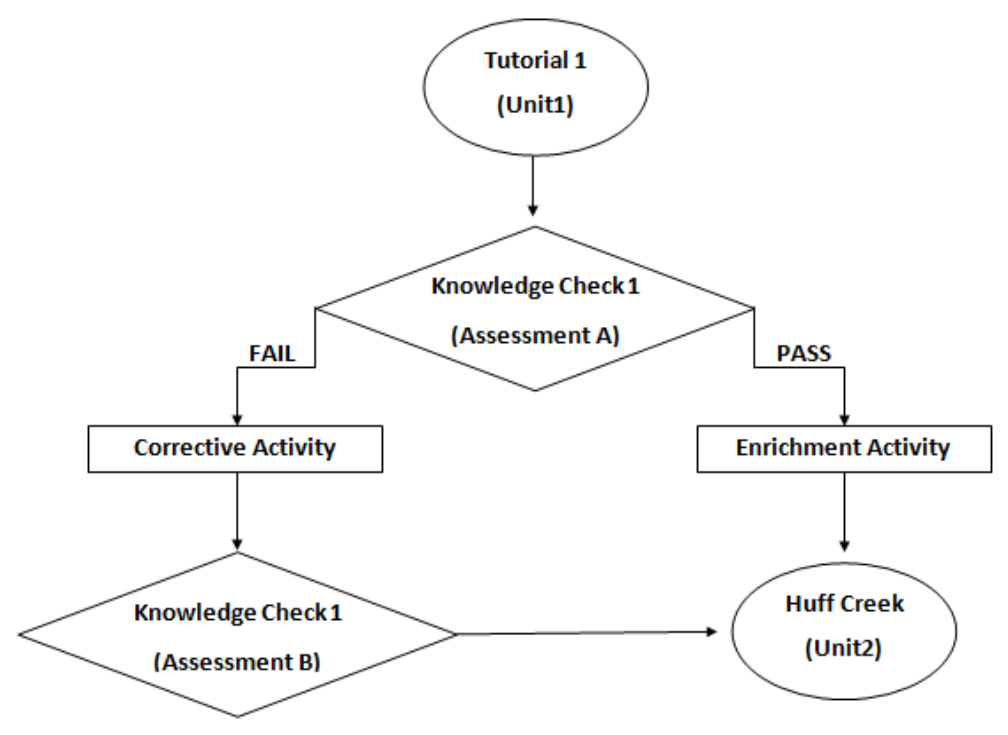

Figure 4.1: Mastery for Learning Model for Tutorial 1 Learning Module

As seen in the schematic above, all students begin together within the same learning module, for example Tutorial 1, but move through the module at their own pace one topic to the next. In order to ensure that learning objectives are being met, user knowledge and comprehension of the desired LaModel concepts and skills are assessed at the end of each module (Knowledge Check 1). If the user has mastered the learning objectives, they will continue on to the next training module (in this case Huff Creek), building upon previously mastered knowledge and skills. If a student does not provide sufficient evidence of material mastery, the student will be provided with a corrective activity which offers further, instruction. Through the incorporation of instructive feedback and tailored learning activities, students who are struggling with LaModel concepts and skills reviewed in the module are encouraged to review and revise the material until mastery has been achieved. After completing the provided corrective activities, students are then reevaluated with another assessment. If the user is then judged to have mastered the material, he or she will be able to move on to the next instructional unit (Huff Creek) in the online training course.

Implemented in the design of each assessment is a classification system for educational objectives, Bloom's Taxonomy for the Cognitive Domain. This taxonomy provides a framework for sustaining higher-level thinking within the classroom as well as monitoring the student levels 
of learning. Using this pedagogical practice, users are assessed across each of the six cognitive levels; evaluation, synthesis, analysis, application, comprehension, and knowledge.

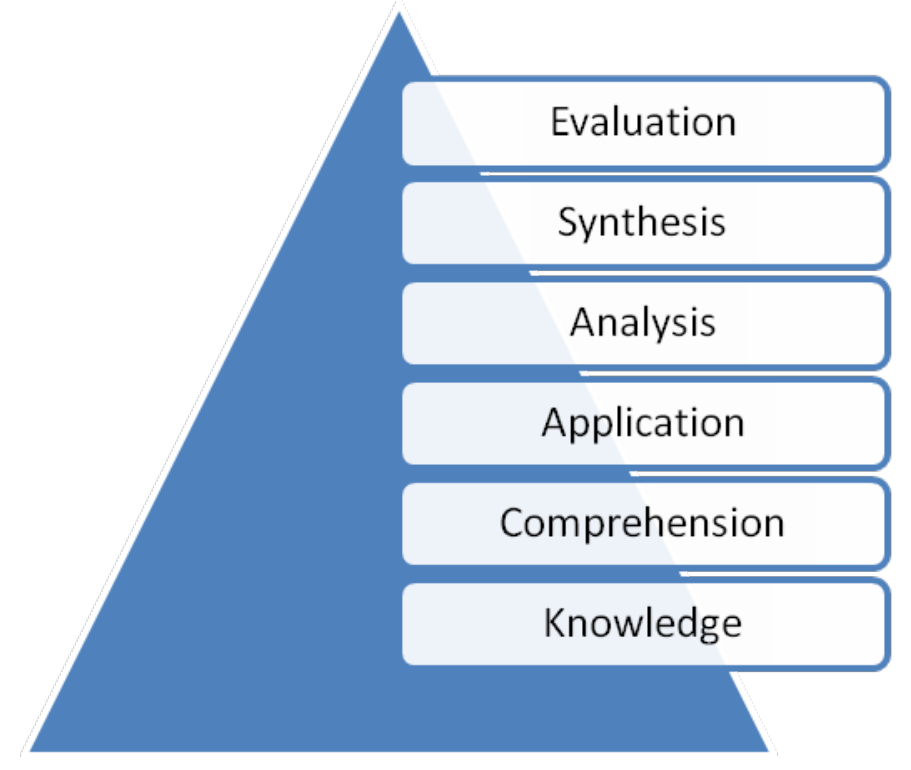

Figure 4.2: Bloom's Taxonomy for the Cognitive Domain Hierarchy

With respect to the hierarchy structure shown in Figure 4.2, student learning begins at the foundation, or "Knowledge", level and progresses to the next cognitive level until the student reaches the apex of higher order thinking, "Evaluation". Progressing from lower to higher levels of cognitive ability, students build upon previously developed knowledge and skills increasing repetition and validating their understanding of the material. Referring to Question 2 of Knowledge Check 7 for the Stability Mapping module, (see Appendix III) in order for a student to determine an adequate element width for surface elements (Evaluation), one needs to understand the definition (Knowledge), surface stress calculation (Application), and consider the limitation of the given equation (Synthesis). In developing each formative assessment with respect to Bloom's Taxonomy, classroom administrators are able to track the growth and development of a student by identifying mismatches between what is being taught and what is being retained by the student. For example, in reviewing an assessment, a student correctly answers questions in the lower registry of the cognitive domain (Knowledge and Comprehension) and misses questions which appraise the relationship between the Rock Mass Modulus and the Lamination Thickness. Here, there is a disconnect between the student's ability to reproduce definitions and evaluate the association between these two parameters with respect 
to the fundamental differential equation. In designing formative assessments with respect to Bloom's Taxonomy for the Cognitive Domain, classroom administrators are provided with a structured process from which they can investigate student performance and the effectiveness of pedagogical practices to facilitate learning and exceed educational standards.

\subsection{Training Module Example for Energy Release Rates}

While each aspect of the training course has been thoroughly explained throughout this chapter, this section looks to provide readers with a more detailed personalized experience within the online learning environment. By progressing in detail through the Energy Release Rate training module, users will gain a better appreciation for the course's accessibility, functionality, and learning materials. This section looks to highlight the depth at which online materials discuss and present LaModel topics as well as the utilization of Bloom's Mastery for Learning model within the online learning environment. However, before one begins, users must first create a student account with the Learning Management System (LMS), Coursesites, and enroll in the LaModel Training Course.

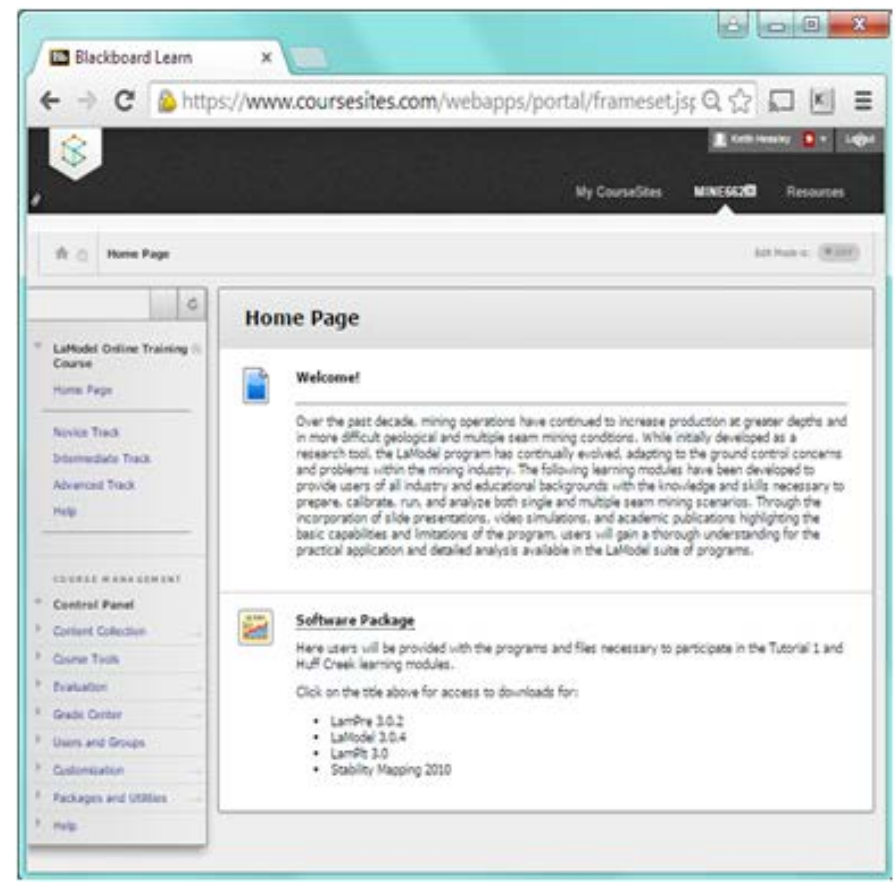

(a) Desktop Display

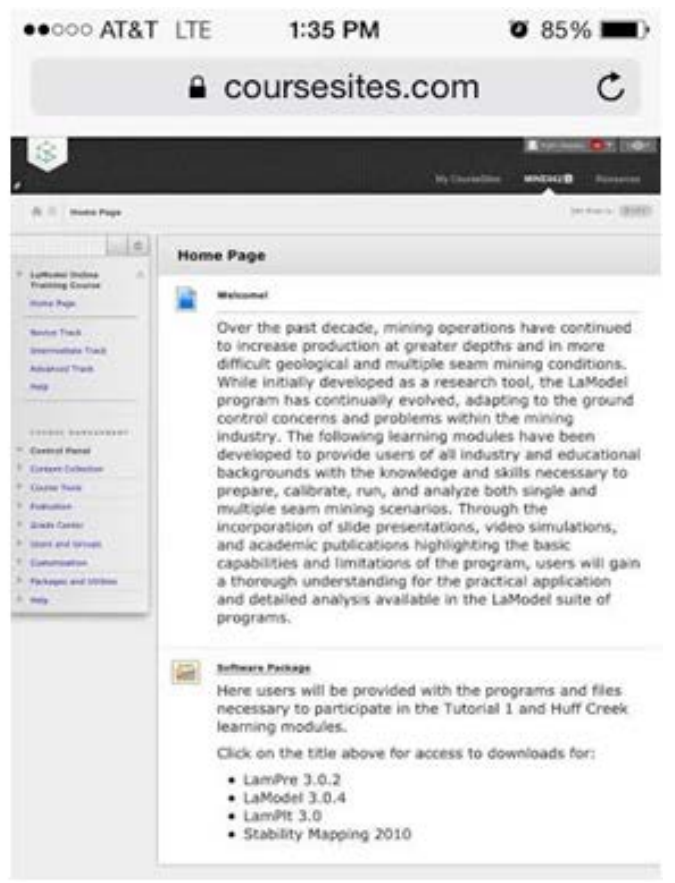

(b) iPhone Display

Figure 4.3: LaModel Online Training Course Home Page 
Upon launching the course, users are brought to the course Home Page as shown in Figure 4.3. At the top of the screen, the Tab Area provides users access to tabs which allow for universal navigation through the CourseSites System including direct access to My CourseSites page, the Course page, and the Resources or help page. Directly below these tabs, one will see a Breadcrumb trail beginning with the course home page designated by the silhouette of a house. As users open learning tracks and progress through the provided learning modules, the breadcrumb trail will lengthen with respect to the modules and material users have accessed. This trail of links can be used to step back as necessary. On the left of the page is the Course Menu. When the user clicks on a link or button found in the Course Menu, such as Advanced Learning Track, a variety of content will be displayed in the Content Frame to the right, depending on what has been provided by the course designer.

Assuming that a user has completed the necessary educational assessments to gain access to the Solution Options II training modules within the Advanced Learning Track, users can select the Solution Options II content folder from within the Content Area followed by the selection of the Energy Release Rates module link. 


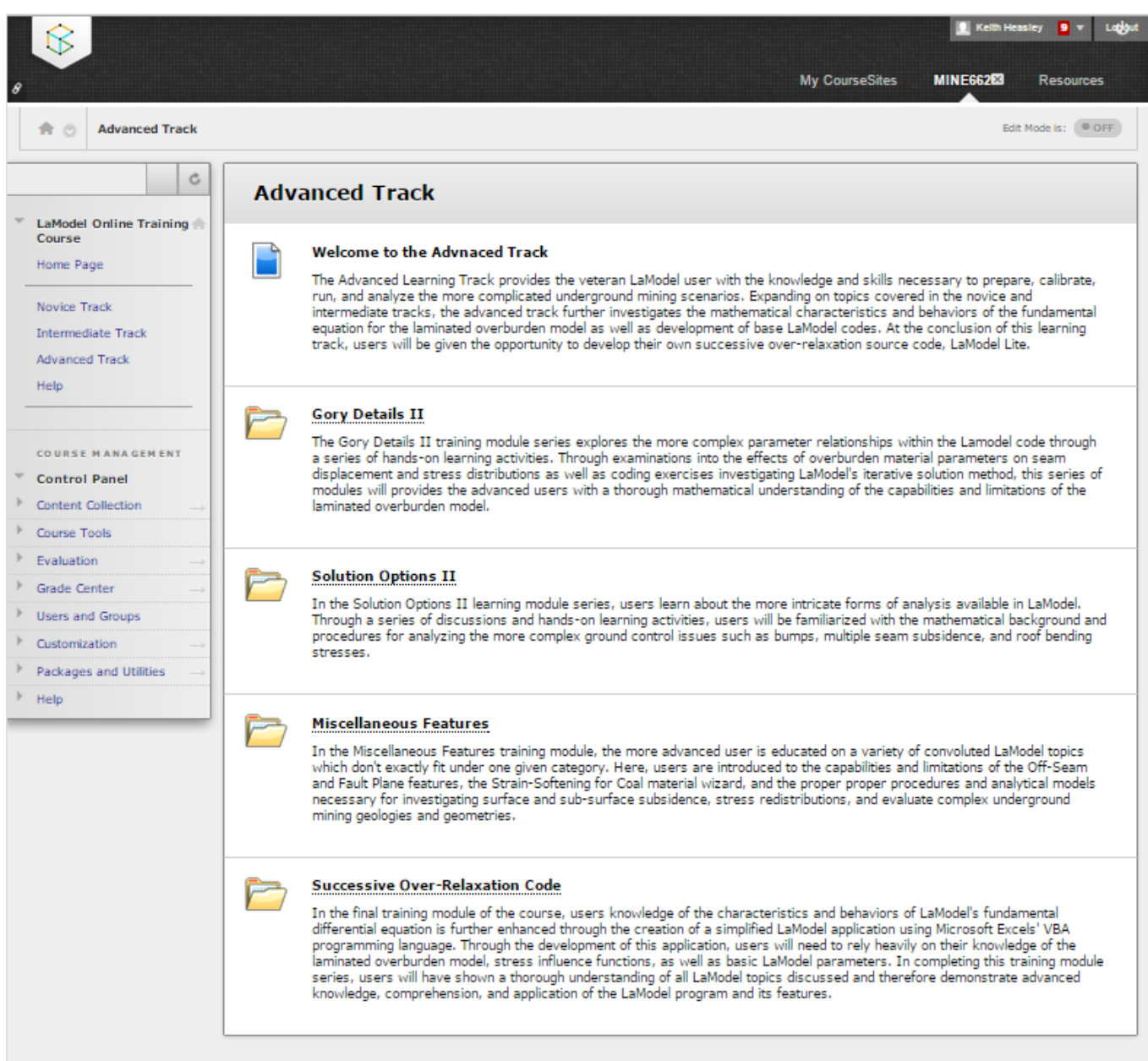

Figure 4.4: LaModel Online Training Course's Advanced Learning Track 

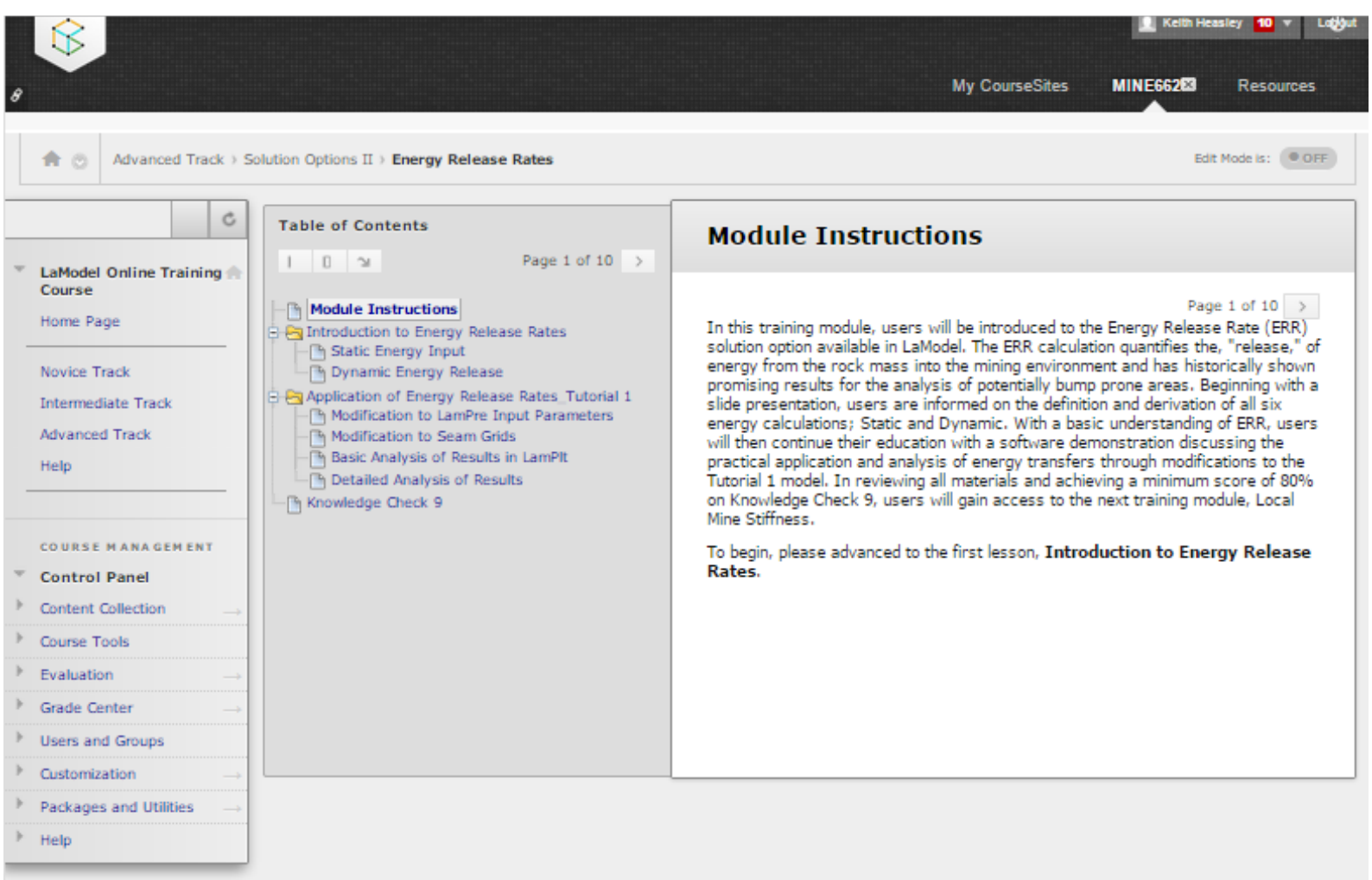

Figure 4.5: Energy Release Rates Training Modules, Module Instructions

Opening this learning module, the Content Area is populated with a training module descriptions as well as a Table of Contents to the left. Given the comprehensive nature of the LaModel course, the Table of Contents provides users with a structured path for progression through the available learning materials. By selecting the first available content folder, Energy Release Rates, within the Table of Contents, or using the navigation arrows at the top of the Course Content area, users will gain access to an introductory slide presentation discussing the basic application and derivation of both the Static and Dynamic Energy calculations. 


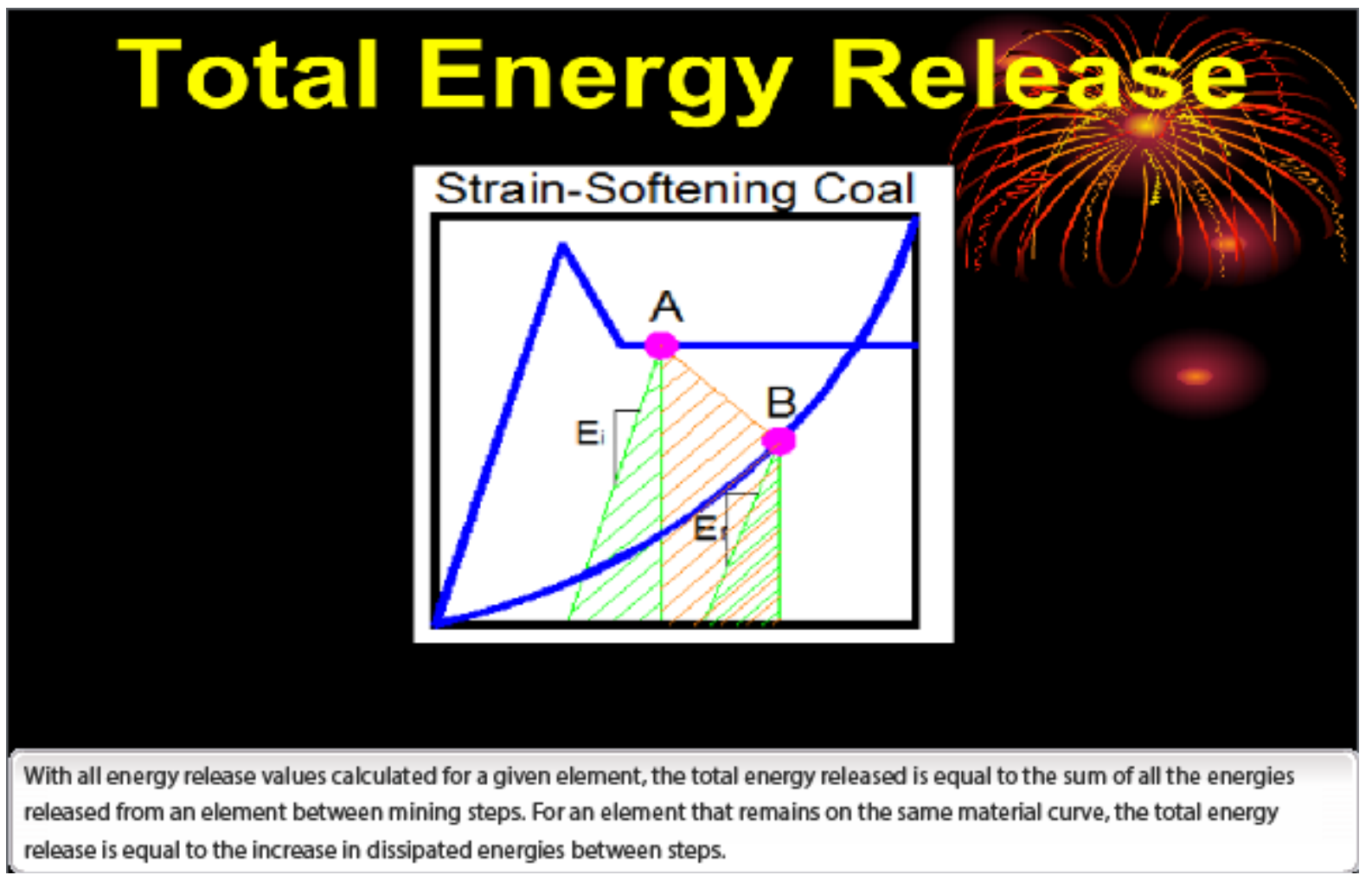

Figure 4.6: Presentation Slide on Dynamic Energy Release

Following this introduction, the subsequent Static and Dynamic slide presentations, similar to that shown Figure 4.6, provide users with more detailed explanation and derivation of the six calculated energy values available for analysis; Total Energy Input, Stored Elastic Energy, Dissipated Energy, Stored Energy Release, Kinetic Energy Released, Total Energy Release. These slide presentations provide users with a detailed description and understanding of each energy calculation. Through the use of open captioning accompanied by audio recordings and graphs providing a picturesque description theses slide presentations provide users with a detailed description and understanding of each energy calculation. 


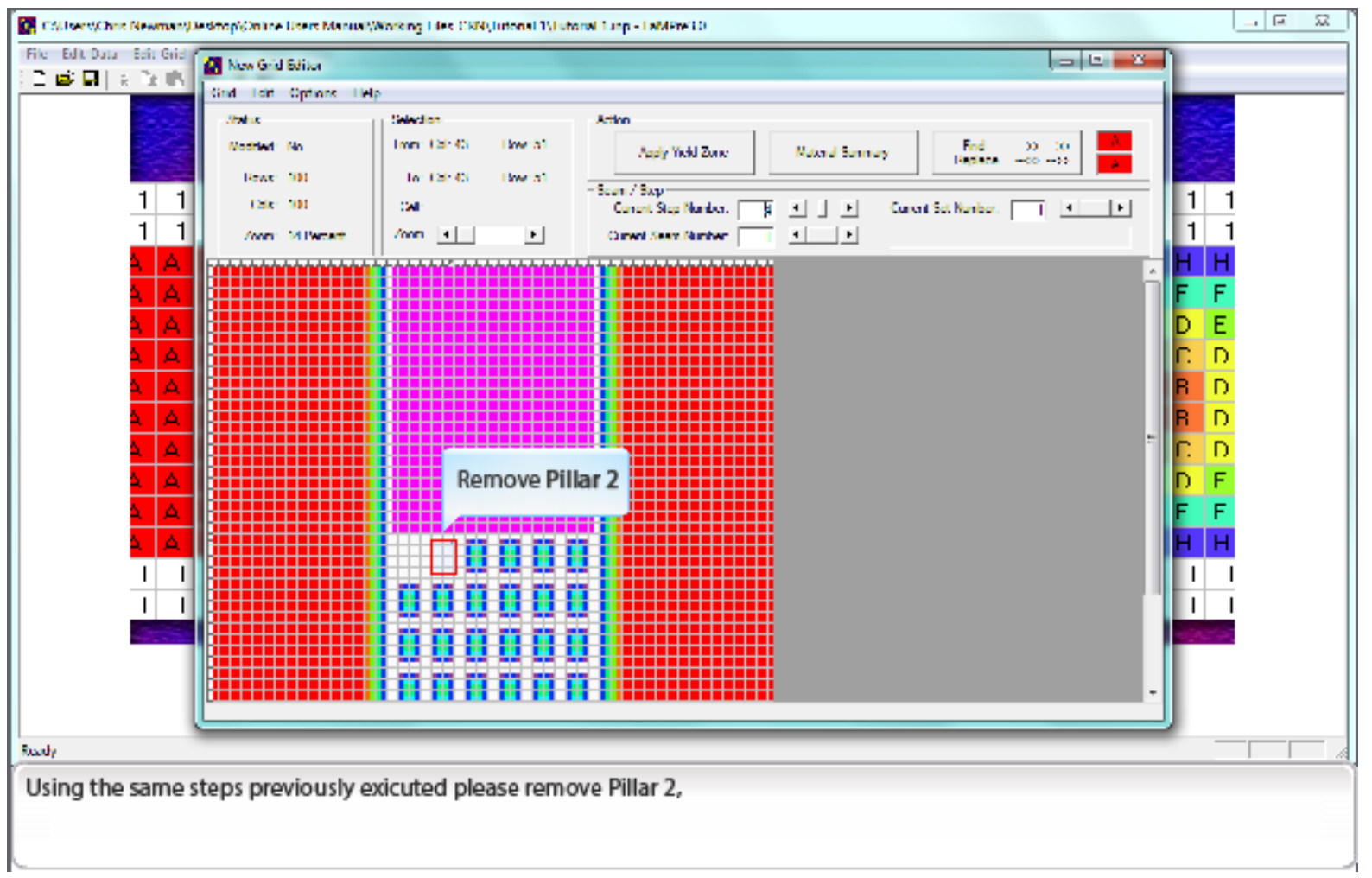

Figure 4.7: Software Demonstration for Modification to the Tutorial 1 Seam Grids

With a clear understanding of the Static and Dynamic energy calculations, and following module progression as suggested by the Table of Contents, users continue their education in energy release rates by selecting and launching the Application of Energy Release Rates_Tutorial 1. In this video demonstration, users will modify the Tutorial 1 model parameters and seam grid for the analysis of energy release rates. As shown in Figure 4.7, through the use of audio recordings, open captioning, and on-screen mouse movements, users will be walked through the development of a "cut-by-cut" model with strain-softening coal pillars such that energy stored and released by the pillar can be tracked by pillar and by modeling step. Through the course of this video, users will be informed about each displayed parameter and, if appropriate their mathematical derivation. In discussing a given parameter or operation within the program, red highlight boxes and blue dialog bubbles are used to help the user better locate and focus their attention on the information that is being relayed. Following the development of the Tutorial 1 Energy Release Rate model, users will continue their instruction with a detailed analysis and explanation of the model's output results. By progressing through this series of presentations and video demonstrations, users will obtain the knowledge and skills necessary for 
the application and accurate analysis for the potential of rock bumps or burst using the energy release calculations available in LaModel.

With all module material completed, users will then prove their knowledge and understanding of the discussed energy calculations by taking the formative assessment, Knowledge Check 9. Designed in accordance to Bloom's Taxonomy, this assessment will investigate a student's grasp of the material by evaluating student knowledge across the six levels of cognitive learning. If the user obtains an initial assessment grade equal to or above $80 \%$, they will have shown mastery of the subject and will gain access to the next unit within the Solution Options II module series, Local Mine Stiffness. However, if a student fall short of this $80 \%$ benchmark, they have not proven mastery of the material and will be returned to the Energy Release Rates module series to further review the available materials.

Upon returning to the training module, users will have access to all previously viewed materials as well as additional information provided within the Corrective Activity folder. Within this folder users will have access to a series of technical papers which will not only reiterate information previously discussed, but will provide users with additional information on the definition, derivation, and application of the energy release solution options.

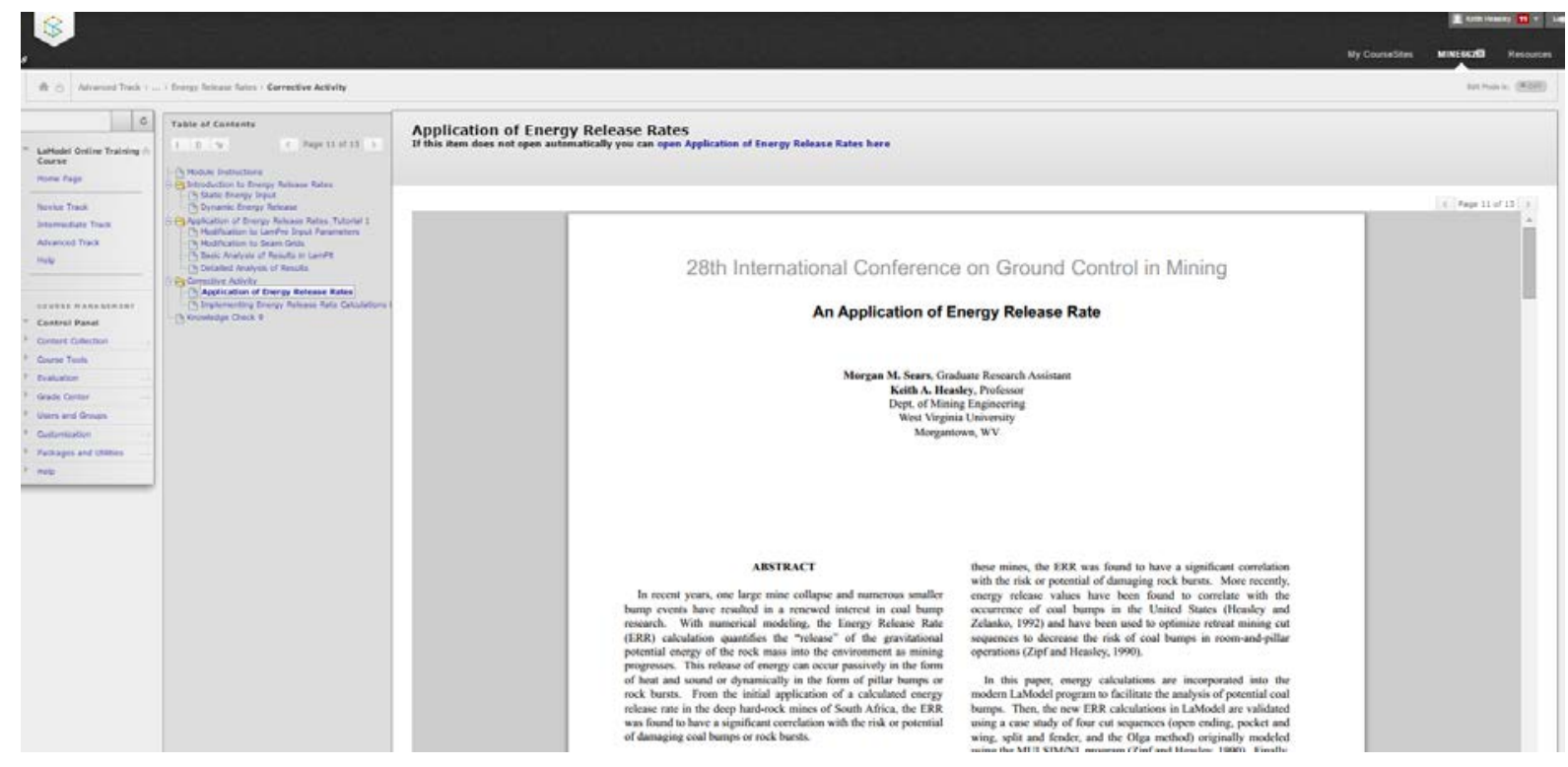

Figure 4.8: Correction Activity for the Energy Release Rates Training Module Series 
Two Energy Release Rate papers will be supplied to the user to help tie together loose ends and further their knowledge. The first paper, "An Application of Energy Release Rates" by Morgan Sears (2010), begins be introducing the reader to the energy calculations through very basic derivation descriptions followed by the application and in-depth analysis of a bump-prone mine in Southern Appalachia. In reading this paper, users will be able to reaffirm the definition of the energy calculations while providing a second look at the application of these calculations to a real life scenario. The second paper provided to users, with respect to the energy release calculations, is a master thesis which provides users with in-depth technical derivation of the energy calculations. This thesis, "Implemented Energy Release Rate Calculation into the LaModel Program" by Morgan Sears (2010), goes to great length to effectively and efficiently detail each aspect of the energy calculations. Through this thesis, users will be provided with the most in-depth look into the energy release calculation with verifications of the calculation provided through the analysis of actual mining conditions. Upon reviewing the previously presented module materials and reading the provided papers, users will then be allowed to retake Knowledge Check 9 until they have achieved a passing grade of $80 \%$ thereby obtaining access to the subsequent Solution Options II training module, Local Mine Stiffness. 


\subsection{Analysis and Results}

Due to a lack of face-to-face contact between the student and instructor within the LaModel online course, educational assessments have been implemented as the primary means of obtaining classroom data. Through the statistical analysis of student assessments from three independent learning environments (traditional college classroom lectures, industry workshops, and online course), course administrators are provided with a means of tracking and comparing student achievement levels as well as evaluating the quality of the LaModel learning materials. Currently, assessment data have been collected for the Introductory and Tutorial 1 lessons in all three learning environments. By investigating classroom grade distributions and performing analyses on individual assessment questions, each learning environment was compared and monitored each for its ability to deliver quality education to the student.

\subsection{Description of Learning Environments \& Student Populations}

When investigating a learning environment for student performances and educational quality through statistical procedures it is important to have a clear understanding of student population diversities (cultural, educational, physical, etc.) and course characteristics (location, student interaction, content organization, etc.). The following section classifies and describes the three LaModel learning environments (traditional college classroom lectures, industry workshops, and online course) currently available to students trying to better understand and apply the LaModel program. By maintaining equivalent educational objectives between each environment and then evaluating students using precisely the same educational assessments, each specific learning environment has been evaluated for its ability to convey LaModel concepts and effectively train future program users.

\subsubsection{Traditional Learning Environment}

In the "traditional" learning environment students attend "brick and mortar" classroom settings in which an instructor delivers learning materials with a lecture style format. The offthe-cuff lecture style within the traditional learning environment allows instructors to determine how the material should be presented and which concepts to emphasize. While this lecture style provides appropriate topic discussions, it might not present a uniform and organized structure for the comprehensive delivery of learning materials. Therefore, student involvement is vital during the lecture time in order to control the pace of the lesson. Students should be asking questions 
when they get lost or are confused, should be listening intently, and should be diligently taking notes for future review of presented LaModel topics.

The LaModel traditional learning environment evaluated in this thesis was comprised of 10 senior level undergraduate student volunteers from the 35 students enrolled in the MINE 411 Rock Mechanics course in the Fall of 2014. Over the course of eight days, three one-hour lectures were given introducing the background and basic operation of LaModel; the History \& Background of LaModel, Tutorial 1 LamPre Input Parameters, and Tutorial 1 Analysis. Immediately upon completion of the Introductory and Tutorial 1 lectures, student volunteers were provided with the Knowledge Check 1 and Knowledge Check 2 assessments from the online training course for the evaluating student comprehension of lecture materials. The majority of these assessments were completed and submitted by students shortly after class had concluded with the rest being received later that night.

\subsubsection{Workshop Learning Environment}

While the LaModel workshops are primarily focused on providing industry professionals with an on-site classroom lecture format, enrollment is typically open to all interested parties (practicing engineers, college interns, regulatory agencies, etc.). While LaModel training material is presented in a similar off-the-cuff lecture style as seen in the traditional learning environment, the workshop greatly differs in the amount of material covered and the length of time in which it is covered. By the end of an 8- to 12-hour workshop, students will not only have been introduced to the LaModel basics but will also have discussed model calibration, surface subsidence prediction, and the detailed analysis of underground stabilities. While the workshop provides students with more technical discussion of LaModel topics, the lecturing style does not present a very relaxed structure for the comprehensive delivery of learning materials. While the on-site workshop learning environment typically maintains smaller class sizes, participants involvement in the lecture is vital in order to control the pace of the lessons. Similar to the traditional classroom participants should be asking questions when they get lost or confused, should be listening intently, and should be diligently taking notes for the future review of presented LaModel topics.

The LaModel workshop learning environment evaluated in this thesis was comprised of 5 graduate student volunteers and 3 industry graduate engineers who enrolled in an 8-hour on-site 
industry workshop. Over the course of the one day workshop, students were introduced to the background, basic operation, calibration, and detailed analysis using the LaModel program through the History \& Background, Tutorial 1, Huff Creek, Gory Details, Subsidence, and Energy Release Rate lessons. Upon completion of the first two lessons, History \& Background and Tutorial 1, student volunteers were provided with the Knowledge Check 1 and Knowledge Check 2 assessments during their workshop breaks for evaluating student comprehension of learning materials. These assessments were completed and submitted by the following afternoon.

\subsubsection{Online Learning Environment}

The online learning environment provides students with a more individualized, one-on-one lecture style through the implementation of self-paced narrated and captioned slide presentations and video demonstrations as well as academic publications. Through the rigid organization of LaModel topics users are provided with a very detailed and comprehensive delivery of learning materials. By progressing through lessons at their own pace students are able to slow down or speed up lesson tempo, or immediately review, with respect to their familiarity with a given LaModel topic. In using CourseSites as an online learning platform, students are able to access all LaModel material for future reference at any location and at any time using qualified devices (Android, iOS, Windows, etc.).

The online learning environment group assessed in this thesis was comprised of 6 graduate level students enrolled in the course through the CourseSites Learning Management System with access to the Introduction \& Background and Tutorial 1 training modules. At the conclusion of a given training module users had to complete the provided educational assessment in order to gain access to the subsequent training module (as previously explained in Chapter 4 of this thesis).

\subsection{Normal Distribution of Assessment Results by Learning Environment}

At this point in the evaluation of student performance within a given learning environment (traditional, workshop, and online) all students have completed both the introductory and Tutorial 1 LaModel topics and were subsequently evaluated using the same associated assessments, Knowledge Check 1 (KC1) and Knowledge Check 2 (KC2). The grade distributions from all three learning environments are plotted in Figure 5.1. 


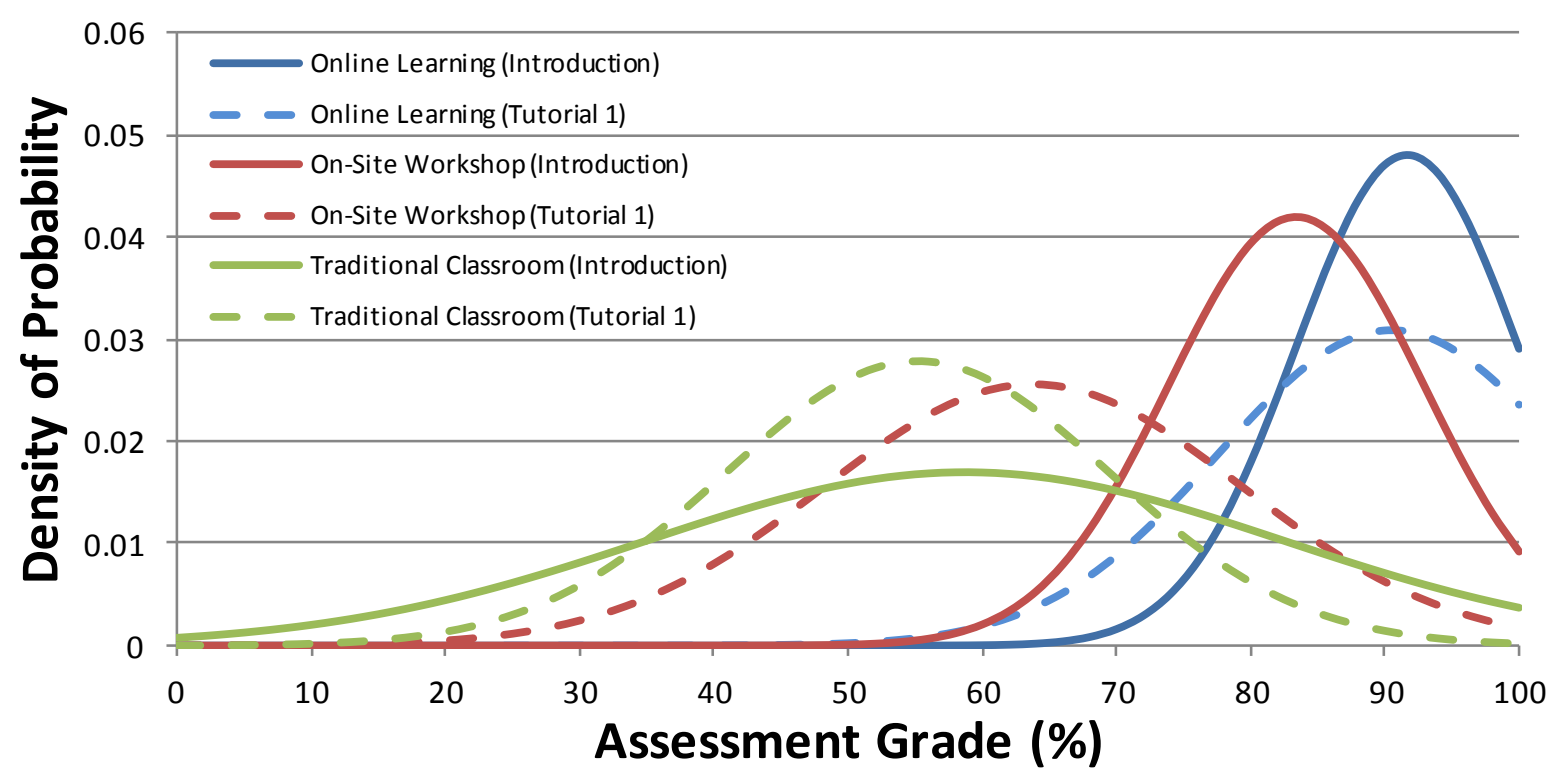

Figure 5.1: Assessment Grade Distribution

As one might expect, the graduate students' higher level of education and strong work ethic may have influenced the results, and indeed, as shown in Figure 5.1, the undergraduate students within the traditional learning environment obtained the lowest average grade for both KC1 (55\%) and KC2(59\%) with assessment scores ranging from 22 to 94\% (standard deviation of 19\%). Graduate students within the LaModel workshop obtained slightly better assessment scores of $83 \%$ on KC1 and 64\% on KC2 with scores ranging from39 to 89\% (standard deviation of 12.5\%). However, students enrolled in the self-paced online course obtained the highest overall assessment averages. Online graduate students achieved assessment averages of $92 \%$ on KC1 and $91 \%$ on KC2 with a standard deviation of $10 \%$. Using Z-Tables for Standard Normal Probability further illustrated the superiority of student achievement within the online learning environment with $87 \%$ probability that students enrolled online will receive a passing grade $(\geq 80 \%)$ on their first attempts. This compared to an estimated passing rate of $12 \%$ for traditional students and $42 \%$ for workshop students.

Student t-Tests were also performed to further support the hypothesis that the self-paced online learning classroom will produce more competent and knowledgeable LaModel users. Commonly applied when the observed data follows a normal distribution, the Student t-Test allows course administrators to statistically verify whether two sets of data (sample size $(n)<30$ ) 
are significantly different from each other. From the current data sets, it was determined that LaModel's online classroom average was significantly larger than that found in the workshop or traditional classroom settings given a 95\% confidence level. Using these basic statistical analysis procedures provides course administrators with quantitatively data from which to compare student performance levels while investigating educational discrepancies within the learning environments.

The results obtained from investigations into grade distributions and the conducted Student tTests suggest that the online learning environment provides users with a better understanding of the practical application and operation of the LaModel program. However, due to the current limitation in student population sizes within all three learning environments tested and the cohorts being confounded by the participation of only undergraduates within the traditional and graduates in the workshop and online learning environments, results obtained from these statistical analyses cannot absolutely confirm that the online learning environment provides quality instruction to cultural, educational, and industry diverse populations and therefore the continual collection of assessment data is necessary. Therefore, from the data currently available, these results provide only an initial evaluation of the traditional, workshop, and online course. Further analysis needs to be conducted for each learning environment as the information becomes available.

\subsection{Item Analysis}

While the analysis of assessment averages provides insight into overall student performance within a given learning environment, individual assessment questions can also be further investigated for their ability to accurately and fairly evaluate student understanding of the learning materials. Item analyses, such as difficulty and discrimination, provide classroom administrators with a statistical tool for the evaluation of question quality and the identification of necessary improvements and/or revisions to the assessment (Kehoe, 1995). Due to the fact that current levels of student participation are statistically insignificant, Item Difficulty and Item Discrimination analyses were conducted on a population which combined all of the student assessment results from the traditional, workshop, and online learning environments. While this cohort only contains undergraduate and graduate level students, it provides a larger (21 students) cultural and more diverse population in comparison to the evaluation of individual learning 
environments. By comparing student performance trends within the online learning environment to that of the traditional classroom and industry workshops learning environments, item analyses highlight areas in need of improvement through the reevaluation of intended questions difficulties and the modification of wording for the enhancement of question clarity. However, with a small educationally homogeneous student population, future analysis should be conducted on the growing traditional, workshop, and online learning environments to provide more significant conclusions.

\subsubsection{Item Difficulty Analysis}

Item Difficulty (ID) is a measure of question easiness and is expressed as the percentage of students who answered the question correctly. Classroom administrators are able to determine whether an assessment question (item) is too easy or too hard by comparing the combined average difficulty of all learning environments (traditional, workshop, and online) to the expected question difficulty. If a large discrepancy (>15\%) between the combined and expected difficulties is observed, further investigation into the cause of this discrepancy and whether question modification or replacement is necessary. 
Table 5.1: Item Difficulty Analysis Results

\begin{tabular}{|c|c|c|c|c|c|c|}
\hline \multicolumn{2}{|c|}{$\begin{array}{l}\text { Question } \\
\text { Number }\end{array}$} & \multirow{2}{*}{$\begin{array}{c}\text { Cognitive Level } \\
\text { Knowledge } \\
\end{array}$} & \multirow{2}{*}{\begin{tabular}{|c|}
$\begin{array}{c}\text { Expected } \\
\text { Difficulty }\end{array}$ \\
$85 \%$ \\
\end{tabular}} & \multirow{2}{*}{\begin{tabular}{c|}
$\begin{array}{c}\text { Combined } \\
\text { Difficulty }\end{array}$ \\
$77 \%$ \\
\end{tabular}} & \multirow{2}{*}{\begin{tabular}{|c|}
$\begin{array}{c}\text { Item } \\
\text { Difficutly } \\
\text { (ID) }\end{array}$ \\
Good
\end{tabular}} & \multirow{2}{*}{\begin{tabular}{|c|c}
$\begin{array}{c}\text { Item } \\
\text { Discrepency }\end{array}$ \\
$-8 \%$ \\
\end{tabular}} \\
\hline \multirow{9}{*}{ 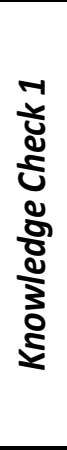 } & 1 & & & & & \\
\hline & 2 & Knowledge & $85 \%$ & $65 \%$ & Moderate & $-20 \%$ \\
\hline & 3 & Analysis & $70 \%$ & $73 \%$ & Good & $3 \%$ \\
\hline & 4 & Evaluation & $40 \%$ & $40 \%$ & Hard & $0 \%$ \\
\hline & 5 & Analysis & $75 \%$ & $81 \%$ & Good & $6 \%$ \\
\hline & 6 & Analysis & $75 \%$ & $88 \%$ & Easy & $13 \%$ \\
\hline & 7 & Analysis & $75 \%$ & $92 \%$ & Easy & $17 \%$ \\
\hline & 8 & Analysis & $75 \%$ & $73 \%$ & Good & $-2 \%$ \\
\hline & 9 & Analysis & $75 \%$ & $85 \%$ & Good & $10 \%$ \\
\hline \multirow{9}{*}{ 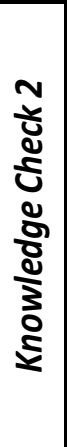 } & 1 & Application & $70 \%$ & $62 \%$ & Moderate & $-8 \%$ \\
\hline & 2 & Knowledge & $80 \%$ & $57 \%$ & Moderate & $-23 \%$ \\
\hline & 3 & Knowledge & $80 \%$ & $71 \%$ & Good & $-9 \%$ \\
\hline & 4 & Analysis & $70 \%$ & $62 \%$ & Moderate & $-8 \%$ \\
\hline & 5 & Application & $65 \%$ & $57 \%$ & Moderate & $-8 \%$ \\
\hline & 6 & Analysis & $75 \%$ & $76 \%$ & Good & $1 \%$ \\
\hline & 7 & Comprehension & $85 \%$ & $48 \%$ & Hard & $-37 \%$ \\
\hline & 8 & Knowledge & $85 \%$ & $81 \%$ & Good & $-4 \%$ \\
\hline & 9 & Analysis & $80 \%$ & $81 \%$ & Good & $1 \%$ \\
\hline
\end{tabular}

The ID parameter can range from $0 \%$, none of the students answered the item correctly, to $100 \%$, all students answered the item correctly (see Table 5.1). In calculating the ID, each question is further categorized as either Easy (ID $>85 \%)$, Good $(85 \% \geq \mathrm{ID}>70 \%)$, Moderate $(70 \% \geq \mathrm{ID}>55 \%)$, or Hard $(55 \% \geq \mathrm{ID}>25 \%)$. The observed difficulty is then compared to the expected difficulty of a question with respect to its cognitive level of thinking as defined in Bloom's Taxonomy for the Cognitive Domain. Questions assessing higher levels of cognitive ability, such as Synthesis and Evaluation, have an expected difficulty ranging from Moderate to Hard or 55 to 25\% correctness. Questions assessing mid-level cognitive thinking, i.e. Analysis or Application, maintain an expected difficulty ranging from Good to Moderate (85 to 55\%). Lower-level questions assessing student Knowledge and Comprehension have an expected difficulty ranging from Good to Easy (70 to 100\%). By relating the question difficulty to the assigned cognitive level, classroom administrators are able to determine whether a question effectively represents the desired educational objective. All questions which result in an ID $<25 \%$ are placed under direct review to determine if the difficulty level observed was a result of the questions being too 
challenging relative to the overall ability of the students, not clearly written or defined, misleading, incorrectly keyed answers, etc. For more information on the question type, wording, cognitive level, and expected difficulty for either Knowledge Check 1 or Knowledge Check 2

please refer to Appendix III. In evaluating each question with respect to the expected difficulty, course administrators are provided with insights into student performance by assessment and by question as well as validating how well the assessment questions accurately evaluate student understanding for the presented LaModel materials.

\subsubsection{Item Discrimination Analysis}

In determining Item Discrimination (IDisc), classroom administrators are able to measure a question (item) for its ability to differentiate among students with varying degrees of material comprehension. Ranking all students according to total assessment score, IDisc is calculated as the difference between high achieving students (top 33\% of the class) and low achieving students (bottom 33\%). This parameter ranges from 100\% to negative (-) 100\% where the higher the value, the better the discrimination. Discrimination of $100 \%$ is achieved when students in the top $33 \%$ of the class answer the question correctly and those in the bottom 33\% answer incorrectly. A discrimination of $0 \%$ is obtained when an equal number of students in both achievement groups answer the question correctly. A negative discrimination is obtained when more students in the bottom $33 \%$ of the class answer the question correctly in comparison to the top 33\%. Items with a negative discrimination should be immediately reviewed for errors in the answer key, ambiguous wording, misleading questions, etc. 
Table 5.2: Item Discrimination Analysis

\begin{tabular}{|c|c|c|c|c|c|}
\hline \multicolumn{2}{|c|}{$\begin{array}{l}\text { Question } \\
\text { Number }\end{array}$} & \multirow{2}{*}{\begin{tabular}{|c|}
$\begin{array}{c}\text { Upper } \\
\text { 33\% of } \\
\text { Students }\end{array}$ \\
1.00
\end{tabular}} & \multirow{2}{*}{ 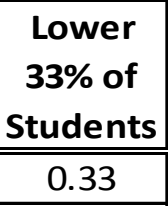 } & \multicolumn{2}{|c|}{$\begin{array}{c}\text { Item } \\
\text { Discrimination }\end{array}$} \\
\hline \multirow{9}{*}{ 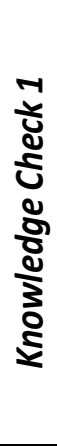 } & 1 & & & 0.67 & Great \\
\hline & 2 & 0.89 & 0.33 & 0.56 & Great \\
\hline & 3 & 1.00 & 0.33 & 0.67 & Great \\
\hline & 4 & 0.67 & 0.17 & 0.50 & Good \\
\hline & 5 & 1.00 & 0.44 & 0.56 & Great \\
\hline & 6 & 1.00 & 0.56 & 0.44 & Good \\
\hline & 7 & 1.00 & 0.78 & 0.22 & Fair \\
\hline & 8 & 1.00 & 0.44 & 0.56 & Great \\
\hline & 9 & 0.89 & 0.56 & 0.33 & Good \\
\hline \multirow{9}{*}{ 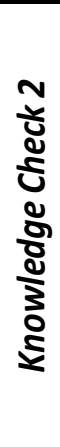 } & 1 & 0.86 & 0.57 & 0.29 & Fair \\
\hline & 2 & 1.00 & 0.29 & 0.71 & Great \\
\hline & 3 & 1.00 & 0.29 & 0.71 & Great \\
\hline & 4 & 0.71 & 0.71 & 0.00 & Poor \\
\hline & 5 & 1.00 & 0.14 & 0.86 & Excellent \\
\hline & 6 & 1.00 & 0.71 & 0.29 & Fair \\
\hline & 7 & 0.57 & 0.14 & 0.43 & Good \\
\hline & 8 & 0.98 & 0.67 & 0.31 & Good \\
\hline & 9 & 1.00 & 0.57 & 0.43 & Good \\
\hline
\end{tabular}

In calculating the IDisc, each question if categorized as either having Excellent (IDisc>75\%), Great (75\% $\geq$ IDisc $>50 \%)$, Good (50\% $\geq$ IDisc $>30 \%)$, Fair (30\% $\geq$ IDisc $>10 \%)$, or Poor (IDisc $\leq 10 \%$ ) discrimination of students (see Table 5.2). When interpreting the item results, it is important to consider the relationship between the difficulty and discrimination of a question. If a question is too east or too hard it is not likely to be very discriminating of student achievement. Through the analysis of Item Discriminations classroom administrators are provided with a means of measuring whether a given questions can accurately indicate if a student understands the material being assessed. Questions which obtain a very low or negative discrimination could be an indication of poorly prepared students guessing correctly, well prepared students justifying the wrong answer, a miskeyed answer, etc.

\subsubsection{Knowledge Check 1 Item Analysis}

Item Analysis results for the KC1 assessment were first analyzed with respect to individual learning environment by comparing the observed and expected item difficulties (see Figure 5.2). As expected, and previously observed in the analysis of grade distributions, the undergraduate 
students within the traditional learning environment (blue) obtained the lowest averages for all assessment questions only exceeding the expected item difficulty (black) in two instances. Averages for all questions increased in the on-site graduate workshop exceeding the expected question difficulty in all but two instances. However, again observed in the previous distribution of assessment grades, graduate students within the online learning environment (green) outperformed all others exceeding the expected difficulty by an average of 19\%. Further analyses were performed to determine the ability of each question to properly assess students on the appropriate educational objectives by highlighting items of low student discrimination as well as discrepancies between the expected item difficulty and average combined difficulty.

Table 5.3: Knowledge Check 1 Item Analysis Results

\begin{tabular}{|c|c|c|c|c|c|c|c|}
\hline \multicolumn{2}{|c|}{$\begin{array}{l}\text { Question } \\
\text { Number }\end{array}$} & \multirow{2}{*}{$\begin{array}{c}\text { Cognitive Level } \\
\text { Knowledge } \\
\end{array}$} & \multirow{2}{*}{$\begin{array}{c}\begin{array}{c}\text { Expected } \\
\text { Difficulty }\end{array} \\
85 \% \\
\end{array}$} & \multirow{2}{*}{$\begin{array}{c}\begin{array}{c}\text { Combined } \\
\text { Difficulty }\end{array} \\
77 \% \\
\end{array}$} & \multirow{2}{*}{$\begin{array}{c}\begin{array}{c}\text { Item } \\
\text { Difficutly }\end{array} \\
\text { Good } \\
\end{array}$} & \multirow{2}{*}{$\begin{array}{c}\text { Item } \\
\text { Discrimination } \\
\text { Great }\end{array}$} & \multirow{2}{*}{$\begin{array}{c}\begin{array}{c}\text { Item } \\
\text { Discrepency }\end{array} \\
-8 \%\end{array}$} \\
\hline \multirow{9}{*}{ 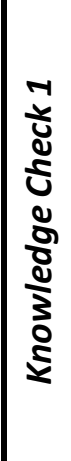 } & 1 & & & & & & \\
\hline & 2 & Knowledge & $85 \%$ & $65 \%$ & Moderate & Great & $-20 \%$ \\
\hline & 3 & Analysis & $70 \%$ & $73 \%$ & Good & Great & $3 \%$ \\
\hline & 4 & Evaluation & $40 \%$ & $40 \%$ & Hard & Good & $0 \%$ \\
\hline & 5 & Analysis & $75 \%$ & $81 \%$ & Good & Great & $6 \%$ \\
\hline & 6 & Analysis & $75 \%$ & $88 \%$ & Easy & Good & $13 \%$ \\
\hline & 7 & Analysis & $75 \%$ & $92 \%$ & Easy & Fair & $17 \%$ \\
\hline & 8 & Analysis & $75 \%$ & $73 \%$ & Good & Great & $-2 \%$ \\
\hline & 9 & Analysis & $75 \%$ & $85 \%$ & Good & Good & $10 \%$ \\
\hline
\end{tabular}

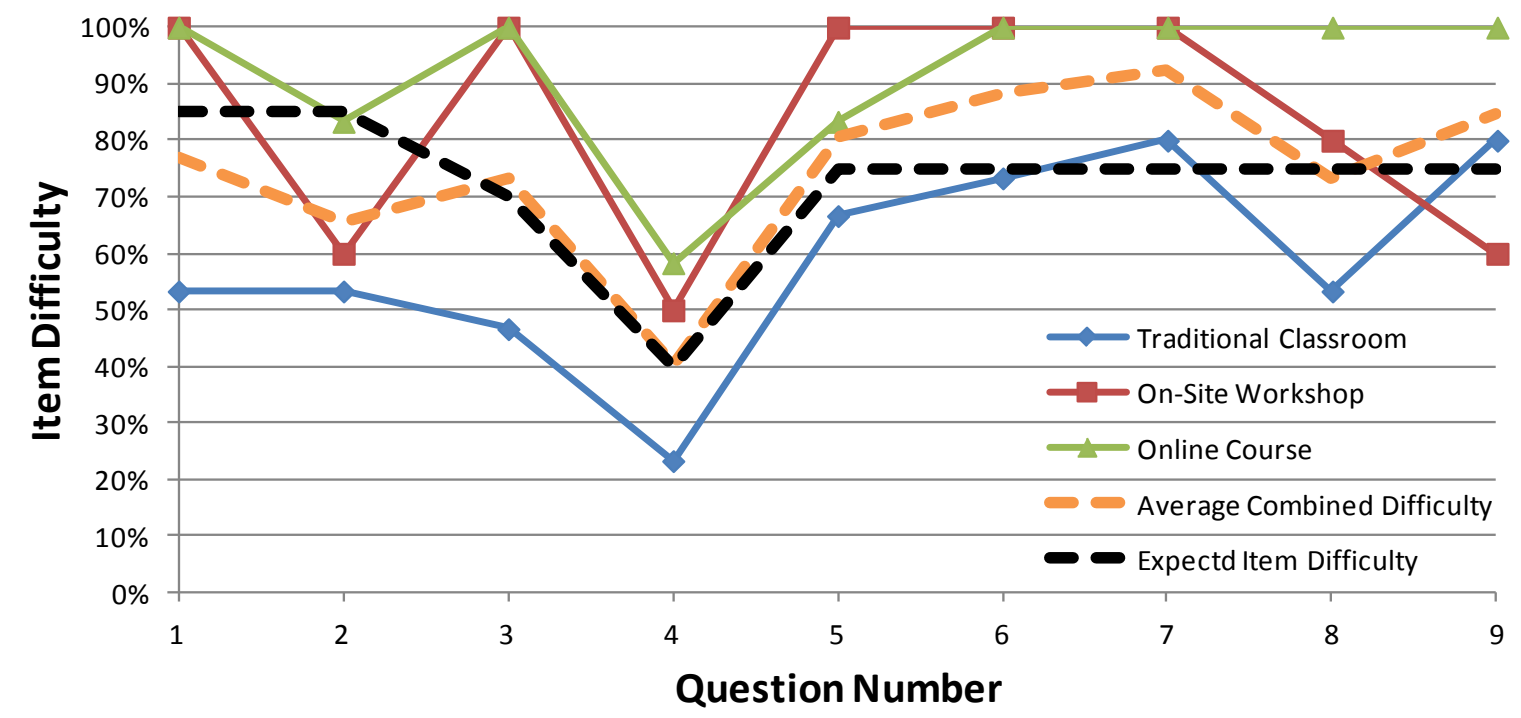




\section{Figure 5.2: Item Difficulty Plot for Knowledge Check 1 Assessment}

The first question of KC1 assesses student lower level cognitive abilities (Knowledge) with an expected difficulty of 85\%. As shown in Figure 5.2, the average combined difficulty for question one was observed to be $77 \%$, slightly below the expected difficulty of $85 \%$. Analyzing the distribution of student answers resulted in an overall "Good" question difficulty and "Great" discrimination among students (see Table 5.3)

Question two again evaluates the lower level cognitive knowledge of the student with an expected difficulty of 85\%. Question two was further categorized as having a "Moderate" difficulty with a large discrepancy (23\%) between an observed difficulty of $65 \%$ and the expected difficulty of 85\% (Figure 5.2). While this large discrepancy has been noted by classroom administrators, the question provides "Great" discrimination between upper and lower student achievement levels (see Table 5.3). Further investigating the question and associated educational objective, classroom administrators found that while the question clearly assessed the student's understanding of LaModel grid sizing the question difficulty was underestimated. In reviewing the education materials presented to students, only one bulleted item discussed LaModel's current grid size. While this may provide an adequate reference point for the more experienced LaModel users, those new to the program may require more emphasis or reiteration within the presented materials. Therefore it is suggested that more focus be placed within the learning material on the maximum grid size currently available in LaModel. This can be accomplished through the addition of a simple sentence in the audio or figure reiterating a current 2000 by 2000 element seam grid.

Question three of KC1 assesses students at a slightly higher cognitive ability, Analysis, with an expected difficulty of 70\%. With an average combined difficulty and small discrepancy between the observed and expected difficulties, question three has an overall "Good" difficulty rating and provides a "Great" discriminator between upper and lower student achievement levels (see Table 5.3). Therefore, question three accurately evaluates the student's ability to differentiate between the mechanical behaviors of the homogeneous and laminated overburden models. Question four was similarly found to accurately evaluate student understanding of the presented LaModel materials. Assessing students with respect to the highest level of cognitive ability Evaluation, question four is the hardest question on the assessment with an expected 
difficulty of $40 \%$. With a matching average combined difficulty of $40 \%$, a difficulty rating of "Hard", and a "Good" discrimination rating, question four accurately assesses student parameter recommendations for the efficient and effective specification of overburden behavior with respect to the fundamental differential equation.

Questions five through nine were developed as a series of related LaModel topic questions all having been categorized as assessing student thinking at the Analysis level of cognitive ability with an expected difficulty of 75\%. This series of questions focuses on the student's ability to effectively compare the mathematical and operational natures of the LaModel and ARMPS programs. Question five had an average combined difficulty of 81\% slightly above the expected difficulty (Figure 5.2). In analyzing the distribution of student answers, question five was categorized as having a "Good" overall difficulty and "Great" discrimination among students (see Table 5.3). Question six a slightly increased discrepancy of 13\% between an average combined difficulty of 88\% and expected difficulty of 75\% (Figure 5.2). Question six was further categorized as a question of "Easy" difficulty while providing "Good" discrimination between student achievements (Table 5.3).

Although being categorized as having an "Easy" difficulty, question seven was observed to have a large discrepancy (17\%) between the average combined and expected difficulties (Table 5.3). Further investigating the distribution of student answers, classroom administrators found question seven to be a "Fair" discriminator of student achievement. In reviewing educational materials, multiple instances were identified in which LaModel's ability to analyze complex single and multiple seam geometries was highly emphasized. This focus on the geometric abilities of LaModel most likely resulted in the high percentage of students answering the question correctly and suggests that the question difficulty was over-estimated. Due to the inherent ease observed for this question, the expected difficulty has been decreased to $82 \%$ for a 10\% discrepancy between the averaged combined and expected item difficulties.

Question eight has an average combined difficulty of 73\% maintaining a small discrepancy between the observed and expected difficulty (Figure 5.2). Question eight has been further categorized as providing an overall "Good "question difficulty with "Great" discrimination between upper and lower student achievement levels (see Table 5.3). From these results, 
classroom administrators suggest that question eight accurately evaluates the student's ability to differentiate between the calibration needs of the AMRPS and LaModel programs.

The final question, question nine, has an increased discrepancy of $10 \%$ between the average combined difficulty of 85\% and the expected difficulty of 75\% (Figure 5.2). Question nine was further categorized with an overall difficulty of "Good" while providing "Good" discrimination between student achievement levels.

\subsubsection{Knowledge Check 2 Item Analysis}

The KC2 assessment questions were evaluated using the same analysis procedures as previously outlined in the analysis of KC1. The KC2 assessment questions were first analyzed independently through comparisons to the expected item difficulty. As expected, and previously observed in the analysis of grade distributions (Figure 5.1), graduate students enrolled in the online course outperformed both workshop and traditional students exceeding the expected item difficulty for all but two instances (Figure 5.3). While the on-site course maintained an overall higher assessment average than the traditional classroom, breaking down the assessment by question shows similar trends since the two learning environments obtained comparable results on five of the nine assessment questions. Through Item Difficulty and Discrimination analyses course administrators evaluated each question on their ability to properly assess students on the

educational objectives of the learning material. In reviewing the results, classroom administrators found two large discrepancies between the expected and observed item difficulty for questions two and seven as well as a "Poor" discrimination rating for question four.

Table 5.4: Knowledge Check 2 Item Analysis Results 


\begin{tabular}{|c|c|c|c|c|c|c|c|}
\hline \multicolumn{2}{|c|}{$\begin{array}{l}\text { Question } \\
\text { Number }\end{array}$} & Cognitive Level & $\begin{array}{l}\text { Expected } \\
\text { Difficulty }\end{array}$ & $\begin{array}{c}\text { Combined } \\
\text { Difficulty }\end{array}$ & $\begin{array}{c}\text { Item } \\
\text { Difficutly }\end{array}$ & $\begin{array}{c}\text { Item } \\
\text { Discrimination }\end{array}$ & $\begin{array}{c}\text { Item } \\
\text { Discrepency }\end{array}$ \\
\hline \multirow{9}{*}{ 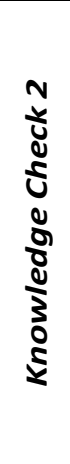 } & 1 & Application & $70 \%$ & $62 \%$ & Moderate & Fair & $-8 \%$ \\
\hline & 2 & Knowledge & $80 \%$ & $57 \%$ & Moderate & Great & $-23 \%$ \\
\hline & 3 & Knowledge & $80 \%$ & $71 \%$ & Good & Great & $-9 \%$ \\
\hline & 4 & Analysis & $70 \%$ & $62 \%$ & Moderate & Poor & $-8 \%$ \\
\hline & 5 & Application & $65 \%$ & $57 \%$ & Moderate & Excellent & $-8 \%$ \\
\hline & 6 & Analysis & $75 \%$ & $76 \%$ & Good & Fair & $1 \%$ \\
\hline & 7 & Comprehension & $85 \%$ & $48 \%$ & Hard & Good & $-37 \%$ \\
\hline & 8 & Knowledge & $85 \%$ & $81 \%$ & Good & Good & $-4 \%$ \\
\hline & 9 & Analysis & $80 \%$ & $81 \%$ & Good & Good & $1 \%$ \\
\hline
\end{tabular}

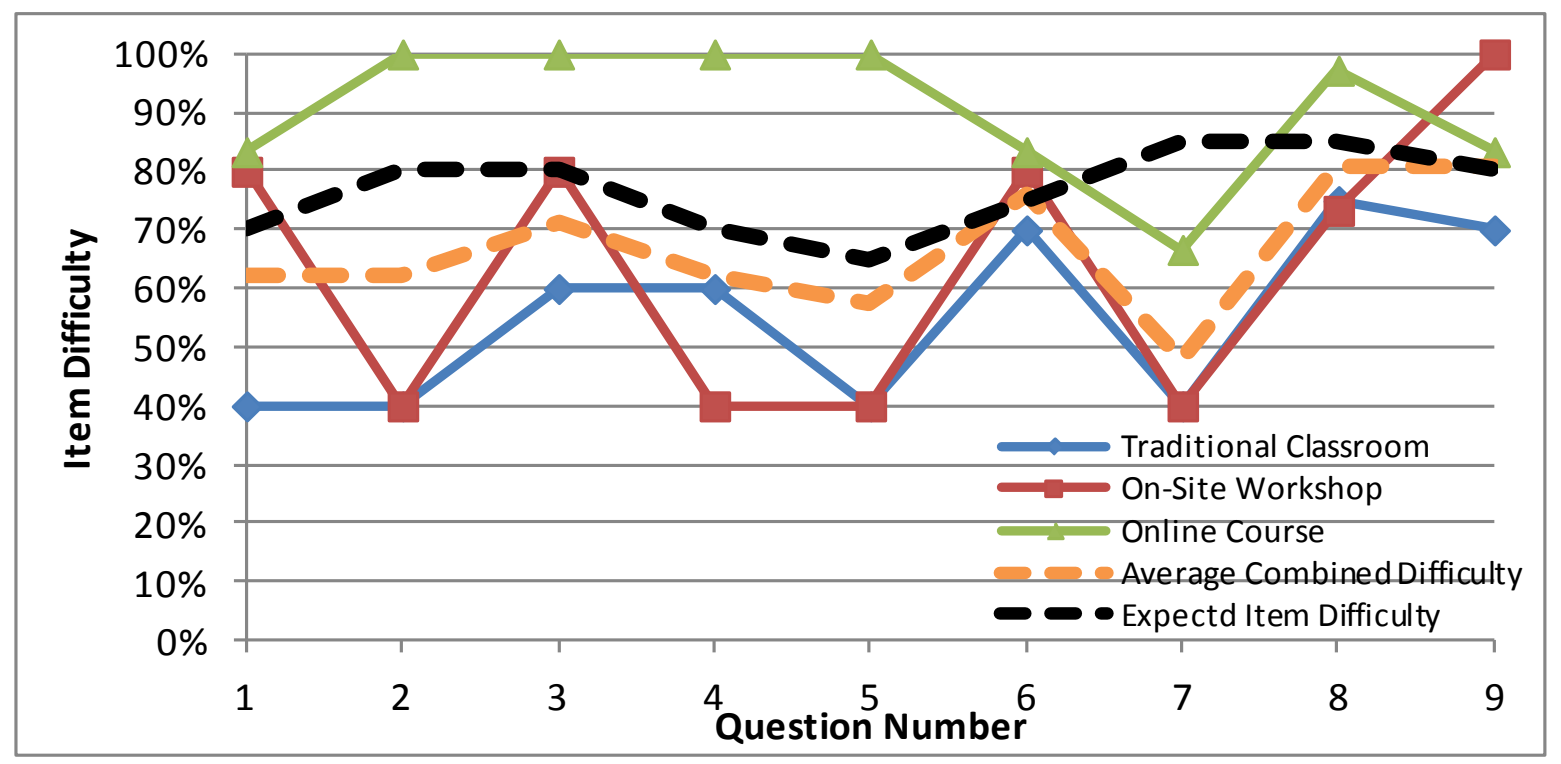

Figure 5.3: Item Difficulty Plot for the Knowledge Check 2 Assessment

The second question of the KC2 assessment uses a fill-in-the-blank answer input style in evaluating students on their lower level cognitive knowledge of the rigid boundary condition. Question two was further categorized as having a "Moderate" difficulty although assessing users on their lower register of understanding providing "Great" discrimination of student achievement groups. The large discrepancy (23\%) between the average combined difficulty of $62 \%$ and the 80\% expected difficulty invited further investigation of the assessment and learning materials. In reviewing the item analyses results of the KC2 assessment, classroom administrators found a 
decrease in difficulty (10\%) in question three which similarly evaluated user Knowledge of the boundary conditions available in LaModel. In further reviewing student answer inputs, many of the incorrect answers given had no relation to either the rigid or symmetric boundary conditions. Therefore it is suggested, that at the end of both question two and question three, the following instructional clause be added: "Please input appropriate boundary condition."

While question four has a low discrepancy between the average combined and expected difficulties, a discrimination rating of "Poor" suggests that the question does not accurately assess student understanding of the course material. In reviewing question data sets, classroom administrators determine that the majority of students who missed question four had answered "Bieniawski Formula" in place of the correct answer "Mark-Bieniawski Formula." With two of the four possible answers mentioning Bieniawski it is likely that high achieving students were mislead while lower achieving students were drawn to these answers providing a statistical advantage in selecting the correct answer. It is suggested that "Bieniawski Formula" answer option be replaced with "Heasley Formula" for better discrimination of student achievement groups.

In Question seven, which assessed the lower level cognitive "Comprehension" of the student, results from all learning environments were below the expected level of difficulty with a large discrepancy of 37\%. Although categorized as having "Good" discrimination of student achievement, such a large discrepancy in the level of difficulty suggests issues in the wording of a question. Modifications to sentence structure and use of more proper terminology instead of program lingo were suggested by classroom administrators to increase the directness of the questioning and hopefully increasing question clarity. 


\subsection{Summary and Conclusion}

For the past 20 years the LaModel program has been utilized by academic and industry engineers as a reliable design tool for the analysis of seam displacements and stress distributions. With more difficult mining conditions (depth and geometry) and an increase in design standards for safety and stability within the mining industry the use of LaModel as an aid in underground mine design has greatly increased in recent years. Along with the increase in program use, there was an accompanying demand for better user support and training in the practical application and technical details of the program for the evaluation of mine stability. The work presented in this thesis details the development and implementation of both an online user's manual and an online training course for the LaModel program. This user's manual and training course are designed to provide users with instantaneous access to current and comprehensive reference materials, and they are designed to accommodate users from multiple educational and industry backgrounds.

\subsection{Summary of LaModel User's Manual}

The online user's manual has been developed to provide users with comprehensive support on the technical knowledge and practical experience needed to proficiently use LaModel. The manual was developed in an HTML format so that users can be provided with on-demand access to detailed information about the program and so that the information can be accessed on any Windows, iOS, Android, and Blackberry phone or PC device. The user's manual was subdivided into five major topic sections and has been composed from a core technical document with over 32,000 words detailing the definition, application, and typical ranges, of critical parameters. The text documentation is further supplemented by over 200 PowerPoint presentation slides and over 600 Captivate video frames with about 33,000 words of narrated dialog providing an estimated 3.7 hours of hands-on demonstrations. Fourteen technical publications (14) have also been hyperlinked within the manual text providing users with additional information on the mathematical details and examples of the practical application of LaModel. Utilizing these multimedia outputs (text documentation, slide presentations, video simulations, and technical publications) the online manual strives to provide users with an engaging information delivery system encompassing all program features in order to better educate and train a proficient end user. 


\subsection{Summary of LaModel Online Training Modules}

An extensive online training course has also been developed as a complement and expansion to the LaModel user's manual. The online course consists of numerous individual training modules which have been designed in accordance with traditional educational pedagogies to provide both novice and experienced users with knowledge and experience on the mathematical background and practical application of the LaModel program. The course is hosted by CourseSites, a learning management system powered by Blackboard technology. With CourseSites users of all educational and industry backgrounds are provided with free and open enrollment into a modern, user-friendly, and full-featured online course available on any Windows, iOS, Android, and Blackberry phone or PC device. Subdivided into three learning tracks (Novice, Intermediate, and Advanced), the online training course has been composed from 314 PowerPoint presentation slides and over 1,700 Captivate video frames with over 58,000 words of narrated dialog and an estimated 3.2 hours of recorded audio. The self-paced training modules have been further supplemented with 20 technical publications providing more detail on the mathematical derivation as well as providing examples on the practical application of LaModel. Students who complete the online training course will have developed the knowledge and skills necessary to analyze the most complex underground mining scenarios using LaModel.

\subsection{Summary of Course Analysis}

In developing the online training course, quality standards were evaluated and student performance was tracked in order to determine whether the online learning environment provided at least the same quality of education as either the previous traditional or workshop learning environments. Educational assessments designed in accordance with standard educational pedagogies were developed as a means of evaluating a student's grasp of the presented classroom materials and the effectiveness of the instructional format. Using these educational assessments, preliminary data was collected for the Introduction and Tutorial 1 training modules as conducted in the traditional, workshop, and online learning environments. From the normal distribution of assessment results, the students within the online classroom outperformed students within the workshop and traditional environments by an average of 21 and 31 percentage points respectively. 
While the distribution of student assessment results provided insights into overall classroom performances, assessment questions were individually investigated for their ability to accurately and fairly evaluate student understanding of learning materials through Item Difficulty and Item Discrimination analyses. While the overall classroom averages indicated superior performance by students enrolled in the online classroom, the item analyses indicated a need for the reevaluation of the intended question difficulty for questions two and seven of Knowledge Check 1 as well as modifications to questions two, four, and seven of Knowledge Check 2 to increase question/answer clarities.

With the distribution of beta versions for both the user's manual and online training course, course developers will continue monitoring student comprehension and performance within each of the three learning environments. Through the continual collection and analysis of educational assessments, course materials will be continually reviewed and updated. The development of a user's manual and online training course for the LaModel program, users will be provided with a comprehensive, online and multimedia based support and training materials on the technical details and practical application of the program for the evaluation of mine stabilities. Educating and training academic, industry, and regulatory users on the application and technical background of LaModel will improve the design of underground mines and thereby improve overall mine safety and productivity. 


\subsection{Suggestions for Future Work}

The previously detailed LaModel user's manual and online training modules have been designed to provide users with instantaneous access to current and comprehensive reference materials. However, in developing the user's manual and training modules additional questions were raised which suggest topics for additional research and development of the online learning environment.

As discussed previously, the results obtained from investigations into the grade distributions and item analyses are to be considered preliminary due to the current limitation in student populations within all three learning environments tested. The results obtained from the statistical analyses performed on each learning environment are statistically insignificant (sample size (n) $<30$ ) and therefore cannot definitively prove that the online learning environment provides quality instruction on the mathematical derivation and practical application of LaModel. In order to obtain statistically significant results it is suggested there be a minimum of 30 students ( $\mathrm{n}>30$ ) enrolled within each learning environment. Upon achieving a minimum of 30 student participants within a given classroom, users are to perform a z-test to statistically verify whether the means of two data sets are significantly different from each other. Using these basic statistical analyses on a statistically significant sample size will provide developers with more conclusive data from which to compare student performance levels while investigating educational discrepancies within a given learning environment.

Apart from the population size, another concerning issue is population diversity within each learning environment. Currently, cohorts are confounded by the participation of only undergraduates within the traditional environment and graduates in the workshop and online learning environments. Therefore, the results obtained from the statistical analysis of these data sets cannot confirm that the online learning environment provides quality instruction and training to educational and industry diverse student populations. It is suggested that classroom administrators continue to collect and statistically analyze a given learning environment until the environment populations are statistically similar. An optimum distribution might contain 33\% undergraduate, 33\% graduate, and 33\% industry participants. As more students enter each learning environment (traditional, workshop, and online) it is important that assessments and course materials are continually evaluated in order to potentially improve material delivery as 
well as student assessments. By updating the online course materials and educational assessment with respect to grade distributions and item analyses, course designers are able to ensure effective communication of materials to better the education and training of the student.

While the current user's manual and online training course provide users with a comprehensive support aid and training modules for the LaModel 3.0.2 program, it is important that both the manual and course content be continually updated as new features and analysis options are added to the LaModel program. For example, in the coming update (LaModel 3.1), users will be introduced to a new solution algorithm, subsidence calibration, CMMR, etc. As these new features are released for public use, the user's manual should be updated with new LaModel topic entries while the course is updated with Captivate video simulations of newly available features and options. In doing this, both the user's manual and training course will remain relevant as users seek to educate and train themselves in these newly developed features.

In developing the LaModel training course it was found that one downside of the open online learning environment is a lack of communication between students and educators. Therefore, in order to open lanes of communication, it is suggested that a internet forum be integrated into the online learning environment such that users can hold conversations with their peers and educators. Using this form, all students will be able to post conversation, "threads," on the application and derivation of LaModel as well as any troubleshooting issues. These posts can then be answered by either peers or educators. In keeping the internet forum open to all users, it is important that a forum admin be assigned to troll through conversation threads to correct any misinformation about the program or its application posted by users.

As the online learning environment evolves to reach and educate diverse student populations, so too will the educational pedagogies. It is important that course designers continue to research and evaluate these new educational pedagogies for the potential enhancement of online material delivery and communication within the online learning environments. 


\section{Works Cited}

Alexander, S. and D. Boud (2001). "Learners still learn from experience when online" Teaching and Learning Online: Pedagogy for New Technologies Edited by J. Stephenson. Stylus Publishing Inc, Sterling, VA, p. 3-15.

Bloom, B.S. (1968) "Learning for mastery" Evaluation Comment. Vol. 1(2), 112 p.

Bloom, B.S. (1976) Human Characteristics and School Learning. McGraw-Hill, New York, NY, $284 \mathrm{p}$.

Bumen, N.T. (2007) "Effects of the original versus revised Bloom's Taxonomy on lesson planning skills: a Turkish study among pre-services teachers" Review of Education. Vol. 53, p. 439-455.

Clark, C.R., T.R. Guskey, and J.S. Benninga (1983) "The effectiveness of mastery learning strategies in undergraduate education courses" Journal of Educational Research. Vol. 76(4), p. 210-214.

Coomey, M. and J. Stephenson (2001) "Online learning: it is about dialogue, involvement, support, and control - according to the research" Teaching and Learning Online: Pedagogy for New Technologies Edited by J. Stephenson. Stylus Publishing Inc, Sterling, VA, p. 37-52.

Eber, P.A. and T.S. Parker (2007) "Assessing student learning: applying Bloom's Taxonomy" Human Service Education. Vol. 27(1), p. 45-53

Ertmer, P.A., Sadaf, A., and Ertmer, D.J. (2011) "Student-content interactions in online courses: the role of question prompts in facilitating higher-level engagement with course content" Journal for Computing in Higher Education. Vol. 23., p. 157-186.

Finder, A. (2013) "A surge in growth for a new kind of online course" The New York Times Online. 15 September 2013. Web. 16 July 2015.

Guskey, T.R. (2007) "Closing achievement gaps: revisiting Benjamin S. Bloom's 'Learning for Mastery"' Journal of Advanced Academics. Vol. 19(1) p. 8-31.

Heasley, K.A., and M.D.G. Salamon (1996). "A new laminated displacement-discontinuity program: fundamental behavior" Proc. of the 15th Conf. on Ground Control in Mining. Colorado School of Mines, Golden, CO, August 13-15, p. 111-125.

Heasley, K.A. (1998) "Numerical modeling of coal mines with a laminated displacementdiscontinuity code" Ph.D. Dissertation. Colorado School of Mines, 179 p.

Heaskey, K.A., and Z. Agioutantis (2001). "LaModel: a boundary-element program for coal mine design" Proc. of the 10th Int. Conf. on Computer Methods and Advances in Geomechanics. Tucson, AZ, January 7-12, p. 1679-1682. 
Heasley, K.A. (2008). "Some thoughts on calibrating LaModel" Proc. of the 27th Int. Conf. on Ground Control in Mining. West Virginia University, Morgantown, WV, July 29-31m p.713.

Heasley, K.A. (2011). “A retrospective on LaModel (or Dr. Heasley’s wild wide)” Proc. of the $30^{\text {th }}$ Int. Conf. on Ground Control in Mining. West Virginia University, Morgantown, WV, July 26-28, p. 21-29.

Heasley, K.A. (2012). "Calibrating the LaModel program for site specific conditions” Proc. of the $31^{\text {st }}$ Int. Conf. on Ground Control in Mining. West Virginia University, Morgantown, WV, July 31 - August 2. Web. 16 July 2015.

Herman, J.L. and E. Baker (2005) "Making benchmark testing work" Educational Leadership. Vol. 63(3), p. 48-54.

Itin, C. (1999) "Reasserting the philosophy of experiential education as a vehicle for change in the 21st century" Journal of Physical Education. Vol.22(2), p. 91-98.

Jackson, B. and K. Anagnostopoulou (2001) "Making the right connections: improving quality in online learning" Teaching and Learning Online: Pedagogy for New Technologies Edited by J. Stephenson. Stylus Publishing Inc, Sterling, VA, p. 53-66.

Kehoe, J. (1995). "Basic Item Analysis for Multiple-Choice Tests" Practical Assessment, Research \& Evaluation. Vol.4(10). Web. 14 July 2015.

Kolb, A. and Kolb, D. (2012) "Kolb's Learning Styles" Encyclopedia of the Sciences of Learning. Springer, US, p. 1698-1703.

Kolb, D. (1984). Experiential Learning: Experience as the Source of Learning and Development. Prentice-Hall, Englewood Cliffs, NJ, 256 p.

Krathwohl, D.R. (2002) "A revision of Bloom's Taxonomy: an overview" Theory into Practice. Vol. 41(4) p. 221-264.

Marginson, S. and M. van der Wende (2007) "Globalization and higher education" OECD Directorate for Education. 06 July 2007. Web. 29 Sept. 2014.

Mayes, T. (2001) "Learning technology and learning relationships" Teaching and Learning Online: Pedagogy for New Technologies Edited by J. Stephenson. Stylus Publishing Inc, Sterling, VA, p. 16-26.

McKinnon, K.R., S.H. Walker, and D. David (2000) "Benchmarking: a manual for Australian universities" Canberra, ACT: Higher Education Division, Department of Employment, Education, and Youth Affairs. 167 p. 
Meade, P.H (1998) A Guide to Evaluation for Quality Improvement. Griffith University, Brisbane, Australia, 45 p.

Olson, L. (2005) "Benchmark assessments offering regular checkups on student achievement" Education Week. Vol. 25(13), p. 13-14.

O'Neil, K., Singh, G. O'Donoghue, J. (2004) "Implementing eLearning programmes for higher education: a review of literature" Journal for Information Technology Education. Vol. 3(1), p. 313-323.

Oxford. (2013) "28 August 2013: Oxford dictionaries online quarterly update: new words added to oxforddictionaries.com today" Oxford Dictionaries Online. 28 Aug. 2013. Web. 24 Sept. 2014.

Pappano, L. (2012) "The yeah of the MOOC" The New York Times 4 Nov. 2012:ED26. Web. 24 Sept. 2014.

Sears, M. (2010) "An Application of Energy Release Rate" Proc. of the $28^{\text {th }}$ Int. Conf. on Ground Control in Mining. West Virginia University, Morgantown, WV, July 28-30. Web. 16 July 2015.

Shah, D. (2013) "MOOCs in 2013: breaking down the numbers" edSurge 22 Dec. 2013. Web. 24 Sept. 2014.

Skiles, M.E., and K.G. Stricklin (2009). "General Guidelines for the Use of Numerical Modeling to Evaluate Ground Control Aspects of Proposed Coal Mining Plans" Mine Safety and Health Administration Program Information Bulletin No. P09-03. U.S. Department of Labor, March 16, 7p.

Stephenson, J. (2001) "Learning technology and learning relationships" Teaching and Learning Online: Pedagogy for New Technologies Edited by J. Stephenson. Stylus Publishing Inc, Sterling, VA, p. 219-224.

Skiles, M.E., and K.G. Stricklin (2009). "General Guidelines for the Use of Numerical Modeling to Evaluate Ground Control Aspects of Proposed Coal Mining Plans" Mine Safety and Health Administration Program Information Bulletin No. P09-03. U.S. Department of Labor, March 16, 7p.

Stricklin, K.G. and G. Triebsch (2012). "Report on Coal Pillar Recovery under Deep Cover" Mine Safety and Health Administration Program Information Bulletin No. P12-10. U.S. Department of Labor, July 11, 5p.

Stricklin, K.G. (2013). "Roof Control Plan Approval and Review Procedures" Mine Safety and Health Administration Handbook Number PH13-V-4. U.S. Department of Labor, December, 81p. 
Woelz, C. (2009). "The KDE Documentation Primer" KDE English Documentation Team. Web. 17 April 2015. 


\section{Appendix A}

Contents of the LaModel User's Manual 
Table A-1: LaModel User's Manual: Introduction Contents

\begin{tabular}{|c|}
\hline LaModel User's Manaul Table of Contents \\
\hline \hline 1.0 Welcome to LaModel \\
\hline 1.1 Introduction to La Model \\
\hline 1.2 History of La Model \\
\hline 1.3 La Model Background \\
\hline 1.3.1 Finite vs Boundary Element Methods \\
\hline 1.3.2 Homogeneous vs Laminated Overburden \\
\hline 1.3.3 La Model Overview \\
\hline 1.4 La Model Software Package \\
\hline 2.0 LamPre 3.0.2 \\
\hline 3.0 LaModel 3.0.4 \\
\hline 4.0 LamPlt 3.0 \\
\hline 5.0 Stability Mapping \\
\hline
\end{tabular}

Table A-2: LaModel User's Manual: LamPre Contents

\begin{tabular}{|c|}
\hline LaModel User's Manaul Table of Contents \\
\hline \hline 1.0 Welcome to LaModel \\
\hline 2.0 LamPre 3.0.2 \\
\hline 2.1 Introduction to La mPre \\
\hline 2.2 Getting Started with La mPre \\
\hline 2.3 La mPre Input Parameters \\
\hline 2.3.1 Project Para meters \\
\hline 2.3.2 Seam Geometry \& Boundary Conditions \\
\hline 2.3.3 Overburden / Rock Mass Parameters \\
\hline 2.3.3.1 Lamination Thickness Wizard \\
\hline 2.3.4 Material Models \\
\hline 2.3.4.1 Edit In-Seam Material Models \\
\hline 2.3.4.2 Create Using Material Wizard \\
\hline 2.3.4.2.1 Elastic-Plastic for Coal Wizard \\
\hline 2.3.4.2.2 Strain-Softening for Coal Wizard \\
\hline 2.3.4.2.3 Strain-Hardening for Gob Wizard \\
\hline 2.3.5 Program Controls \\
\hline 2.3.6 Off-Seam Plane \\
\hline 2.3.6.1 La Model Off-Seam Results File \\
\hline 2.4 Getting Started with the Grid Editor \\
\hline 4.0 LamPlt 3.0 \\
\hline 5.0 Stability Mapping \\
\hline 3.0.4 \\
\hline
\end{tabular}


Table A-3: LaModel User's Manual: LaModel Contents

\begin{tabular}{|c|}
\hline LaModel User's Manaul Table of Contents \\
\hline \hline 1.0 Welcome to LaModel \\
\hline 2.0 LamPre 3.0.2 \\
\hline 3.0 LaModel 3.0.4 \\
\hline 3.1 Getting Started in La Model 3.0.4 \\
\hline 3.1.1 La Model Input File \\
\hline 3.1.2 La Model Topography File \\
\hline 3.1.3 La Model Output File \\
\hline 3.1.4 La Model Results File \\
\hline 4.0 LamPlt 3.0 \\
\hline 5.0 Stability Mapping \\
\hline
\end{tabular}

Table A-4: LaModel User's Manual: LamPlt Contents 


\begin{tabular}{|c|}
\hline LaModel User's Manaul Table of Contents \\
\hline 1.0 Welcome to LaModel \\
\hline 2.0 LamPre 3.0.2 \\
\hline 3.0 LaModel 3.0.4 \\
\hline 4.0 LamPlt 3.0 \\
\hline 4.1 Getting Started in La mPlt 3.0 \\
\hline 4.1.1 Colored Square Plot \\
\hline 4.1.2 Cross Section Plot \\
\hline 4.1.3 History Plot \\
\hline 4.1.4 FishNet Plot \\
\hline 4.2 Stress Items \\
\hline 4.2.1 Default Solutions \\
\hline 4.2.1.1 Seam Convergence \\
\hline 4.2.1.2 Total Vertical Stress \\
\hline 4.2.1.3 Overburden Stress \\
\hline 4.2.1.4 Multiple Seam Stress \\
\hline 4.2.2 Surface Effect Stress \\
\hline 4.2.3 Sa fety Factor Solutions \\
\hline 4.2.3.1 Element Strain SF \\
\hline 4.2.3.2 Pillar Stress SF \\
\hline 4.2.3.3 Pillar Strain SF \\
\hline 4.2.4 Multiple Seam Subsidence Solutions \\
\hline 4.2.4.1 Remote Displacement \\
\hline 4.2.4.2 X Strain \\
\hline 4.2.4.3 Y Strain \\
\hline 4.2.5 Energy Release Rate Solutions \\
\hline 4.2.5.1 Stored Elastic Energy \\
\hline 4.2.5.2 Dissipated Energy \\
\hline 4.2.5.3 Total Input Energy \\
\hline 4.2.5.4 Stored Energy Released \\
\hline 4.2.5.5 Kinetic Energy Released \\
\hline 4.2.5.6 Total Energy Released \\
\hline 4.2.6 Roof Beam Bending Solutions \\
\hline 4.2.6.1 Roof X Stress \\
\hline 4.2.6.2 Roof Y Stress \\
\hline 4.2.6.3 Maximum Roof Compression \\
\hline 4.2.6.4 Maximum Roof Tension \\
\hline 4.2.6.5 Maximum Roof Stress \\
\hline 5.0 Stability Mapping \\
\hline
\end{tabular}

Table A-5: LaModel User's Manual: Stability Mapping Contents 


\begin{tabular}{|l|}
\hline \multicolumn{1}{|c|}{ LaModel User's Manaul Table of Contents } \\
\hline \hline 1.0 Welcome to LaModel \\
\hline 2.0 LamPre 3.0.2 \\
\hline 3.0 LaModel 3.0.4 \\
\hline 4.0 LamPlt 3.0 \\
\hline 5.0 Stability Mapping \\
\hline 5.1 Getting Started in Stability Mapping \\
\hline 5.2 Gridding Modules \\
\hline 5.2.1 Topography Grid Generation \\
\hline 5.2.2 Seam Grid Generation \\
\hline 5.3 Transfer of Results \\
\hline 5.3.1 Transfer of La Model/MulSim Results \\
\hline 5.3.2 Grid Utilities \\
\hline
\end{tabular}




\section{Appendix B}

Contents of the Online LaModel Training Course 
Table B-1: Online Learning Tracks

Online LaModel Training Course Table of Contents

Novice Learning Track

Intermediate Learning Track

Advanced Learning Track

Table B-2: Novice Learning Tracks

Online LaModel Training Course Table of Contents

Novice Learning Track

1.0 Introduction \& Background

2.0 Tutorial 1

3.0 Tutorial 2 - Huff Creek

Intermediate Learning Track

Advanced Learning Track

Table B-3: Introduction \& Background training module series

Online LaModel Training Course Table of Contents Novice Learning Track

1.0 Introduction \& Background

1.1 Introduction to La Model

1.2 History of LaModel

1.3 LaModel Background

1.3.1 Finite vs Boundary Element Methods

1.3.2 Homogeneous vs Laminated Overbruden

1.3.3 La Model Overview

1.4 LaModel Software Package

Knowledge Check 1

Corrective Activity 1

2.0 Tutorial 1

3.0 Tutorial 2 - Huff Creek

Intermediate Learning Track

Advanced Learning Track 
Table B-5: Tutorial 1 training module series

Online LaModel Training Course Table of Contents

Novice Learning Track

1.0 Introduction \& Background

2.0 Tutorial 1

2.1 Introduction to Tutorial 1

2.2 Getting Started with LamPre 3.0.2

2.2.1 Project Parameters

2.2.2 Seam Geometry \& Boundary Condidtions

2.2.3 Overburden / Rock Mass Parameters

2.2.4 Wizard for Defining In-Seam Materials

2.2.4.1 Elastic-Plastic for Coal Wizard

2.2.4.2 Strain-Hardening for Gob Wizard

2.2.5 Program Controls

2.3 Getting Started with the Grid Editor

2.4 Getting Started with La Model 3.0.4

2.5 Getting Started with LamPlt 3.0

2.5.1 Seam Convergence

2.5.2 Total Vertical Stress

2.5.3 Pillar Safety Factors

2.5.3.1 Element Strain Safety Factor

2.5.3.2 Pillar Stress Safety Factor

2.5.3.3 Pillar Strain Safety Factor

2.5.3.4 Stress vs Strain Safety Factors

Knowledge Check 2

Corrective Activity 2

3.0 Tutorial 2 - Huff Creek

Intermediate Learning Track

Advanced Learning Track 
Table B-6: Huff Creek training module series

Online LaModel Training Course Table of Contents

Novice Learning Track

1.0 Introduction \& Background

2.0 Tutorial 1

3.0 Tutorial 2 - Huff Creek

3.1 Introduction to Huff Creek

3.2 Stability Mapping Grid Generation

3.2.1 Huff Creek Grid Generation

3.2.2 Darby Fork Grid Generation

3.2.3 Overburden Grid Generation

3.3 LamPre 3.0.2 for Huff Creek

3.3.1 Project Parameters

3.3.2 Seam Geometry \& Overburden Parameters

3.3.3 Elastic-Plastic for Coal Wizard

3.3.4 Strain-Hardening for Gob Wizard

3.3.5 Program Controls

3.3.6 LamPre Grid Editor

3.4 La Model 3.0.4 for Huff Creek

3.5 LamPIt 3.0 for Huff Creek

3.5.1 Seam Convergence

3.5.2 Total Vertical Stress

3.5.3 Overburden Stress

3.5.4 Multiple-Seam Stress

3.5.5 Pillar Stress Safety Factor

3.6 Stability Mapping for Huff Creek

Knowledge Check 3

Corrective Activity 3

Intermediate Learning Track

Advanced Learning Track 
Table B-7: Intermediate Learning Track

\begin{tabular}{|l|}
\hline Online LaModel Training Course Table of Contents \\
\hline \hline Novice Learning Track \\
\hline Intermediate Learning Track \\
\hline 4.0 Calibration of La Model \\
\hline 5.0 Gory Details I \\
\hline 6.0 Solution Options I \\
\hline 7.0 Stability Mapping \\
\hline Advanced Learning Track \\
\hline
\end{tabular}

\section{Table B-8: Calibration of LaModel training module series}

\begin{tabular}{|l|}
\hline Online LaModel Training Course Table of Contents \\
\hline \hline Novice Learning Track \\
\hline Intermediate Learning Track \\
\hline 4.0 Calibration of La Model \\
\hline 4.1 Introduction to La Model Calibration \\
\hline 4.1.1 Calibration of Tutorial 1 \\
\hline 4.2 Rock Mass Stiffness \\
\hline 4.3 Gob Stiffness \\
\hline 4.4 Coal Strength \\
\hline Knowledge Check 4 \\
\hline Corrective Activity 4 \\
\hline 5.0 Gory Details I - The Derivation of La Model \\
\hline 6.0 Solution Options I \\
\hline 7.0 Stability Mapping \\
\hline Advanced Learning Track \\
\hline
\end{tabular}




\section{Table B-9: Gory Details I training module series}

\section{Online LaModel Training Course Table of Contents}

Novice Learning Track

Intermediate Learning Track

4.0 Calibration of La Model

5.0 Gory Details I - The Derivation of La Model

5.1 The Derivation of LaModel

5.1.1 Displacement-Discontinuity Boundary-Elemen

5.1.2 Laminated Overbruden Model

5.1.3 Fundamental Differential Equation

5.1.3.1 Central Difference Solution

5.1.3.2 Over-Relaxation Factor

5.1.3.3 Influence Functions

5.1.3.4 Multiple-Seam Solution

5.2 Derivation Learning Activities

5.2.1 Behavior of the Laminated Overburden Model

5.2.1.1 Rock Mass Modulus \& Lamination Thickn

5.2.1.2 Poisson's Ratio

5.2.2 Investigation on Element Size Effect

5.2.3 Investigation on the Over-Relaxation Factor

5.2.4 Investigation on Multiple Seam Stess

Knowledge Check 5

Corrective Activity 5

6.0 Solution Options I

7.0 Stability Mapping

Advanced Learning Track 
Table B-10: Solution Options I training module series

\begin{tabular}{|l|}
\hline Online LaModel Training Course Table of Contents \\
\hline \hline Novice Learning Track \\
\hline Intermediate Learning Track \\
\hline 4.0 Calibration of La Model \\
\hline 5.0 Gory Details I - The Derivation of La Model \\
\hline 6.0 Solution Options I \\
\hline 6.1 Default Stress Items \\
\hline 6.1.1 Seam Convergence \\
\hline 6.1.2 Total Vertical Stress \\
\hline 6.1.3 Overburden Stress \\
\hline 6.1.4 Multiple Seam Stress \\
\hline 6.2 Safety Factor Stress Items \\
\hline 6.2.1 Element Strain Safety Factor \\
\hline 6.2.2 Pillar Stress Safety Factor \\
\hline 6.2.3 Pillar Strain Safety Factor \\
\hline 6.2.4 Stress vs Strain Safety Factor \\
\hline 6.3 Free Surface Effect \\
\hline Knowledge Check 6 \\
\hline Corrective Activity 6 \\
\hline 7.0 Stability Mapping \\
\hline Advanced Learning Track \\
\hline
\end{tabular}

Table B-11: Stability Mapping training module series

\begin{tabular}{|l|}
\hline Online LaModel Training Course Table of Contents \\
\hline \hline Novice Learning Track \\
\hline Intermediate Learning Track \\
\hline 4.0 Calibration of La Model \\
\hline 5.0 Gory Details I - The Derivation of La Model \\
\hline 6.0 Solution Options \\
\hline 7.0 Sta bility Mapping \\
\hline 7.1 Overburden/Topography Element Sizing \\
\hline 7.2 Overbruden/Topography Offset Distance \\
\hline 7.3 Insitu Stress Results \\
\hline 7.4 LamPlt Scaling \\
\hline Knowledge Check 7 \\
\hline Corrective Activity 7 \\
\hline Advanced Learning Track
\end{tabular}




\section{Table B-12: Advanced Learning Track}

\section{Online LaModel Training Course Table of Contents}

Novice Learning Track

Intermediate Learning Track

Advanced Learning Track

8.0 Gory Details II - Mathematical Behaviors

9.0 Solution Options II

10.0 Miscellaneous Features

11.0 Successive Over-Relaxation Coding Activity

Table B-13: Gory Details II training module series

\section{Online LaModel Training Course Table of Contents}

Novice Learning Track

Intermediate Learning Track

Advanced Learning Track

8.0 Gory Details II - Mathematical Behaviors

8.1 Slot Convergence

8.2 Central Difference Method

Knowledge Check 8

Corrective Activity 8

9.0 Solution Options II

10.0 Miscellaneous Features

11.0 Successive Over-Relaxation Coding Activity 
Table B-14: Solution Options II training module series

\begin{tabular}{|l|}
\hline Online LaModel Training Course Table of Contents \\
\hline \hline Novice Learning Track \\
\hline Intermediate Learning Track \\
\hline Advanced Learning Track \\
\hline 8.0 Gory Details II - Mathematica I Behaviors \\
\hline 9.0 Solution Options II \\
\hline 9.1 Energy Release Rates \\
\hline Knowledge Check 9 \\
\hline Corrective Activity 9 \\
\hline 9.2 Local Mine Stiffness \\
\hline 9.3 Multiple Seam Subsidence \\
\hline 9.4 Roof Beam Bending Stress \\
\hline Knowledge Check 10 \\
\hline Corrective Activity 10 \\
\hline 10.0 Miscellaneous Features \\
\hline 11.0 Successive Over-Relaxation Coding Activity \\
\hline
\end{tabular}

\section{Table B-15: Miscellaneous Features training module series}

\begin{tabular}{|l|}
\hline Online LaModel Training Course Table of Contents \\
\hline \hline Novice Learning Track \\
\hline Intermediate Learning Track \\
\hline Advanced Learning Track \\
\hline 8.0 Gory Details II - Mathe matical Behaviors \\
\hline 9.0 Solution Options II \\
\hline 10.0 Mis cellaneous Features \\
\hline 10.1 Off-Seam Plane \\
\hline 10.2 Fault Plane \\
\hline 10.3 Strain-Softening Coal Wizard \\
\hline Knowledge Check 11 \\
\hline Corrective Activity 11 \\
\hline 11.0 Successive Over-Relaxation Coding Activity \\
\hline
\end{tabular}


Table B-16: Successive Over-Relaxation Coding Activity training module series

Online LaModel Training Course Table of Contents

Novice Learning Track

Intermediate Learning Track

Advanced Learning Track

8.0 Gory Details II - Mathematical Behaviors

9.0 Solution Options II

10.0 Miscellaneous Features

11.0 Successive Over-Relaxation Coding Activity

11.1 La Model Base Code

11.2 Boundary Conditions

11.3 Element Materials

11.4 Zerro Array

11.5 LamLite Run 


\section{Appendix C}

\section{Educational Assessments}




\section{Assessment 1: Introduction \& Background}

1. LaModel is a numerical program that implements which numerical method...
a. Answer: Displacement-Discontinuity Boundary Element
b. Cognitive Level: Knowledge
c. Expected Difficulty: $85 \%$

2. Over the years LaModel has increased its analysis abilities from 250 x 250 element grids in 1994 to a current grid size of $\mathrm{x}$
a. Answer: $\mathbf{2 0 0 0} \times \mathbf{2 0 0 0}$
b. Cognitive Level: Knowledge
c. Expected Difficulty: 85\%

3. The LaModel program employs a Laminated Overburden comprised of frictionless homogeneous stratifications within in the surrounding overburden material. Which statement clearly explains the advantages of the Laminated Overburden model with respect to the Homogeneous Elastic model.
a. Answer: The laminated overburden model simulated more flexible overburden.
b. Cognitive Level: Analysis
c. Expected Difficulty: $70 \%$

4. With respect to LaModel's fundamental differential equation, the two most important parameters for specifying the overburden behaviors are and
a. Answer: Lamination Thickness and Overburden Modulus
b. Cognitive Level: Evaluation
c. Expected Difficulty: $40 \%$

5. LaModel uses a numerical modeling method while ARMPS uses an empirical modeling method. Please identify the characteristics of LaModel and ARMPS.

a. Based on Laws of Physics

i. Answer: LaModel

ii. Cognitive Level: Analysis

iii. Expected Difficulty: $75 \%$

b. Based on large database

i. Answer: ARMPS

ii. Cognitive Level: Analysis

iii. Expected Difficulty: $75 \%$

c. Most flexible geometries

i. Answer: LaModel

ii. Cognitive Level: Analysis

iii. Expected Difficulty: $75 \%$

d. Needs to be calibrated with reality

i. Answer: LaModel

ii. Cognitive Level: Analysis 
iii. Expected Difficulty: $75 \%$

e. Quickest

i. Answer: ARMPS

ii. Cognitive Level: Analysis

iii. Expected Difficulty: $75 \%$ 


\section{Assessment 2: Tutorial 1}

1. Given a mine plan containing 7 entries and 65' by 90' (center-to-center) pillar dimensions, determine the appropriate element width in feet needed to model this scenario.
a. Answer: $\mathbf{5}$ feet
b. Cognitive Level: Application
c. Expected Difficulty: $70 \%$

2. This boundary condition fixes its displacements at the model's edge effectively supporting the roof at the grid's edge.
a. Answer: Rigid Boundary Condition
b. Cognitive Level: Knowledge
c. Expected Difficulty: $80 \%$

3. This boundary condition fixes the displacements outside the edge of the model such that the slope of the convergence at the grid's edge is zero.
a. Answer: Symmetric Boundary Condition
b. Cognitive Level: Knowledge
c. Expected Difficulty: $80 \%$

4. In underground coal mines, the strength of a coal pillar increases proportionally to the distance from the edge (or rib) of the pillar. LaModel implements what coal strength formula to mathematically represent this phenomenon?
a. Answer: Mark-Bieniawski Formula
b. Cognitive Level: Analysis
c. Expected Difficulty: $70 \%$

5. With respect to the automatic yield zone, please identify which material codes will be applied along the outside (against the entry) edge and corner elements of the coal pillar and/or barrier.
a. Answer: H (edge) \& I (corner)
b. Cognitive Level: Application
c. Expected Difficulty: 65\%

6. Accurate input properties for the are critical for getting accurate abutment loads on adjacent pillars.
a. Answer: Gob Material
b. Cognitive Ability: Analysis
c. Expected Difficulty: $75 \%$

7. In LaModel, the gob wizard uses this graph to define the Final Gob Modulus with respect to which material curve?
a. Answer: Salamon's Curve
b. Cognitive Ability: Comprehension
c. Expected Difficulty: $85 \%$

8. What six material models are available in LaModel? 

a. Answers: Linear Elastic, Strain-Softening, Elastic Plastic Coal, Linear Elastic, Strain-Hardening, and Bi-linear Hardening Gob
b. Cognitive Level: Knowledge
c. Expected Difficulty: $85 \%$

9. Please organize the following LaModel programs in order of use with respect to the LaModel modeling process.
a. Answers: LamPre $=>$ LaModel $=>$ LamPlt
b. Cognitive Level: Analysis
c. Expected Difficulty: $80 \%$ 


\section{Assessment 3: Huff Creek}

1. When generating Seam or Topography/Overburden grids for LaModel, what AutoCAD run-time extension (.arx) is necessary?
a. Stability Mapping
b. Cognitive Level: Knowledge
c. Expected Difficulty: $85 \%$

2. A co-worker is building a seam grid file for LaModel. However, the gridding algorithm is taking an abnormally long time to complete the grid. What possible polyline errors should have been corrected?
a. Open Polylines, Crossed Polylines, Duplicate Polylines
b. Cognitive Level: Analysis
c. Expected Difficulty: $75 \%$

3. In creating a seam grid, how should large areas of coal at the grid boundaries be constructed?
a. Need to be included in "Pseudo Pillars" to be considered coal by the algorithm
b. Cognitive Level: Application
c. Expected Difficulty: $60 \%$

4. How would you organize your mine map layers to increase the efficiency of the gridding algorithm?
a. Differentiate coal and gob areas by seam with respect to individually defined layers.
b. Cognitive Level: Analysis
c. Expected Difficulty: $60 \%$

5. The seam grid generation algorithm actually determines how much area of an element is Coal, Gob, or Opening to define the element material.
a. Area-Based
b. Cognitive Level: Knowledge
c. Expected Difficulty: $85 \%$

6. The seam grid generation algorithm takes longer to run, but it is more accurate.
a. Area-Based
b. Cognitive Level: Knowledge
c. Expected Difficulty: $85 \%$

7. Given a mining depth of 1000 feet and a 45-degree angle of draw, determine the offset distance from the model's edge to the Topography/Overburden boundary.
a. $\mathbf{1 0 0 0}$ feet
b. Cognitive Level: Application
c. Expected Difficulty: $70 \%$ 
8. Given a mining depth of 1000 feet, determine the most appropriate element size for one's topography/overburden grid.
a. 100 foot element width
b. Cognitive Level: Application
c. Expected Difficulty: $70 \%$ 


\section{Assessment 4: Calibration of LaModel}

1. Which statement best classifies Relative Calibration?

a. The analysis of future mining scenarios from which previous models have been compared previously.

b. Cognitive Level: Understanding

c. Expected Difficulty: $80 \%$

2. Which statement best classifies Absolute Calibration?

a. The analysis of future mining scenarios from which modeling parameters have been determined using the best available site-specific data.

b. Cognitive Level: Understanding

c. Expected Difficulty: $80 \%$

3. For the typical user, the absolute calibration method provides the most realistic modeling results. Which three calibration parameters would you deem most critical?
a. Lamination Thickness, Gob Stiffness, Coal Strength
b. Cognitive Level: Evaluation
c. Expected Difficulty: $40 \%$

4. With respect to the process followed in Tutorial 1, please place the steps for calibration in chronological order.
a. Calculate the Lamination Thickness, define the Coal Strength, and calculate a Gob Stiffness

b. Cognitive Level: Analysis

c. Expected Difficulty: $70 \%$

5. How are result accuracies related to model calibration?
a. The accuracy of modeling results is highly dependent on the accuracy of input parameters.
b. Cognitive Level: Analysis
c. Expected Difficulty: $80 \%$ 


\section{Assessment 5: Gory Details I}

1. With respect to LaModel's boundary-element method, one can accurately calculate the stress and displacement within a given area by applying loads...

a. along the boundary of a homogeneous material

b. Comprehension

2. Please identify the mathematical parameters of the homogeneous laminated overburden which allow for the realistic simulation of overburden behaviors.

a. Rock Mass Modulus, Lamination Thickness, Poisson's Ratio

b. Analyzing

3. A co-worker is having trouble mimicking the underground stress distribution from a deep, single seam longwall. Based on your current knowledge of the Lamination Thickness, what might you recommend?

a. Increase the lamination thickness to simulate the major bedding slip planes

b. Evaluation

4. Which statement best represents the fundamental differential equation for the laminated overburden model?

a. Convergence is a function of the overburden and induced stress

b. Knowledge

5. LaModel calculates the induced stress as a function of what stress items?

a. Overburden, In-seam Material, Surface Effect, and Multiple Seam Stresses

b. Comprehension

6. Please justify LaModel's use of the Central Difference for solving LaModel's fundamental differential equation.

a. The second-order numerical solution provides an exact answer to the secondorder partial differential equation.

b. Analyzing

7. Given LaModel's Successive Over-Relaxation numerical approach to solving equations numerically, how is the over-relaxation factor related to model runtime.

a. By changing the amount of over-relaxation by the solution algorithm, the number of numerical iterations and associated model runtime can be optimized.

b. Analyzing

8. Which statement best explains the displacement influence function?

a. relates the displacement at any point in the surrounding media to the displacement of an in-seam element.

b. Comprehension

9. Which statement best explains the stress influence function?

a. relates the vertical stress at any point in the surrounding media to the vertical displacement of an in-seam element.

b. Comprehension

10. Elaborate on the reason why a multiple seam model take longer than a single seam model 
a. Multiple seam stresses are calculated using the influence functions and then each seam is resolved iteratively until equilibrium. 


\section{Assessment 6: Solution Options I}

1. Users are able to select from a series of available solution options using what input parameter form?

a. Program Controls

b. Remebering

2. What are the four default solution options available in LaModel?

a. seam convergence, total vertical stress, overburden stress, multiple seam stress

b. Remembering

3. What is the function of the pillar safety factor solution options available in LaModel?

a. Given artificial and natural loading conditions on a system, the safety factor relates the stability of a coal element or pillar to regulatory specifications.

b. Understanding

4. Given what you have learned, how does LaModel determine the pre-failure safety factor of a coal element?

a. Stress based safety factor

b. Application

5. Given what you have learned, how does LaModel determine the post-failure safety factor of a coal element?

a. Strain based safety factor

b. Application

6. Which statement best summarizes the Free-Surface Solutions Option?

a. Using a mirror image seam, the sum of propagating displacements at the surface are zero

b. Understanding

7. With respect to LaModel's influence functions, what happens when a user selects the Free-Surface solution option for a three seam model?

a. The displacement and stress influence functions propagate seam influence across 6 seams (3 actual and 3 mirrored seams) greatly increasing model run time.

b. Synthesis

8. Due to the sensitivity of the Free-Surface calculation, this solution option should only be considered...

a. for seams with shallow cover or a Panel Width-to-Depth Ratio greater than 1

b. Evaluation 


\section{Assessment 7: Stability Mapping}

1. Mathematically, how does LaModel represent varying topography?

a. As a collection of normal stress applied to a defined datum within the overburden.

b. Understanding

2. Given an overburden of $1000 \mathrm{ft}$, what is the recommended element width for surface elements?

a. $100 \mathrm{ft}$ to $200 \mathrm{ft}$

b. Evaluation

3. If an element was defined outside of the range indicated above, how would the modeling results be effected?

a. LaModel applies a centralized point load from each surface element to the seam creating a "bulls-eye" effect.

b. Synthesis

4. To account for naturally occurring zones of influence within the overburden, what offset distance from the model boundary should overburden grid files be defined?

a. larger than the area of interest with respect to a 45 degree angle of draw or $50 \%$ of the seam depth

b. Application

5. Given a seam depth of $2000 \mathrm{ft}$, what would your recommended offset distance be?

a. $1000 \mathrm{ft}$

b. Evaluation

6. The insitu stress is defined as...

a. the pre-existing stress state within the rock mass.

b. Remembering

7. Given a multiple seam model, how would you construct the insitu stress results?

a. by adding the multiple seam stress and overburden stress grids together in the Stability Mapping application.

b. Application

8. In analyzing a retreat mining section, what cross-sectional plot changes would you make to better evaluate the stress on and stability of the pillar line?

a. create a custom plot scale using the 'Axes' tab of the '2D Chart Control Properties' form.

b. Synthesis 


\section{Assessment 8: Gory Details II}

1. In order to provide an exact solution to LaModel's fundamental differential equation, a second-order differential solution method is utilized for the approximation of seam convergence.
a. Answer: Central
b. Cognitive Level: Knowledge
c. Expected Difficulty: $85 \%$

2. Using LaModel, the convergence at the center of a longwall panel was determined to be 2 feet. If the Lamination Thickness was reduced by 50\%, please predict the new convergence value at the center of the panel.
a. Answer: $\mathbf{4}$ ft
b. Cognitive Level: Understanding
c. Expected Difficulty: $80 \%$

3. Using LaModel, the convergence at the center of a longwall panel was determined to be 2 feet. If the Elastic Modulus of Rock was doubled, please predict the new convergence value at the center of the panel.
a. Answer: 1 ft
b. Cognitive Level: Understanding
c. Expected Difficulty: $80 \%$

4. In calibrating a multiple-seam model, underground observations indicate more stress interactions between seams then shown in the model. To match the underground observations what should be recommended?
a. Answer: Decrease Lamination Thickness or Elastic Modulus of Rock
b. Cognitive Level: Evaluate
c. Expected Difficulty: 50\%

5. With respect to LaModel's fundamental differential equation, please summarize the relationship between seam convergence and the Lamination Thickness and Elastic Modulus of the Overburden input parameters
a. Answer: Convergence is inversely proportional to the product of the Lamination Thickness and Elastic Modulus of the Overburden.
b. Cognitive Level: Evaluate
c. Expected Difficulty: 50\% 


\section{Assessment 9: Energy Release Rates}

1. Through the incorporation of Energy Release Rates in LaModel, users have the ability to analyze in underground mining operations improving mine design, production, and safety.
a. Answer: Bumps or Bounces prone areas
b. Cognitive Level: Knowledge
c. Expected Difficulty: $85 \%$

2. As defined in LaModel, Static energy is related to the...
a. Answer: strain energy input and/or contained within the material.
b. Cognitive Level: Knowledge
c. Expected Difficulty: $85 \%$

3. As defined in LaModel, Dynamic Energies is related to the...
a. Answer: energy changes in the material that occur between modeling steps.
b. Cognitive Level: Knowledge
c. Expected Difficulty: $85 \%$

4. Please categorize the following energy calculations as either a Static or Dynamic.
a. Answer: Static (Total Input Energy, Stored Elastic Energy, Dissipated Energy) Dynamic (Stored Energy Release, Kinetic Energy Release, Total Energy Release)
b. Cognitive Level: Analysis
c. Expected Difficulty: $75 \%$

5. For the evaluation of bump or bounce proneness, which plot type should be recommended?
a. Answer: History Plot
b. Cognitive Level: Understanding
c. Expected Difficulty: $80 \%$

6. For the analysis of bump or bounce proneness, please select the energy calculations to be considered.
a. Answer: All should be considered
b. Cognitive Level: Analysis
c. Expected Difficulty: $70 \%$ 


\section{Assessment 10: Solution Options II (LMS, MS-Sub, Beam Bending Stress)}

1. Using a two step calculation, the Local Mine Stiffness is used in determining the of a coal pillar.
a. Answer: Failure Behavior
b. Cognitive Level: Knowledge
c. Expected Difficulty: $85 \%$

2. With respect to the Local Mine Stiffness calculation, if the mine stiffness is found to be greater than the post-failure coal pillar stiffness then what can be concluded about the pillar's failure?
a. Answer: Pillar failure will be stable
b. Cognitive Level: Evaluation
c. Expected Difficulty: 50\%

3. With respect to the Local Mine Stiffness calculation, if the mine stiffness is found to be less than the post-failure coal pillar stiffness then what can be concluded about the pillar's failure?
a. Answer: Pillar failure will be violent
b. Cognitive Level: Evaluation
c. Expected Difficulty: $50 \%$

4. Using the Multiple-Seam Subsidence solution option, users are able to determine not only subsidence due to multiple-seam vertical stress transfers but also...
a. Answer: Subsidence induced horizontal strains
b. Cognitive Level: Understanding
c. Expected Difficulty: $80 \%$

5. Please explain why the calculation of multiple-seam stresses is very time consuming.
a. Answer: Because the influence of every element on one seam needs to be calculated on every element of all other seams.
b. Cognitive Level: Analysis
c. Expected Difficulty: $75 \%$

6. Using the Roof Beam Bending Stress solution option, LaModel is able to calculate pure bending stresses in the immediate mine roof with respect to what assumption about the homogeneous laminated overburden?
a. Answer: Elastic-plastic lamination in the overburden never crack or break.
b. Cognitive Level: Understanding
c. Expected Difficulty: $75 \%$

7. The Roof Beam Bending Stress solution option implements what theoretical approach in relating in-seam convergence to bending induced stress and strain in the immediate roof?
a. Answer: Euler-Bernoulli Beam Theory
b. Cognitive Level: Understanding
c. Expected Difficulty: $80 \%$ 
8. Using the Euler-Bernoulli Beam Theory, LaModel is able to identify areas of high compressive and tensile stresses. In LaModel compression is denoted by stress values while tension is denote by stress values.
a. Answer: Positive, Negative
b. Cognitive Level: Understanding
c. Expected Difficulty: 90\% 


\section{Assessment 11: Miscellaneous Features}

1. Using the Off-Seam Plane solution option users are able to determine...
a. Answer: Surface/Sub-Surface Subsidence and Boundary Displacements
b. Cognitive Level: Knowledge
c. Expected Difficulty: $85 \%$

2. The accuracy of LaModel depends entirely on the accuracy of the input parameters. With respect to the accuracy of the subsidence calculation, what two input parameters are most important?
a. Answer: Post-failure behavior of pillars and Gob Compaction Curve
b. Cognitive Level: Analysis
c. Expected Difficulty: $75 \%$

3. In using the Off-Seam Plane for determining subsidence due to underground mining operations, it is imperative that the of the off-seam element is aligned with the of the seam element.
a. Answer: Center, Center
b. Cognitive Level: Application
c. Expected Difficulty: $70 \%$

4. Mathematically, LaModel implements the vertical frictionless fault plane as a...
a. Answer: Symmetric Boundary Condition within the seam grid
b. Cognitive Level: Knowledge
c. Expected Difficulty: $80 \%$

5. Using the Symmetric Boundary Condition to represent a simplistic fault plane within the seam grid, LaModel prevents the transfer of what stresses across the plane?
a. Answer: Shear Stress and Bending Stress
b. Cognitive Level: Understanding
c. Expected Difficulty: $75 \%$

6. The strain-softening behavior is defines as...
a. Answer: the progressive loss of strength as a material is loaded beyond its peak strength
b. Cognitive Level: Knowledge
c. Expected Difficulty: $85 \%$

7. The new residual stress equation for the strain-softening model implemented in LaModel builds upon work previously done by...
a. Answer: Karabin \& Evanto
b. Cognitive Level: Knowledge
c. Expected Difficulty: $85 \%$

8. The new residual stress equation implemented in LaModel's Strain-Softening for Coal Wizard is considered to be a great improvement over the previously used equation due to... 
a. Answer: Allows further customization, Equation bounded by field measurements, distance into rib normalized by height, derived from more data points.

b. Cognitive Level: Analysis

c. Expected Difficulty: $60 \%$ 